\title{
Measure Guideline: Incorporating Thick Layers of Exterior Rigid Insulation on Walls
}

Joseph Lstiburek and Peter Baker Building Science Corporation

\section{April 2015}
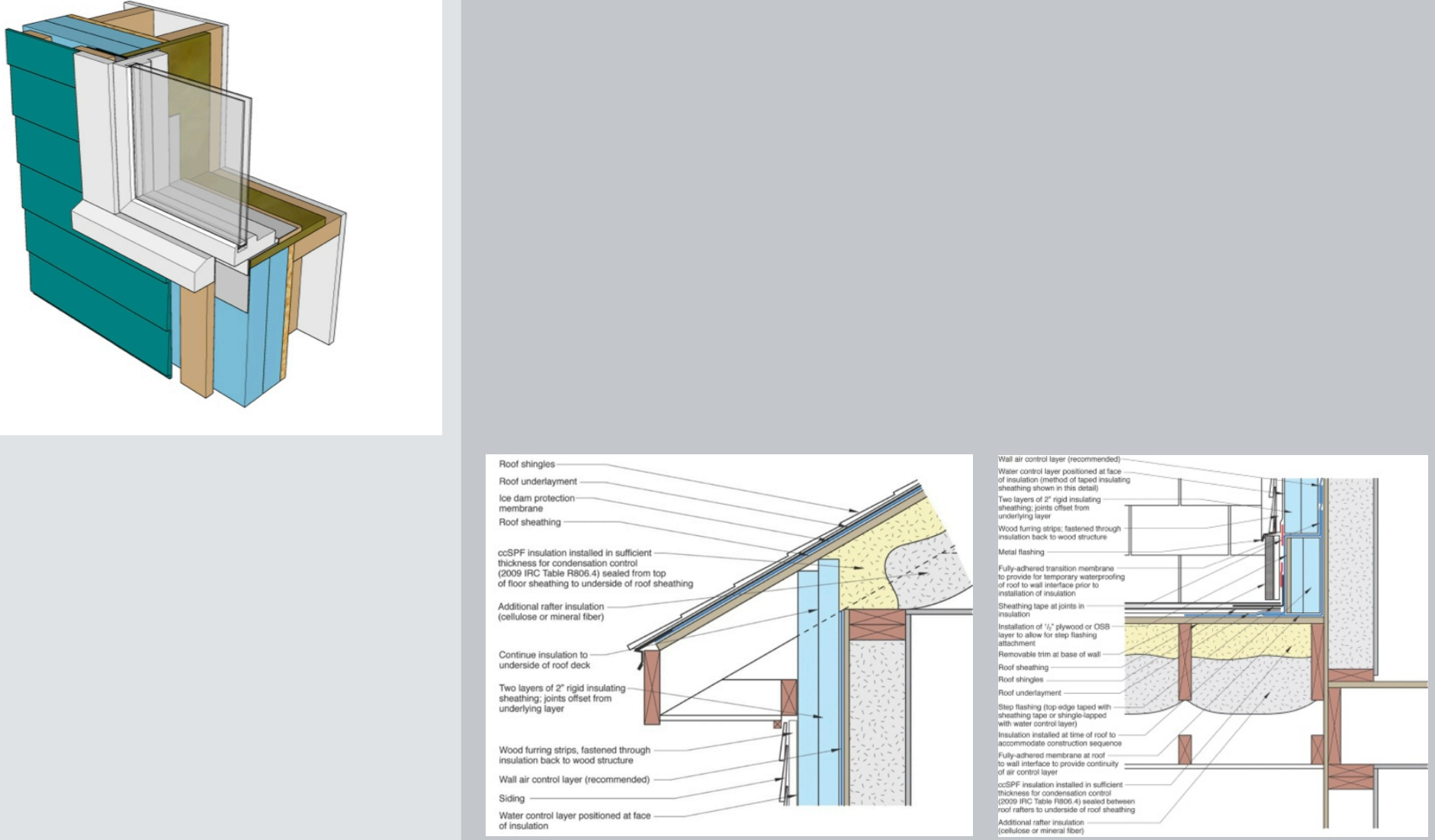


\section{NOTICE}

This report was prepared as an account of work sponsored by an agency of the United States government. Neither the United States government nor any agency thereof, nor any of their employees, subcontractors, or affiliated partners makes any warranty, express or implied, or assumes any legal liability or responsibility for the accuracy, completeness, or usefulness of any information, apparatus, product, or process disclosed, or represents that its use would not infringe privately owned rights. Reference herein to any specific commercial product, process, or service by trade name, trademark, manufacturer, or otherwise does not necessarily constitute or imply its endorsement, recommendation, or favoring by the United States government or any agency thereof. The views and opinions of authors expressed herein do not necessarily state or reflect those of the United States government or any agency thereof.

Available electronically at http://www.osti.gov/scitech

Available for a processing fee to U.S. Department of Energy

and its contractors, in paper, from:

U.S. Department of Energy

Office of Scientific and Technical Information

P.O. Box 62

Oak Ridge, TN 37831-0062

phone: 865.576 .8401

fax: 865.576 .5728

email: mailto:reports@adonis.osti.gov

Available for sale to the public, in paper, from:

U.S. Department of Commerce

National Technical Information Service

5285 Port Royal Road

Springfield, VA 22161

phone: 800.553 .6847

fax: 703.605.6900

email: orders@ntis.fedworld.gov

online ordering: $\underline{\text { http://www.ntis.gov/help/ordermethods.aspx }}$ 


\title{
Measure Guideline: Incorporating Thick Layers of Exterior Rigid Insulation on Walls
}

\author{
Prepared for: \\ The National Renewable Energy Laboratory \\ On behalf of the U.S. Department of Energy’s Building America Program \\ Office of Energy Efficiency and Renewable Energy \\ 15013 Denver West Parkway \\ Golden, CO 80401 \\ NREL Contract No. DE-AC36-08GO28308
}

Prepared by:

Joseph Lstiburek, Ph.D., P.Eng. and Peter Baker, P.Eng.

Building Science Corporation

3 Lan Drive, Suite 102

Westford, MA 01886

NREL Technical Monitor: Stacey Rothgeb

Prepared under Subcontract No. KNDJ-0-40337-05

April 2015 
The work presented in this report does not represent performance of any product relative to regulated minimum efficiency requirements.

The laboratory and/or field sites used for this work are not certified rating test facilities. The conditions and methods under which products were characterized for this work differ from standard rating conditions, as described.

Because the methods and conditions differ, the reported results are not comparable to rated product performance and should only be used to estimate performance under the measured conditions. 


\section{Contents}

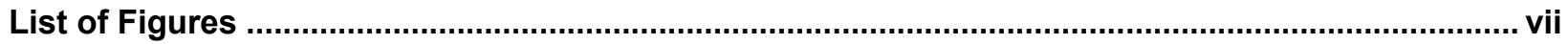

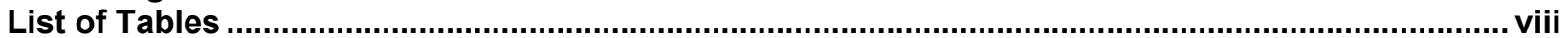

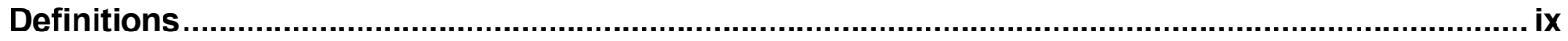

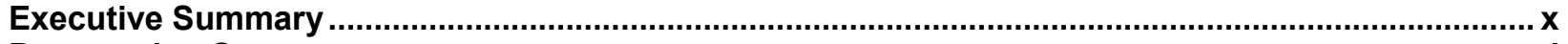

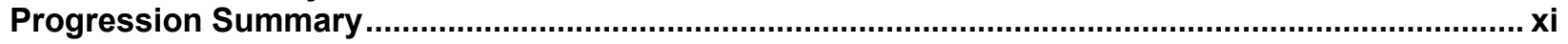

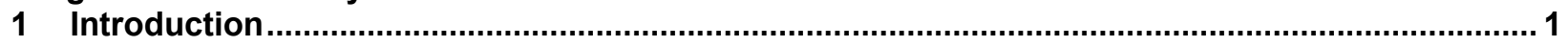

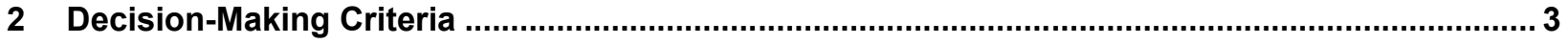

2.1 Cost

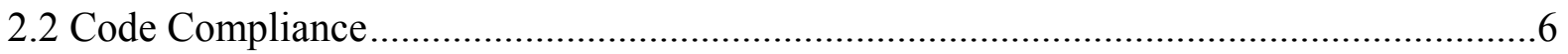

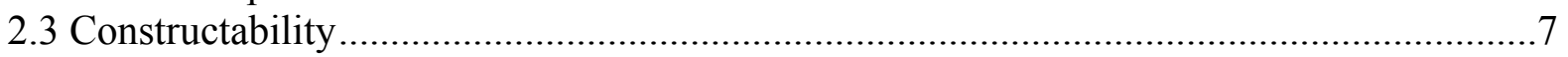

2.4 Water Management Performance ......................................................................... 7

2.5 Moisture Management Performance .................................................................... 7

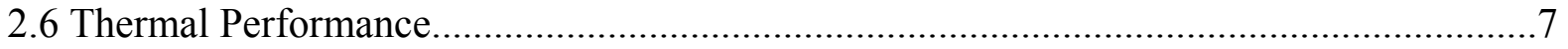

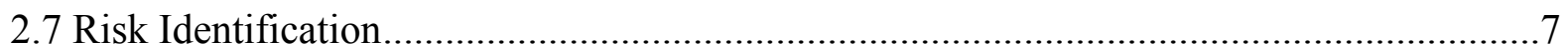

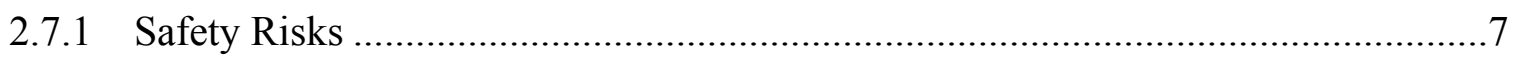

2.7.2 Durability and Structural Risks.............................................................

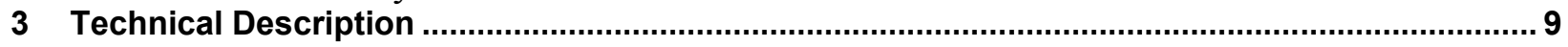

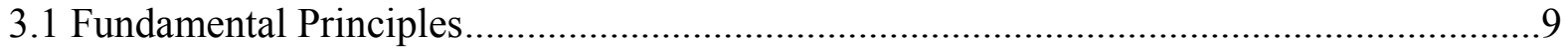

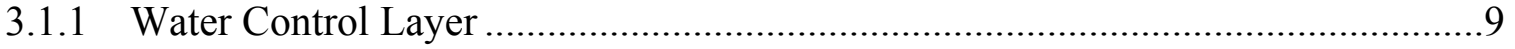

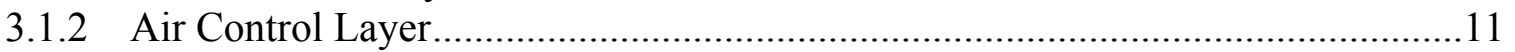

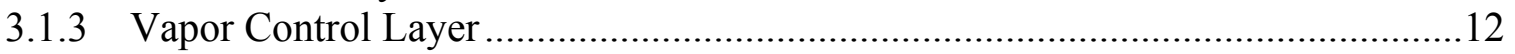

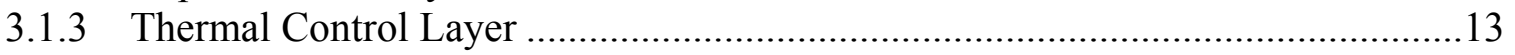

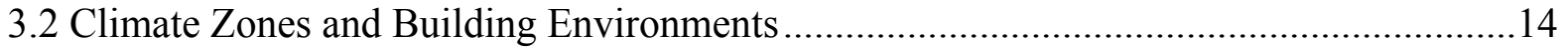

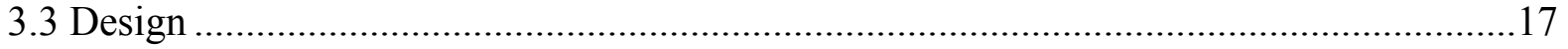

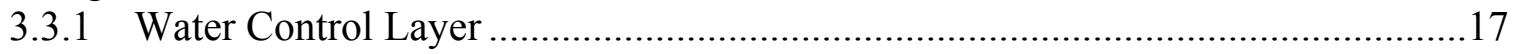

3.3.2 Air Control Layer........................................................................................ 18

3.3.3 Vapor Control Layer ............................................................................... 19

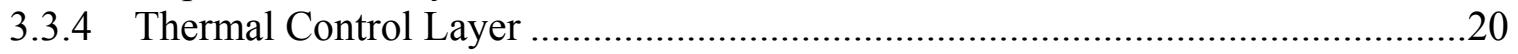

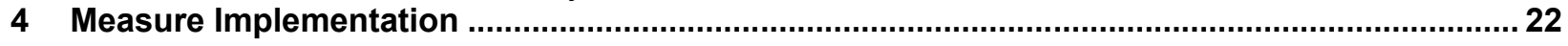

4.1 Option 1: Water Control Layer in Front of the Rigid Insulation .................................22

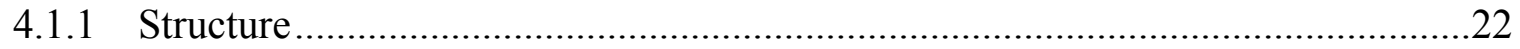

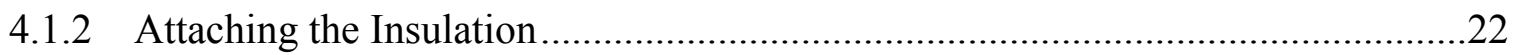

4.1.3 Water-Resistive Barriers .................................................................................23

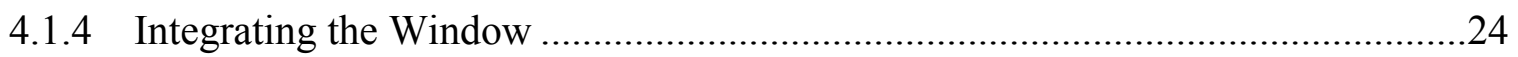

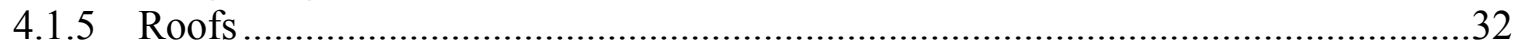

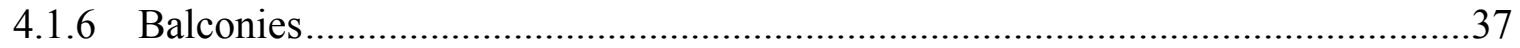

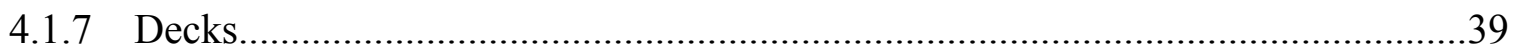

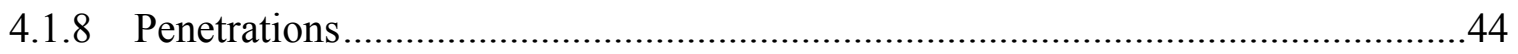

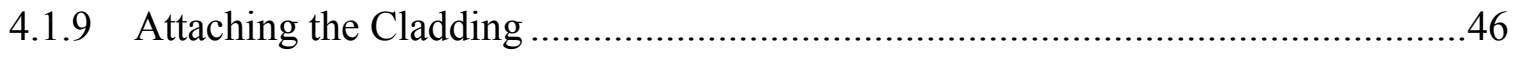

4.2 Option 2: Water Control Layer Behind the Rigid Insulation.........................................54

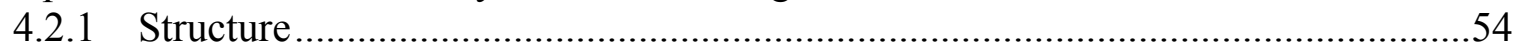

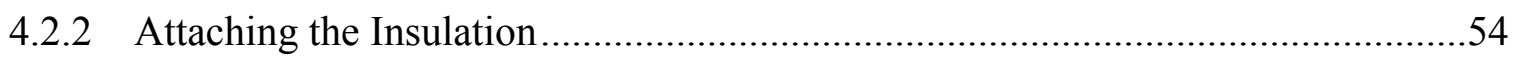

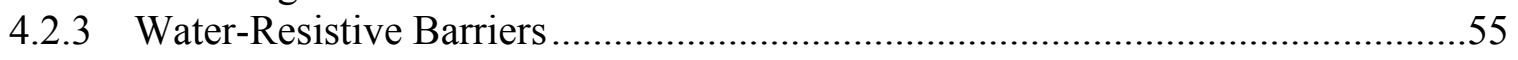

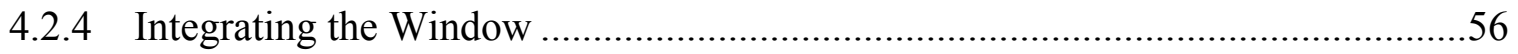




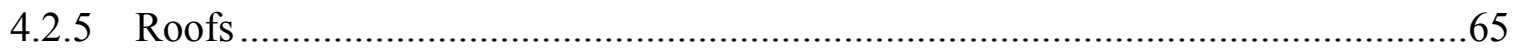

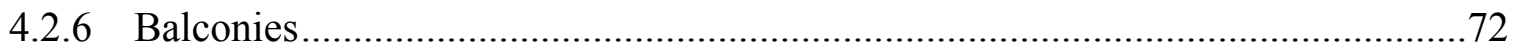

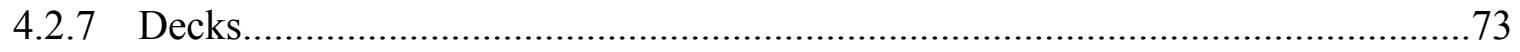

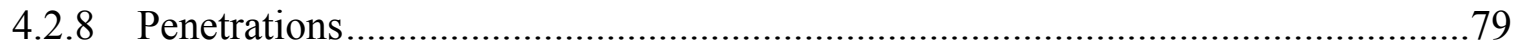

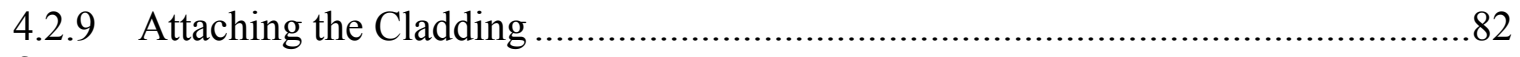

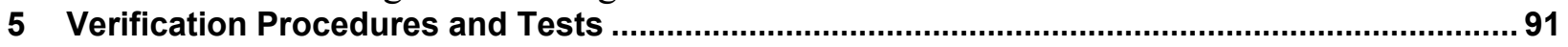

5.1 Water Control Layer in Front of the Rigid Insulation ........................................... 91

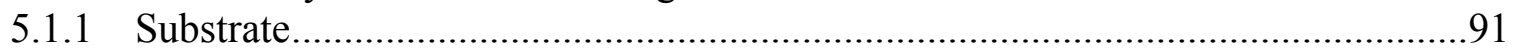

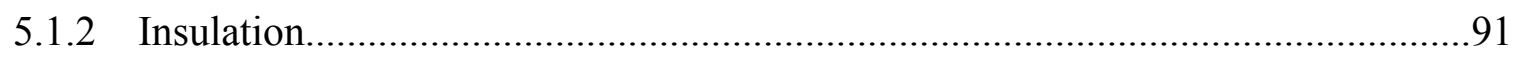

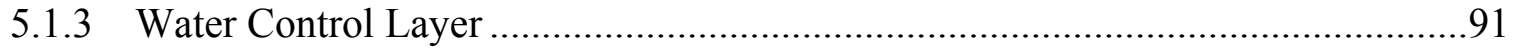

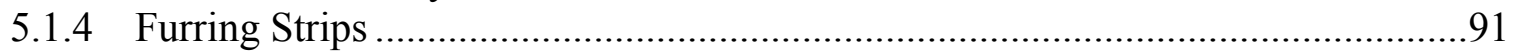

5.2 Water Control Layer Behind the Rigid Insulation.................................................99

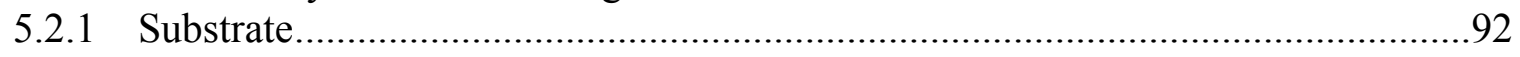

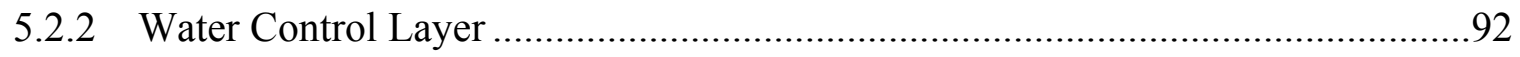

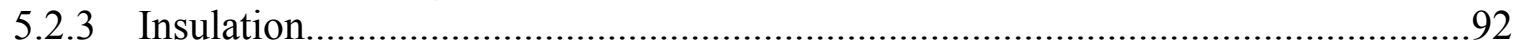

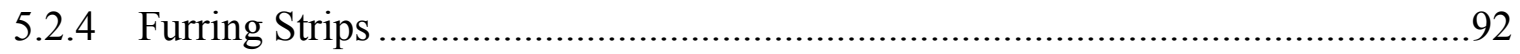

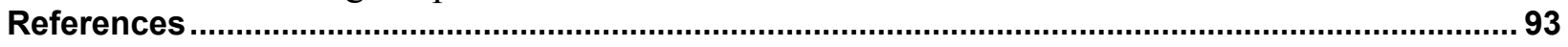

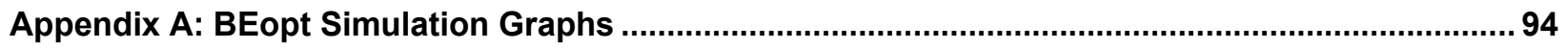

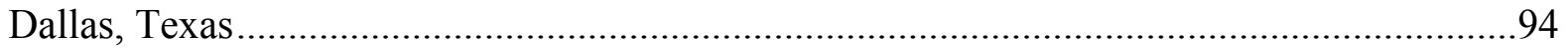

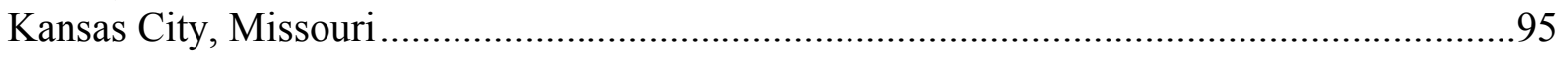

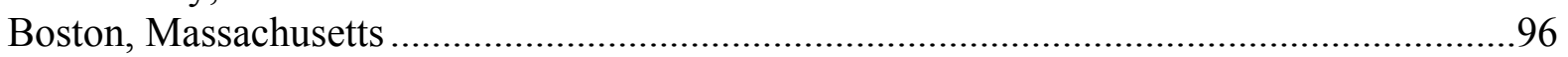

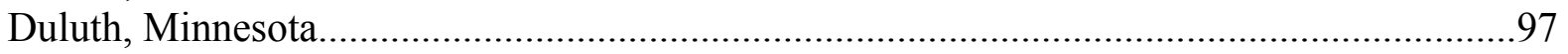

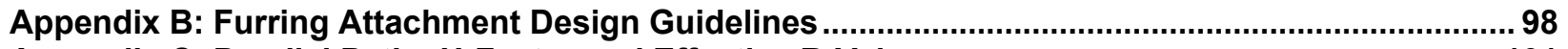

Appendix C: Parallel Paths U-Factor and Effective R-Value ......................................................... 101 


\section{List of Figures}

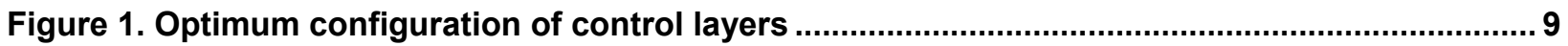

Figure 2. The "down" and "out" approach to flashing …............................................................ 11

Figure 3. Flashing integrated with the water control layer with lapped joints ................................... 11

Figure 4. Taped rigid insulation water control layer with sealed joints ........................................ 11

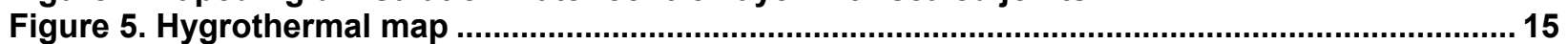

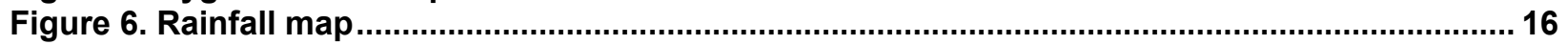

Figure 7. U.S. Department of Energy and IECC climate zones......................................................... 17

Figure 8. Water control layer behind the insulation ...................................................................... 18

Figure 9. Water control layer in front of the insulation ................................................................. 18

Figure 10. Water control layer using the face of the foam with taped joints ................................... 18

Figure 11. Water control layer in between the layers of insulation .............................................. 18

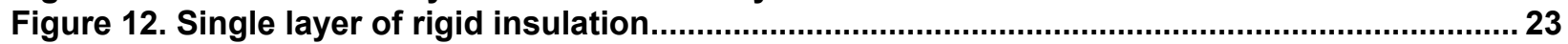

Figure 13. Multiple layers of rigid insulation with offset joints .................................................. 23

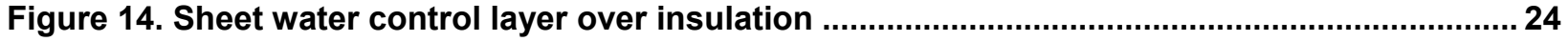

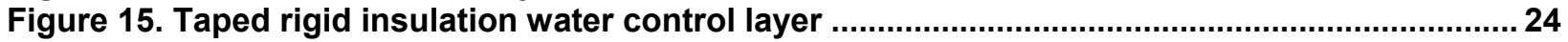

Figure 16. Window flush with the face of the exterior rigid insulation (sill installation sequence) . 25

Figure 17. Window flush with the face of the exterior rigid insulation (head installation sequence)26

Figure 18. Window head-water control layer in front of the rigid insulation.................................. 27

Figure 19. Window sill-water control layer in front of the rigid insulation .......................................28

Figure 20. Window jamb-water control layer in front of the rigid insulation ..................................29

Figure 21. Window recessed from the face of the rigid insulation (sill installation sequence)........ 30

Figure 22. Window recessed from the face of the rigid insulation (head installation sequence) .... 31

Figure 23. Vented attic water control layer in front of the rigid insulation ...................................... 32

Figure 24. Unvented attic water control layer in front of the rigid insulation ....................................33

Figure 25. Upper wall to lower roof construction sequence ............................................................ 35

Figure 26. Vented attic or porch water control layer in front of the rigid insulation..........................36

Figure 27. Unvented attic water control layer in front of the rigid insulation..................................... 37

Figure 28. Balcony water control layer in front of the rigid insulation............................................... 38

Figure 29. Balcony water control layer in front of the rigid insulation........................................... 39

Figure 31. Ledger inboard of rigid insulation construction sequence ........................................... 44

Figure 32. Mechanical penetration construction sequence .........................................................46

Figure 32. Lap siding attached directly through rigid insulation ...................................................... 46

Figure 33. Stucco attached directly through rigid insulation............................................................ 46

Figure 34. Furring strips attachment location for lap siding ....................................................... 48

Figure 35. Additional intermediate furring used to facilitate the installation of stucco and

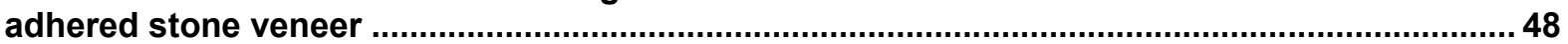

Figure 38. Cladding and trim attachment around a window (recessed sill condition) ......................52

Figure 39. Cladding and trim attachment around a window (recessed head condition)...................54

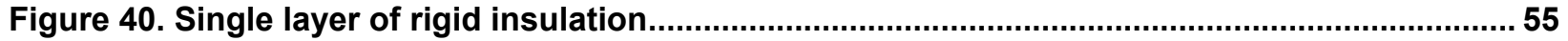

Figure 41. Multiple layers of rigid insulation with offset joints ...................................................55

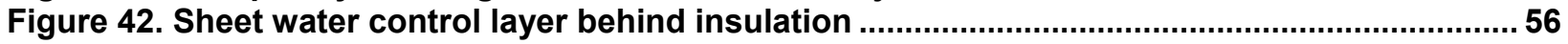

Figure 43. Taped water control layer behind insulation ............................................................. 56

Figure 45. Window recessed from the face of the rigid insulation (head installation sequence) .... 59

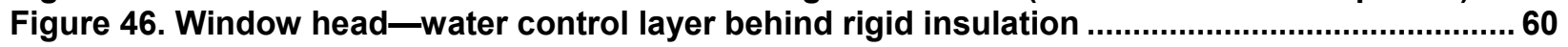

Figure 47. Window sill-water control layer behind rigid insulation .................................................60

Figure 48. Window jamb-water control layer behind rigid insulation .........................................61

Figure 49. Window flush with the face of the exterior rigid insulation (sill installation sequence) . 63

Figure 50. Window flush with the face of the exterior rigid insulation (head installation sequence)65

Figure 51. Vented attic water control layer behind rigid insulation...................................................66

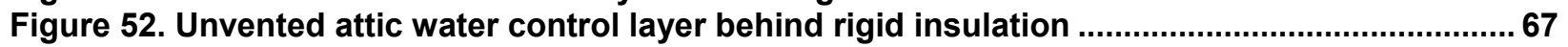

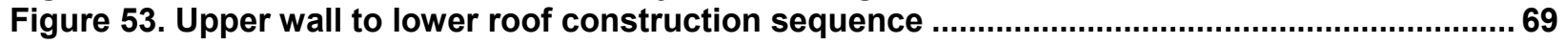


Figure 54. Vented attic or porch water control layer behind the rigid insulation.............................. 70

Figure 55. Unvented attic water control layer behind the rigid insulation.......................................... 71

Figure 56. Balcony water control layer behind the rigid insulation............................................... 72

Figure 57. Balcony water control layer behind the rigid insulation ................................................. 73

Figure 59. Ledger inboard of rigid insulation construction sequence ................................................ 79

Figure 61. Mechanical penetration construction sequence ...................................................... 82

Figure 60. Lap siding attached directly through the rigid insulation ............................................. 82

Figure 61. Stucco attached directly through the rigid insulation .................................................... 82

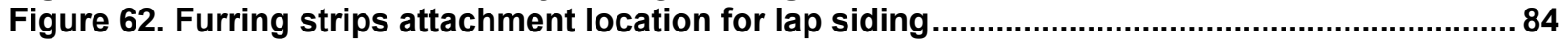

Figure 63. Additional intermediate furring used to facilitate the installation of stucco and

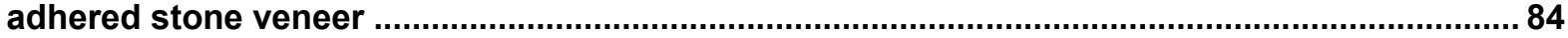

Figure 64. Cladding and trim attachment around a window (sill condition)...................................86

Figure 65. Cladding and trim attachment around a window (head condition) .................................... 87

Figure 66. Cladding and trim attachment around a window (recessed sill condition) ..................... 88

Figure 67. Cladding and trim attachment around a window (recessed head condition)..................90

Figure 68. Annualized energy related costs versus average source energy savings for Dallas...... 94

Figure 69. Average source energy savings reduction versus insulation level for Dallas................ 94

Figure 70. Annualized energy-related costs versus average source energy savings for

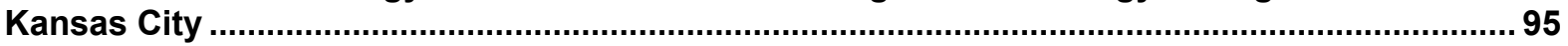

Figure 71. Average source energy savings reduction versus insulation level for Kansas City....... 95

Figure 72. Annualized energy-related costs versus average source energy savings for Boston.... 96

Figure 73. Average source energy savings reduction versus insulation level for Boston ............... 96

Figure 74. Annualized energy-related costs versus average source energy savings for Duluth..... 97

Figure 75. Average source energy savings reduction versus insulation level for Duluth ............... 97

\section{Unless otherwise noted, all figures were created by Building Science Corporation.}

\section{List of Tables}

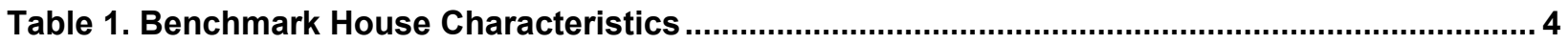

Table 2. Benchmark House Enclosure Specifications ...................................................................... 4

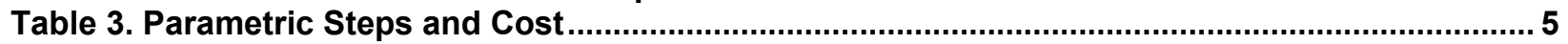

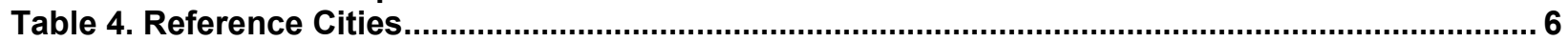

Table 5. Thermal Resistance Values To Control Condensation for Climate Zones 5, 6, 7, 8, and

Marine 4 From (2009 IRC and 2012 IRC)................................................................................ 13

Table 6. Framed Wall Minimum R-Values ........................................................................................... 17

Table 7. Minimum Exterior Insulation Required for Common Wall Framing Dimensions................ 19

Table 8. Typical Thermal Resistance of Common Rigid Insulation Materials .................................. 20

Table 9. 2009 IECC Compliance Minimum Insulation and Vapor Retarder Requirements* ............. 21

Table 10. 2012 IECC Compliance Minimum Insulation and Vapor Retarder Requirements* ............ 21

Table 11. Vertical Screw Spacings for Attaching Wood Furring Strips to the Structure for up to 4

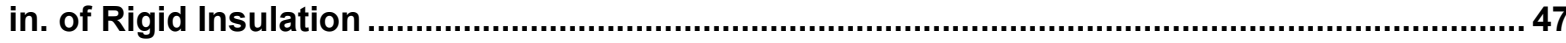

Table 12. Vertical Screw Spacings for Attaching Wood Furring Strips to the Structure for up to 4

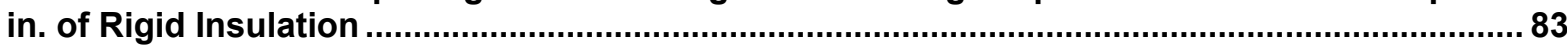

Table 13. Minimum Furring and Attachment Requirements ....................................................... 98

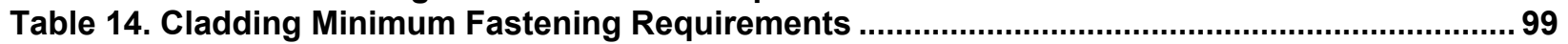

Table 15. Furring Minimum Fastening Requirements .............................................................. 100

Table 16. Effective R-Value Calculation Using Parallel Paths Method ............................................. 103

Unless otherwise noted, all tables were created by Building Science Corporation. 


\section{Definitions}

AFPA/NDS American Forest and Paper Association: National Design Specification

APA

ASHRAE

ASTM

BEopt $^{\mathrm{TM}}$

EPS

IECC

IRC

MF

o.c.

OSB

PIC

WRB

XPS
American Plywood Association

American Society of Heating, Refrigerating and Air-Conditioning Engineers

American Society for Testing and Materials

Building Energy Optimization Software

Expanded Polystyrene

International Energy Conservation Code

International Residential Code

Mineral Fiber

On Center

Oriented Strand Board

Foil-Faced Polyisocyanurate

Water-Resistive Barrier

Extruded Polystyrene 


\section{Executive Summary}

This measure guideline, written by the U.S. Department of Energy's Building America team Building Science Corporation, provides information about the design and construction of wall assemblies that use layers of rigid exterior insulation thicker than $1-1 / 2$ in. and that require a secondary cladding attachment location exterior to the insulation. The guideline is separated into several distinct sections that cover: (1) fundamental building science principles relating to the use of exterior insulation on wall assemblies; (2) design principles for tailoring this use to the specific project goals and requirements; and (3) construction detailing to increase understanding about implementing the various design elements. 


\section{Progression Summary}

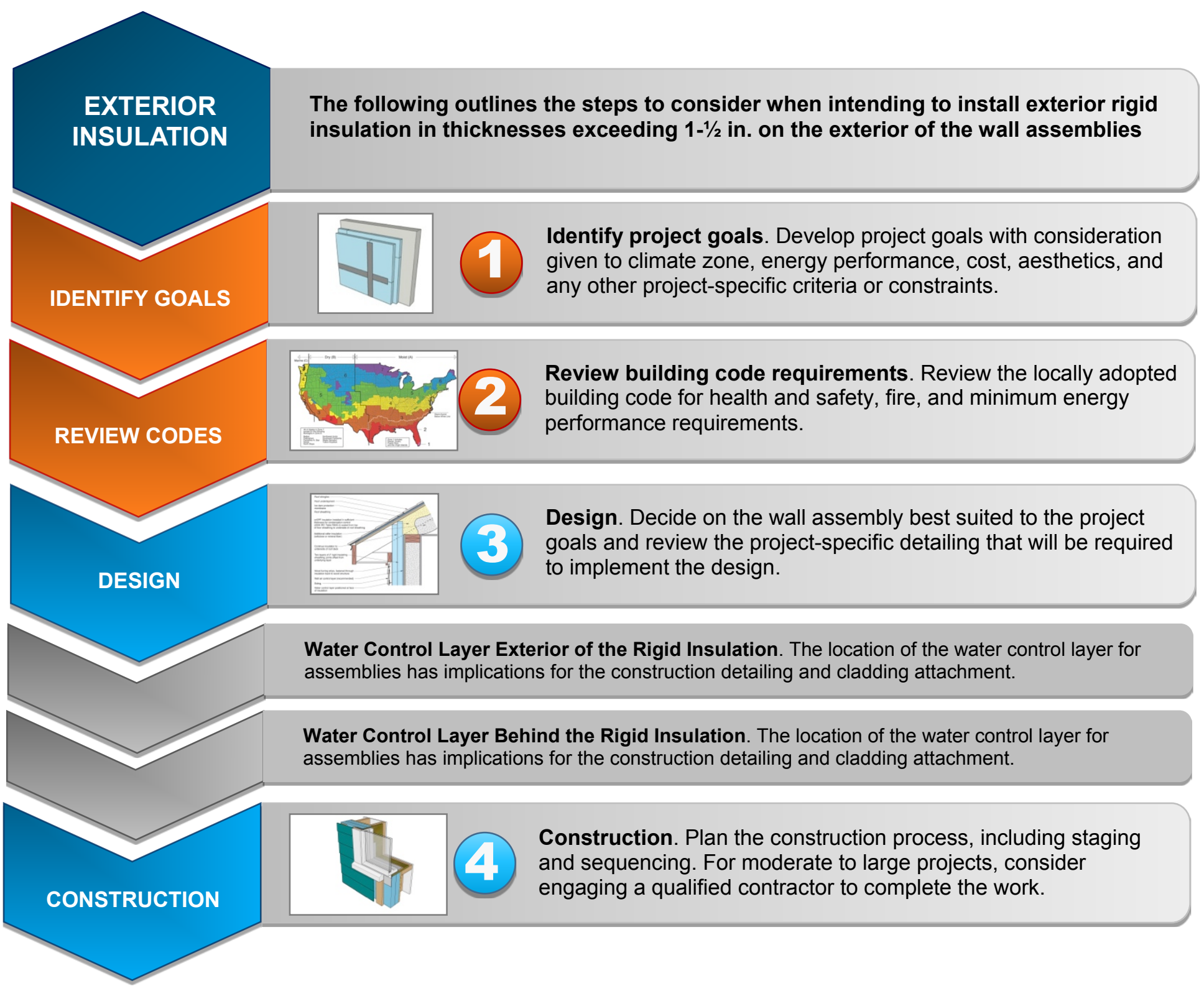




\section{Introduction}

This measure guideline provides information about the design and construction of wall assemblies that use layers of rigid exterior insulation thicker than $1-1 / 2$ in. The use of exterior insulation on wall assemblies is an effective strategy to address many common building enclosure energy and durability issues experienced in the industry. Insulation on the exterior of the structure can increase the overall thermal resistance of the assembly (beyond what is possible with cavity fill insulation) and provides increased condensation resistance in cold climates (Hutcheon 1964; Straube and Burnett 2005; Lstiburek 2007).

The guideline is separated into several distinct sections that cover: (1) fundamental building science principles relating to the use of exterior insulation on wall assemblies; (2) design principles for tailoring this use to the specific project goals and requirements; and (3) construction detailing to increase understanding about implementing the various design elements.

Designers, contractors, and building code officials will benefit from the information contained in the guide. The use of exterior rigid insulation on wall assemblies is becoming more common in the building industry, and is even part of the prescriptive requirements of the 2012 International Energy Conservation Code (IECC); however, a lack of information about effectively incorporating it in projects has prevented the widespread adoption of this energy reduction measure. Gaps in the building code that do not explicitly allow or provide guidance on the implementation create resistance for designers, builders, and building code officials who are responsible for the construction. This is not surprising, because improper detailing and construction can lead to water management and other building durability problems. It is important to understand the materials being used in the design and the detailing of how those materials are incorporated into the wall assemblies.

This guide covers the use of rigid exterior insulation boards ${ }^{1}$ such as expanded polystyrene (EPS), extruded polystyrene (XPS), polyisocyanurate (PIC), and rigid mineral fiber (MF) as exterior insulation on wall assemblies. The guide also focuses on the use of layers of insulation thicker than $1-1 / 2$ in. (exceeding the practical limit of directly attaching siding through the insulation back to the structure) that require a secondary cladding attachment location exterior to the insulation. The cladding attachment strategy is the use of wood furring strips attached back through the insulation to the structure. This approach provides an effective cladding attachment location when thick layers of exterior rigid insulation are used (Straube and Smegal 2009; Pettit 2009; Joyce 2009; Ueno 2010).

Once the decision to incorporate exterior rigid insulation into the design of the wall assemblies has been made, the next decision is where to place the water control layer. This layer will most commonly be either in front of or behind the insulation. Either strategy can work, but we strongly recommend that a single strategy be used for the entire project to avoid confusion during construction. One of the most common issues noted during construction are reverse

\footnotetext{
${ }^{1}$ The use of closed-cell spray polyurethane foam is another exterior insulation strategy; however, it is not covered in this guideline.
} 
flashings or other holes resulting from inconsistencies in the locations of the water control layers. To help mitigate the confusion, the construction section of this document is split into two very similar parts. The first part contains details that have the water control layer in front of the insulation; the second section has the water control layer behind the insulation.

For the most part, this measure will be used as part of a larger building project; thus, we strongly recommend that a design professional or a qualified contractor be retained. 


\section{Decision-Making Criteria}

The options for constructing high thermal performance wall assemblies include exterior rigid insulation, double-stud walls, structural insulated panels, insulated concrete forms, and exterior insulation and finish systems. The decision about which assembly to use is complicated by weighing technical attributes, building durability risks, and cost implications (Straube and Smegal 2009). Of the many available variations on high performance wall assemblies, exterior rigid insulation provides a high thermal performance enclosure and many other benefits with respect to building durability (Lstiburek 2007; Straube and Smegal 2009).

The decision to incorporate exterior rigid insulation on a building project depends on many factors. Fundamental to the measure is a desire to increase building thermal performance. Deciding on the project thermal performance goals is one of the first steps in the decisionmaking process. These goals are then compared to other factors to determine the viability of the measure. In most projects, the cost of the measure compared to the thermal performance is the primary consideration. However, other aspects such as code compliance, constructability, and inservice performance must also be considered.

\subsection{Cost}

Evaluating the cost of the measure is probably the first step in determining the viability of incorporating it into the project. There are many ways to evaluate the cost to help guide the decision. The first is a simple project budget evaluation where the full cost of the measure is determined and added to the overall project cost to see the impact. Understanding what should be included in this valuation is important to obtain a realistic view of the increased project cost. For this measure, costs would typically include:

- Installed cost of the insulation material

- $1 \times 3$ wood furring strips spaced at 16 in. on center (o.c.)

- Wood screws spaced at 24 in. o.c. vertically to attach the furring back to the structure

- A markup per window for trim extensions that would be needed to account for the additional thickness of foam added to the exterior of the home.

Other items such as house wrap or sheathing tape, self-adhered membrane flashings, metal flashings, siding, and siding fasteners should be omitted from the analysis because these items are associated with cladding and water management, and would be part of the project with or without exterior insulation.

Depending on the results of this preliminary analysis, project costs may need to be cut in some areas to bring them in line with the budget. At this point, a more detailed cost-benefit analysis may be required to help determine the value of this measure compared to other aspects of the project. Value can be difficult to quantify because it is not simply a measure of cost, but can also include personal values, aesthetics, and other subjective measures. For some who are looking to design, build, or own low energy use buildings, the value of energy reduction may extend 
beyond simple economic payback. In these cases, the end performance may be worth the additional economic investment.

For those who want to provide some economic justification for the additional cost, a cost-benefit analysis designed to examine the cost of the measure in conjunction with cost reductions resulting from lower energy use may provide the best information. This type of analysis combines the present worth of the measure cost with the present worth of the cost of energy used over a chosen period of time. There are two primary types of results:

- Cost-optimized result. A cost-optimized result has the lowest combined present worth of the measure cost and the fuel cost over the analysis period. This is the most economical strategy and results in the best economic payback on the measure implemented.

- Cost-neutral result. A cost-neutral result is one where the combined present worth of the measure and the fuel cost is lower than the present worth of the fuel cost of the baseline building. This result does not necessarily see much economic payback, but does result in lower energy use and is a good metric for those intending to reduce energy use at no additional cost.

The following analysis was completed as an illustrative example of a building retrofit. A benchmark house was chosen to provide a baseline for the analysis. The house was assumed to be single-family detached, two-story, slab-on-grade new construction. Table 1 lists the basic characteristics. The specifications of the home were based on guidance from the B10 Benchmark, as specified in the 2014 Building America House Simulation Protocols (Wilson et. al. 2014). Table 2 lists the enclosure specifications, derived from the 2009 IECC, which is referenced in the B10 Benchmark.

Table 1. Benchmark House Characteristics

\begin{tabular}{c|c}
\hline House Characteristics & $\mathbf{f t}^{\mathbf{2}}$ \\
\hline Finished Floor Area & 2312 \\
Ceiling Area & 1156 \\
Slab Area & 1156 \\
Wall Area & 2799 \\
Window Area & $331(15 \%$ glazing ratio $)$ \\
\hline Infiltration & 7 ACH 50 \\
\hline
\end{tabular}

Table 2. Benchmark House Enclosure Specifications

\begin{tabular}{c|c|c|c|c|c}
\hline City & $\begin{array}{c}\text { Ceiling } \\
\text { R-Value }\end{array}$ & $\begin{array}{c}\text { Frame Wall } \\
\text { R-Value }\end{array}$ & $\begin{array}{c}\text { Window } \\
\text { U-Value }\end{array}$ & $\begin{array}{c}\text { Window } \\
\text { SHGC }\end{array}$ & $\begin{array}{c}\text { Slab R-Value, } \\
\text { Depth }\end{array}$ \\
\hline Dallas, TX & 30 & 13 & 0.37 & 0.30 & 0 \\
\hline Kansas City, MO & 38 & 13 & 0.35 & 0.44 & $10,2 \mathrm{ft}$ \\
Boston, MA & 38 & 19 & 0.35 & 0.44 & $10,2 \mathrm{ft}$ \\
Duluth, MN & 49 & 21 & 0.35 & 0.44 & $10,4 \mathrm{ft}$ \\
\hline
\end{tabular}


To complete the evaluation, we looked at the incremental cost of adding several different thicknesses of insulation to the exteriors of the wall assemblies. PIC was used as the exterior insulation. Cost data for the exterior insulation were taken from RS Means Construction Data (Reed Construction Data 2011). Costs included the installed cost of the insulation material, $1 \times 3$ wood furring strips spaced at 16 in. o.c., and wood screws spaced at 24 in. o.c. vertically to attach the furring back to the structure. A cost markup of $\$ 100$ per window in the reference model was used as an estimate of the additional cost for trim extensions that would be needed to account for the additional thickness of foam added to the exterior of the home.

Simulations were run using Building Energy Optimization (BEopt $\left.{ }^{\mathrm{TM}}\right)$ simulation software, version 2.2.0.1, developed by the National Renewable Energy Laboratory. More specifically, the DOE-2 engine was used to run the simulations in BEopt. The wall conductance performance was isolated from all other aspects of the home to examine the cost effectiveness of this single strategy. For each parametric step the present worth of the measure cost (financed over a 5-year period at a 7\% interest rate) and the cost of energy used (based on a 30-year period and a fuel escalation rate of $2 \%$ ) was calculated. Table 3 illustrates the parametric steps that were run in the analysis. The reference case (parametric step R) is assumed to be fully sheathed $100 \%$ with oriented strand board (OSB). The percentage of OSB is reduced to $25 \%$ when exterior insulation is added to the wall system. This $25 \%$ is a result of installing OSB only where structurally necessary. The analysis was completed for various IECC climate zones ranging from $3 \mathrm{~A}$ through 7A (see Table 4 for the associated reference cities).

Table 3. Parametric Steps and Cost

\begin{tabular}{|c|c|c|c|}
\hline $\begin{array}{l}\text { Parametric } \\
\text { Step }\end{array}$ & Description & $\begin{array}{c}\text { OSB Cost } / \mathrm{ft}^{2} \\
\text { (\% of Wall } \\
\text { Sheathed) } \\
\end{array}$ & $\begin{array}{c}\text { Incremental } \\
\text { Cost } / \mathbf{f t}^{2} \text { Over } \\
\text { Base Wall } \\
\end{array}$ \\
\hline $\mathbf{R}$ & $\begin{array}{c}\text { Base wall: IECC } 2009 \text { wall (Dallas and } \\
\text { Kansas City = R-13, Boston = R19, } \\
\text { Dulles }=\text { R-21) }\end{array}$ & $\begin{array}{c}\$ 1.29 \\
\text { (fully sheathed) }\end{array}$ & N/A \\
\hline 1 & $\begin{array}{c}\text { IECC } 2009 \text { wall + } 1 \text { in. exterior } \\
\text { insulation (R-6.5) }\end{array}$ & $\begin{array}{c}\$ 0.21 \\
(25 \% \text { sheathed })\end{array}$ & $\$ 1.35$ \\
\hline 2 & $\begin{array}{c}\text { IECC } 2009 \text { wall + } 1.5 \text { in. exterior } \\
\text { insulation }(\mathrm{R}-9.75)\end{array}$ & $\begin{array}{c}\$ 0.21 \\
(25 \% \text { sheathed })\end{array}$ & $\$ 0.21$ \\
\hline 3 & $\begin{array}{c}\text { IECC } 2009 \text { wall }+2 \text { in. exterior } \\
\text { insulation }(\mathrm{R}-13)+1 \times 4 \text { wood furring }\end{array}$ & $\begin{array}{c}\$ 0.21 \\
(25 \% \text { sheathed })\end{array}$ & $\$ 1.97$ \\
\hline 4 & $\begin{array}{l}\text { Benchmark }+2 \text { layers of } 1.5 \text { in. exterior } \\
\text { insulation }(\mathrm{R}-19.5)+1 \times 4 \text { wood furring }\end{array}$ & $\begin{array}{c}\$ 0.21(25 \% \\
\text { sheathed })\end{array}$ & $\$ 1.46$ \\
\hline 5 & $\begin{array}{l}\text { Benchmark }+2 \text { layers of } 2 \text { in. exterior } \\
\text { insulation }(\mathrm{R}-26)+1 \times 4 \text { wood furring }\end{array}$ & $\begin{array}{l}\$ 0.21(25 \% \\
\text { sheathed })\end{array}$ & $\$ 0.39$ \\
\hline
\end{tabular}


Table 4. Reference Cities

\begin{tabular}{c|c}
\hline City & Climate Zone \\
\hline Dallas, TX & $3 \mathrm{~A}$ \\
Kansas City, MO & $4 \mathrm{~A}$ \\
Boston, MA & $5 \mathrm{~A}$ \\
Duluth, MN & $7 \mathrm{~A}$ \\
\hline
\end{tabular}

Appendix A provides detailed results of the analysis. In summary, in all climate zones, insulation thickness up to $1-1 / 2$ in. (parametric step 2) was determined to be a cost-optimized solution. This was mainly due to an increase in the cost of the measure with the addition of wood furring strips and screw fasteners when exterior insulation $2 \mathrm{in.} \mathrm{or} \mathrm{thicker} \mathrm{were} \mathrm{used.} \mathrm{Even} \mathrm{with} \mathrm{this} \mathrm{increase,}$ insulation thicknesses of 2-4 in. (parametric steps 3, 4, and 5) were still demonstrated to be cost neutral in all cities as part of this simplified analysis.

The analysis focused on conductance improvements only; however, some argue that adding exterior insulation would likely also improve the overall airtightness of the assemblies (Ueno 2010). The benefits of increased airtightness are known to be very important in cold climate construction; however, isolating and apportioning these benefits to individual measures are also more difficult.

\subsection{Code Compliance}

When evaluating the potential for using exterior rigid insulation on a building project, all locally adopted code requirements must be met.

Structural attachments to resist wind and gravity loads need to be considered and designed. Recent code change proposals have added prescriptive requirements tables to the International Residential Code (IRC) to allow for the use of wood furring strips over exterior rigid insulation as a cladding attachment location. These tables (which are new to the codes in the 2015 code cycle) provide guidance on the attachment of furring strips back to the structure to address wind withdrawal loads and gravity loads from the weight of the cladding. At the time of this writing these tables are likely not part of most locally adopted codes, but are included in Appendix B for reference.

Fire safety is also an important consideration. Most exterior rigid insulation materials are considered foam plastics, which have specific code requirements for their use in buildings. Building type, location, and proximity to other structures may impact the fire rating requirements of the wall assemblies. Fire code requirements should be evaluated early in the design process to ensure that chosen assemblies are permissible. Most insulation manufacturers provide guidance on the use of their products in exterior wall assemblies, including a list of Underwriters Laboratories-approved assemblies that can be used in design.

Finally, the IECC (2012) has added prescriptive requirements requiring the use of exterior rigid insulation for certain wall assemblies in certain climate zones. The need to use exterior rigid insulation may be a code requirement for the project and not just part of the project goals. 


\subsection{Constructability}

The ease of implementing a measure can greatly impact the success of a project. Difficult details and construction sequences often lead to increased costs and performance loss. Efficiency in construction is driven by simple repeatable details and common construction practices. The more a measure deviates from common construction techniques, requires overly complicated sequences, or involves multiple trades, the more likely the work will not have the intended result.

A key benefit to the use of exterior rigid insulation on wall assemblies is that it does not significantly change standard construction practices and details. The framing of the base building elements remains the same, with only slight modifications to interior and exterior trims. The only exception is where there is a wall above a roof. This is the most problematic detail during construction, because it requires a change in typical construction sequences that install roofing before covering the walls. This detail is not difficult to implement, but it does require preplanning to ensure that the correct elements are in place before the roof is installed.

\subsection{Water Management Performance}

Intrinsic to the measure is the use of wood (or other) structural furring strips. These furring strips hold the insulation to the wall and provide a structural attachment location for the cladding. In general, the furring strips are at least $3 / 4$-in. thick to provide sufficient material for the cladding fastener penetration. The gap that is created between the insulation and the cladding provides a significant water management benefit of drainage and back-ventilation of the cladding.

\subsection{Moisture Management Performance}

In cold climates, exterior rigid insulation reduces condensation problems in wood-framed walls. Traditional vapor control strategies try to limit the interior humid air that can come into contact with the exterior sheathing to reduce the condensation potential. Gaps in the interior air control layer (typically drywall) and vapor control layer (typically polyethylene or kraft-faced batts) can lead to condensation problems. Rigid insulation on the exterior of the wall assemblies keeps the exterior sheathing warmer and reduces the condensation potential. In fact, this benefit is recognized in the code, and sufficient exterior rigid insulation can allow the traditional interior vapor control layer to be eliminated.

\subsection{Thermal Performance}

Rigid insulation on the exterior of the wall assembly greatly reduces the thermal bridging potential of the wall assembly. This allows the nominal insulation value to be very close to the in-service or "effective" thermal resistance value. By contrast, the thermal resistance of cavity fill insulation is reduced by the framing's thermal bridging. For framed walls, the assembly's effective thermal resistance can be at least $20 \%$ lower than the nominal value.

\subsection{Risk Identification}

A few risk factors are associated with the general design and performance of this measure.

\subsubsection{Safety Risks}

The measure is installed from the exterior. We recommend typical care and personal protective equipment for general building construction and fall protection. 
Working with exterior insulation products presents minimal health risks from skin contact, cutting, and grinding. In most cases, general skin, eye, or respiratory irritation results. General protective equipment, such as gloves and long-sleeve shirts, is recommended to avoid direct skin contact. In poorly ventilated areas, respiratory equipement may be warranted.

In the event of a fire, toxic fumes are released from foam plastic insulation such as XPS, EPS, and PIC. The area should be cleared to avoid inhalation of fumes.

\subsubsection{Durability and Structural Risks}

Most durability risks are associated with design errors and construction defects if the measure is properly implemented.

Poor flashing details present probably the most significant risk with this approach. However, this is true with almost all wall assemblies that are constructed with moisture-sensitive materials such as wood. Flashings at windows, doors, decks, balconies, roofs, and other penetrations are discussed in this guideline to help mitigate this concern.

The second-largest risk is from improper structural attachment of the various elements. The load transfer path should be considered in the design for temporary and permanent installations. For this measure, the cladding is attached to the wood furring strip and not back to the structure. Therefore, the load transfer path is first to the furring and then from the furring through the insulation to the structure. The furring and the cladding need to be designed for their respective attachment locations and for the gravity and wind loading for their specific project requirements. For other elements, such as decks and balconies, the attachment back to the structure needs to be designed based on the expected loading. Some ideas for attachment are presented in this measure guideline; however, these should be used only with additional analysis to ensure adequacy for each project. The designer is responsible to ensure the adequacy of the building design. 


\section{Technical Description}

\subsection{Fundamental Principles}

This section provides fundamental information about the use of exterior insulation on wall assemblies. The intent is to provide some background physics and logic for how the measure impacts building performance.

Wall assemblies form one part of the building and provide a separation between the inside and outside environments. This separation is often referred to as a building enclosure or a building envelope. For wall assemblies, control of rainwater, airflow, water vapor flow, and heat flow are key factors in providing a durable enclosure. The control of these elements can be separated into four principal control layers, presented in order of importance:

- A water control layer

- An air control layer

- A vapor control layer

- A thermal control layer.

The control layers are best placed on the outside of the structure to protect the structure. The optimum configuration is presented in Figure 1.

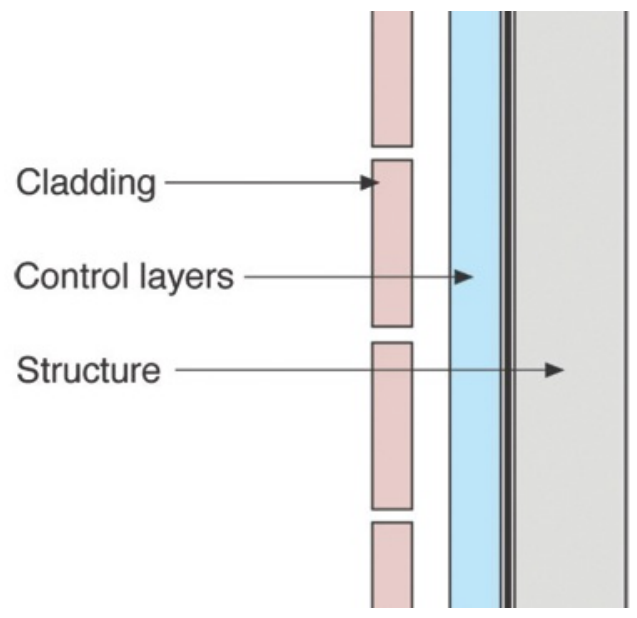

Figure 1. Optimum configuration of control layers

\subsubsection{Water Control Layer}

Rainwater control is the single most important factor in the design and construction of durable wall assemblies. All exterior claddings pass some rainwater through leaks in siding, brick, stucco, and stone. As such, some control of this penetrating rainwater is required. 
In most walls, a water control layer protects the structure. Water control layers are water-repellent materials (building paper, house wrap, sheet membranes, liquid-applied coatings, or taped and sealed rigid insulation boards) that are located behind the cladding and are designed and constructed to drain water that passes through the cladding. They are interconnected with flashings, window and door openings, and other penetrations of the building enclosure to drain water to the exterior of the building. The materials that form the water control layer overlap in a shingle fashion or are sealed so that water drains down and out of the wall. The water control layer is often referred to as the drainage plane, the waterresistive barrier (WRB), or the water control layer.

For the water control layer to be effective, water must drain downward and outward from behind the cladding. For drainage to occur, a drainage space must be provided between the cladding and the water control layer. The width of this space varies depending on cladding type and function. If large enough, the drainage space can also provide ventilation and facilitate the redistribution and removal of absorbed water. Rainwater can be drained effectively in spaces as small as $1 / 16$ to $1 / 8$ in. ( 2 or $3 \mathrm{~mm}$ ). For ventilation, a gap of about $3 / 8$-in. $(10 \mathrm{~mm})$ or larger is typically required.

The "out" direction is typically provided by flashings (see Figure 2). Flashings are the most underrated building enclosure components and arguably the most important. Flashings are integrated with water control layers, creating for all practical purposes a flashing for the entire assembly (Figure 3 and Figure 4).
CODE REQUIREMENTS FOR WRBS ARE AVAILABLE IN SECTION R703 OF THE 2009 AND 2012 IRC. FOAM PLASTIC INSULATING SHEATHINGS CAN BE CLASSIFIED AS WRBS PROVIDED THEY MEET THE REQUIREMENTS OF THE INTERNATIONAL CODE COUNCIL EVALUATION SERVICE ACCEPTANCE CRITERIA AC-12 AND AC-71. SECTION 703.8 REQUIRES FLASHING TO MEET AMERICAN ARCHITECTURAL MANUFACTURERS ASSOCIATION 711 (SELFADHERED) OR 714 (FLUID APPLIED).

In general, the sooner water is directed to the exterior the better. Sooner may not always be practical, such as at window openings where draining a window into a drainage space behind a cladding is often more practical than draining it to the exterior face of the cladding.

Vinyl siding installed directly over continuous insulation, house wrap, or building paper (without furring) does provide an effective drainage path and ventilation despite the direct contact of the siding to these surfaces, because of the airspace resulting from the cross-sectional profile of the vinyl siding and its nonairtight nature. 


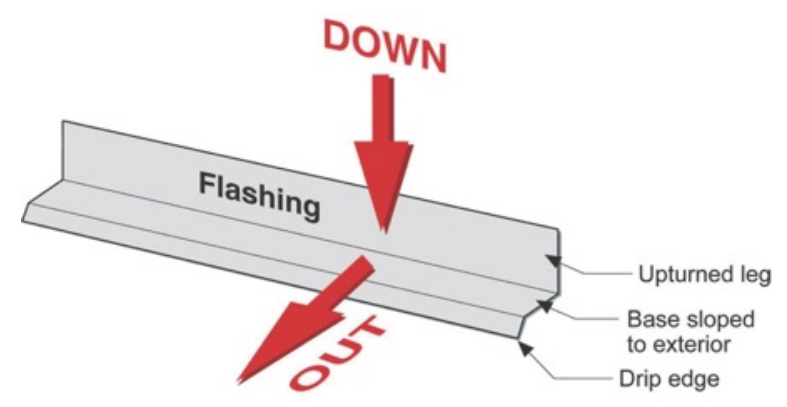

Figure 2. The "down" and "out" approach to flashing

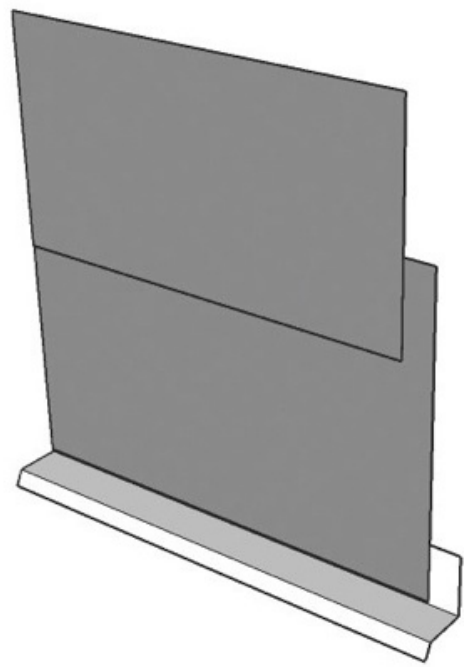

Figure 3. Flashing integrated with the water control layer with lapped joints

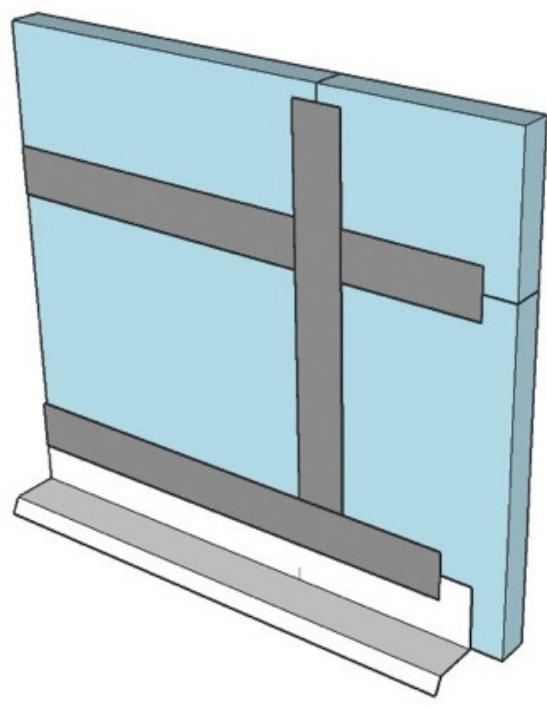

Figure 4. Taped rigid insulation water control layer with sealed joints

\subsubsection{Air Control Layer}

Controlling airflow in a building enclosure is important because it influences heat and moisture flow. A key strategy in the control of airflow is the use of air control layers. These materials systems are designed and constructed to control airflow between a conditioned space and an unconditioned space. The air control layer is the primary air enclosure boundary that separates indoor (conditioned) air from outdoor (unconditioned) air.

Air control layers can be located anywhere in the wall assembly - at the exterior surface, the interior surface, or at any location between these surfaces. Depending on the climate or wall configuration, air control layers might be required to address airflow through the enclosure assembly and to control airflow into or within

Air control layers should be:

- Impermeable to airflow

- Continuous over the entire building enclosure

- Able to withstand the forces that may act on them during and after construction

- Durable over the expected lifetime of the building. the enclosure assembly. In some cases, providing more 
than one air control layer may be preferable for optimum vapor control and thermal performance. A common way of doing this is to use both the exterior sheathing and the interior gypsum board finish as air control layers.

\subsubsection{Vapor Control Layer}

A vapor control layer functions on the fundamental principle of keeping water vapor out of an assembly and letting water vapor out if it enters. In this regard, the vapor control layer is really a vapor control "assembly" or "strategy" that strategically uses materials with specific vapor control properties within the assembly. It can be complicated because sometimes the best strategies to keep water vapor out also trap it in.

Vapor control layers installed on the interiors of assemblies prevent assemblies from drying inward. This is a concern in any air-conditioned building, or in any building where a vapor control layer is also placed on the exterior - the "double vapor barrier" problem. Moisture retention can cause problems if the assemblies start out wet because of rain or because wet materials were used during construction without having sufficient time to dry before being closed in.

The three principal control approaches to dealing with water in the vapor form follow.

- Let the water vapor pass through the assembly from the inside out and from the outside in. This is called a flow-through assembly and can dry to both sides.

- Place a distinctive vapor control layer to retard the flow of water vapor into the wall assembly from either the inside or the outside. This is called vapor control layer assembly. The most common location for a vapor control layer is on the inside "warm in winter" side of the thermal insulation.

- Control the temperature of the surfaces where condensation is likely by raising the surface temperature with insulation. The most common method of achieving this is to use rigid insulation on the exteriors of assemblies. This is called control of condensing surface temperature assembly.

Controlling the condensing surface temperature is the most versatile strategy and works well in all climate zones. In cold climates, it also provides the best protection against air leakage condensation problems, because it functions by preventing condensation instead of by limiting moisture movement. 
When rigid insulation is added to the exterior of the structural sheathing, the interior surface temperature of the structural sheathing increases because the insulation keeps the sheathing warmer. When the temperature of the condensing surface of interest is raised sufficiently, interior water vapor migrating into the wall assembly does not condense. This allows assemblies to be constructed in cold climates without interior vapor control layers. The building codes recognize this and provide guidance on the minimum thermal resistance values of rigid insulation required to control condensation, when class I and II vapor retarders are replaced with class III retarders in specific regions. Table 5 provides information from Table R601.3.1 Class III Vapor Retarders of the 2009 IRC and CODE REQUIREMENTS FOR AIR LEAKAGE ARE AVAILABLE IN SECTION 402.4 OF THE 2009 IECC AND R402.4 OF THE 2012 IECC.

Several methods are used to determine the effective thermal resistance of the wall assembly. Two of the most common are the parallel paths method and the isothermal planes method, as outlined in ASHRAE Fundaments (2013) Chapter 27. See Appendix C for worked examples.

Table R702.7.1 Class III Vapor Retarders of the 2012 IRC and provides guidance for thermal resistance values to control condensation for climate zones 5-8 and Marine 4 .

Table 5. Thermal Resistance Values To Control Condensation for Climate Zones 5, 6, 7, 8, and Marine 4 From (2009 IRC and 2012 IRC)

\begin{tabular}{c|c|c}
\hline Climate Zone & Framing Rigid Insulation & Minimum R-Value \\
\hline \multirow{2}{*}{$4 \mathbf{C}$} & $2 \times 4$ & 2.5 \\
& $2 \times 6$ & 3.75 \\
$\mathbf{5}$ & $2 \times 4$ & 5 \\
& $2 \times 6$ & 7.5 \\
\multirow{6}{*}{} & $2 \times 4$ & 7.5 \\
& $2 \times 6$ & 11.25 \\
$\mathbf{7 / 8}$ & $2 \times 4$ & 10 \\
& $2 \times 6$ & 15 \\
\hline
\end{tabular}

\subsubsection{Thermal Control Layer}

The thermal control layer regulates the flow of heat both from the inside to the outside and from the outside to the inside. As with the other control layers, the most important factor to consider when dealing with the thermal control layer is its continuity.

\subsubsection{Thermal Bridges}

Discontinuities in the thermal control layer are called thermal bridges. The most common thermal bridges in residential buildings are the framing members. In wood-framed construction, the framing is not highly conductive; however, it still provides less thermal resistance than common cavity insulation materials and therefore reduces the wall assembly's effective thermal resistance.
Air control layers are required to resist the air pressure differences that act on them. Rigid materials such as gypsum board and exterior sheathing materials such as plywood, OSB, and rigid insulation are particularly well suited as air control layers. Many flexible materials such as house wraps, sheet polyethylene, fully adhered membranes, and liquid-applied membranes typically need to be coupled with a rigid material to be effective. 
The framing part of the typical "opaque" part of the building enclosure when framing on 16-in. centers (not including windows and doors) is approximately $25 \%$ of the area. The insulated cavity part is $75 \%$ of this area. This is often expressed as a "framing factor" of $25 \%$. With woodframe buildings a framing factor of $25 \%$ reduces the nominal insulation value of the cavity insulation by approximately $20 \%$ for a standard $2 \times 6$ framed wall and $15 \%$ for a standard $2 \times 4$ wall. As an example, a nominal $2 \times 4$ wall with R-13 fiberglass batt insulation has an effective thermal resistance of around R-11.

Exterior rigid insulation in a framed wall assembly can have a significant impact on effective thermal resistance. Because minimal thermal bridging is placed through the rigid insulation, the nominal R-value of the material will be near the effective R-value added to the wall assembly. In the $2 \times 4$ wall example above, adding R-5 continuous exterior insulation increases the nominal insulation value to R-18 (R-13 + R-5) and the effective thermal resistance to R-16 (R-11 + R-5). This increases the wall's effective thermal resistance by $50 \%$.

\subsection{Climate Zones and Building Environments}

Buildings should be suited to their environment. Building enclosures should be designed for a specific hygrothermal region (Figure 5), rain exposure zone (Figure 6), and interior climate.

CODE REQUIREMENTS FOR THERMAL INSULATION ARE AVAILABLE IN SECTION 402 OF THE 2009 IECC AND R402 OF THE 2012 IECC.

For most residential buildings, interiors are assumed to be conditioned to around $70^{\circ} \mathrm{F}$ in the winter and $75^{\circ} \mathrm{F}$ in the summer. Relative humidity should be no higher than $35 \%$ during the coldest month in the winter and no higher than $65 \%$ in the summer.

These conditions also form the basis for the requirements delineated in the model building codes. Figure 7 shows the model climate zones referenced in the 2009 IECC and the 2012 IECC. Table 6 contains the minimum prescriptive thermal resistance (R-value) requirements specified in the 2009 IECC and the 2012 IECC based on climate zone. 


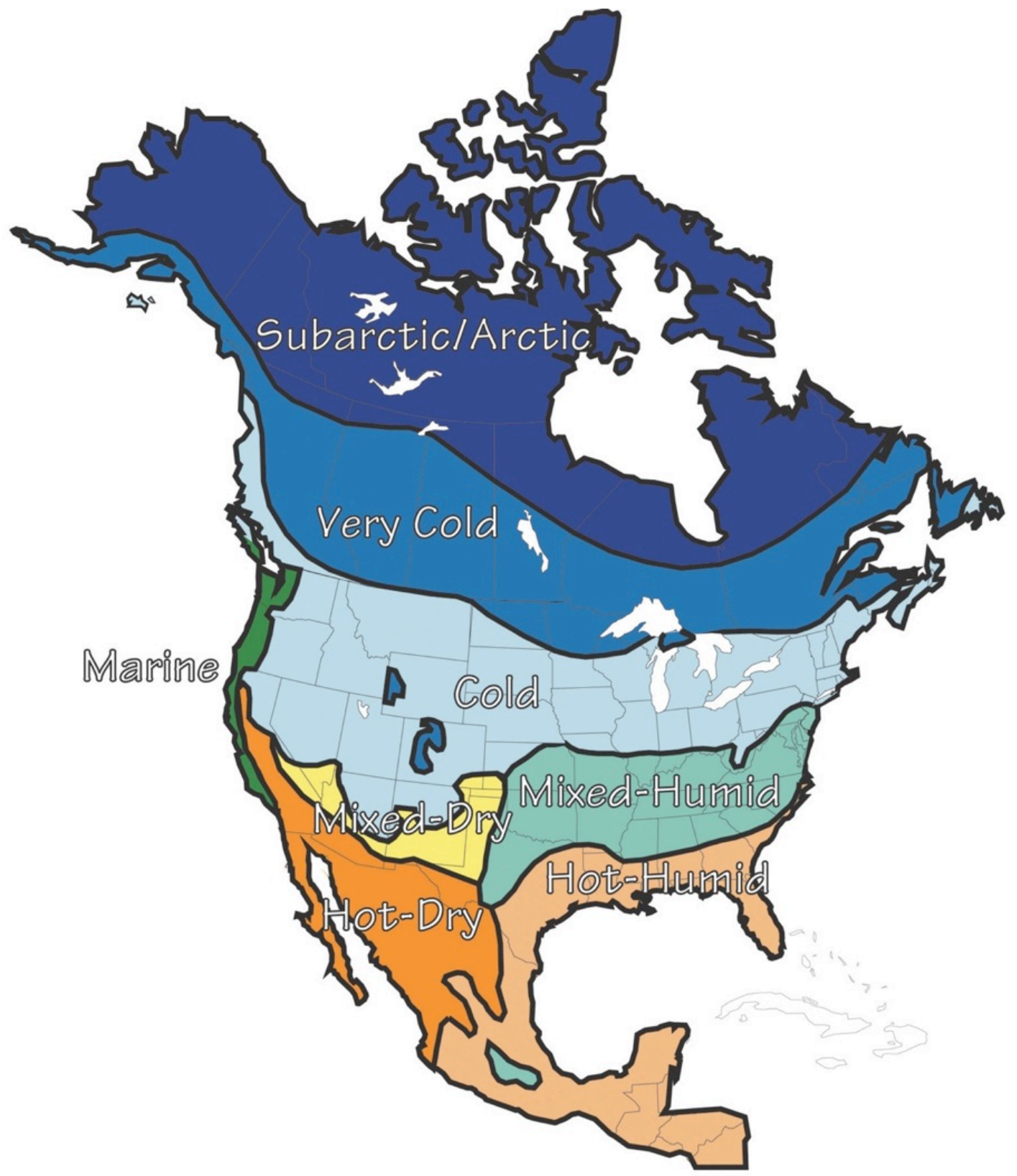

Figure 5. Hygrothermal map

(Lstiburek 2006) 


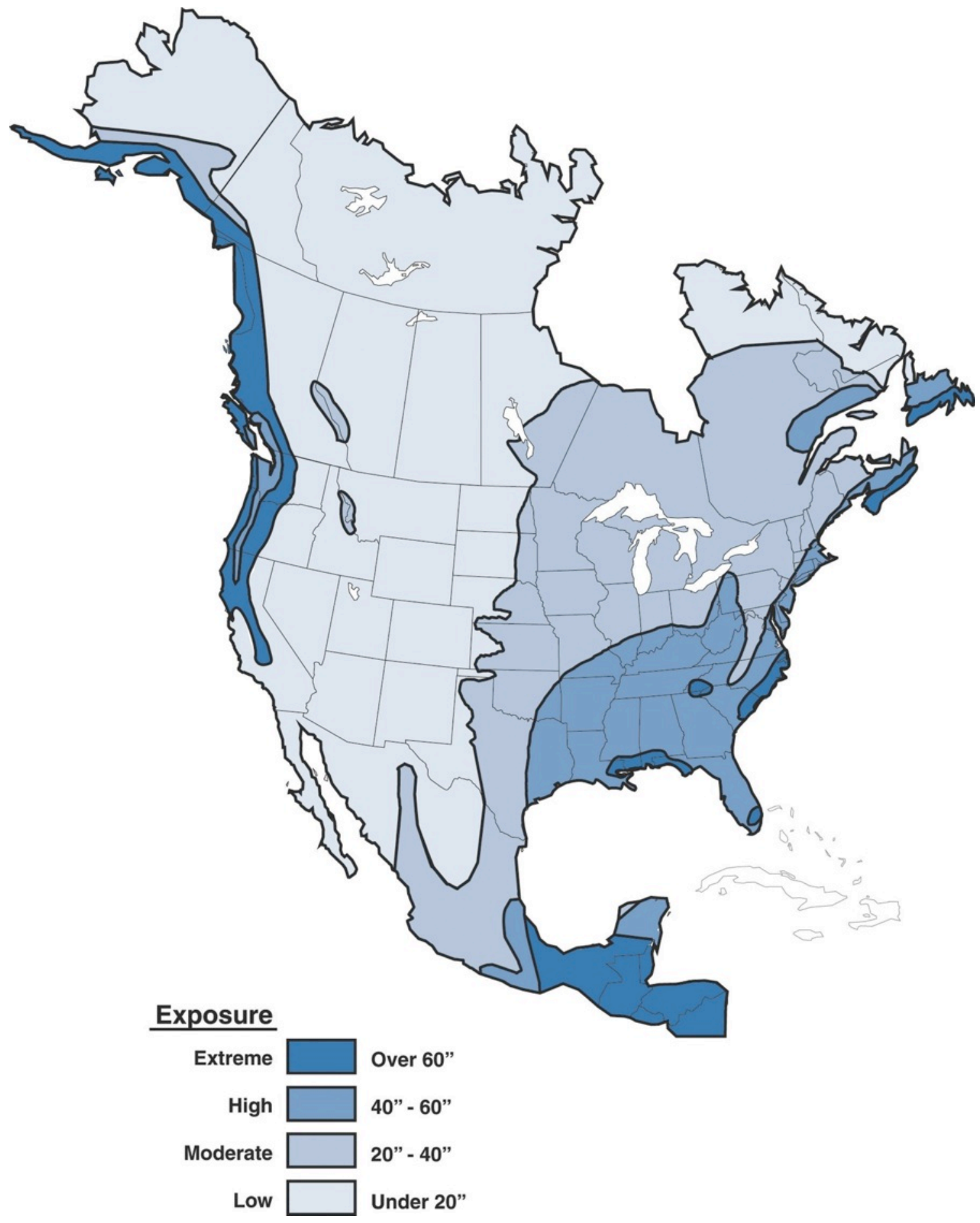

Figure 6. Rainfall map

(Lstiburek 2006) 


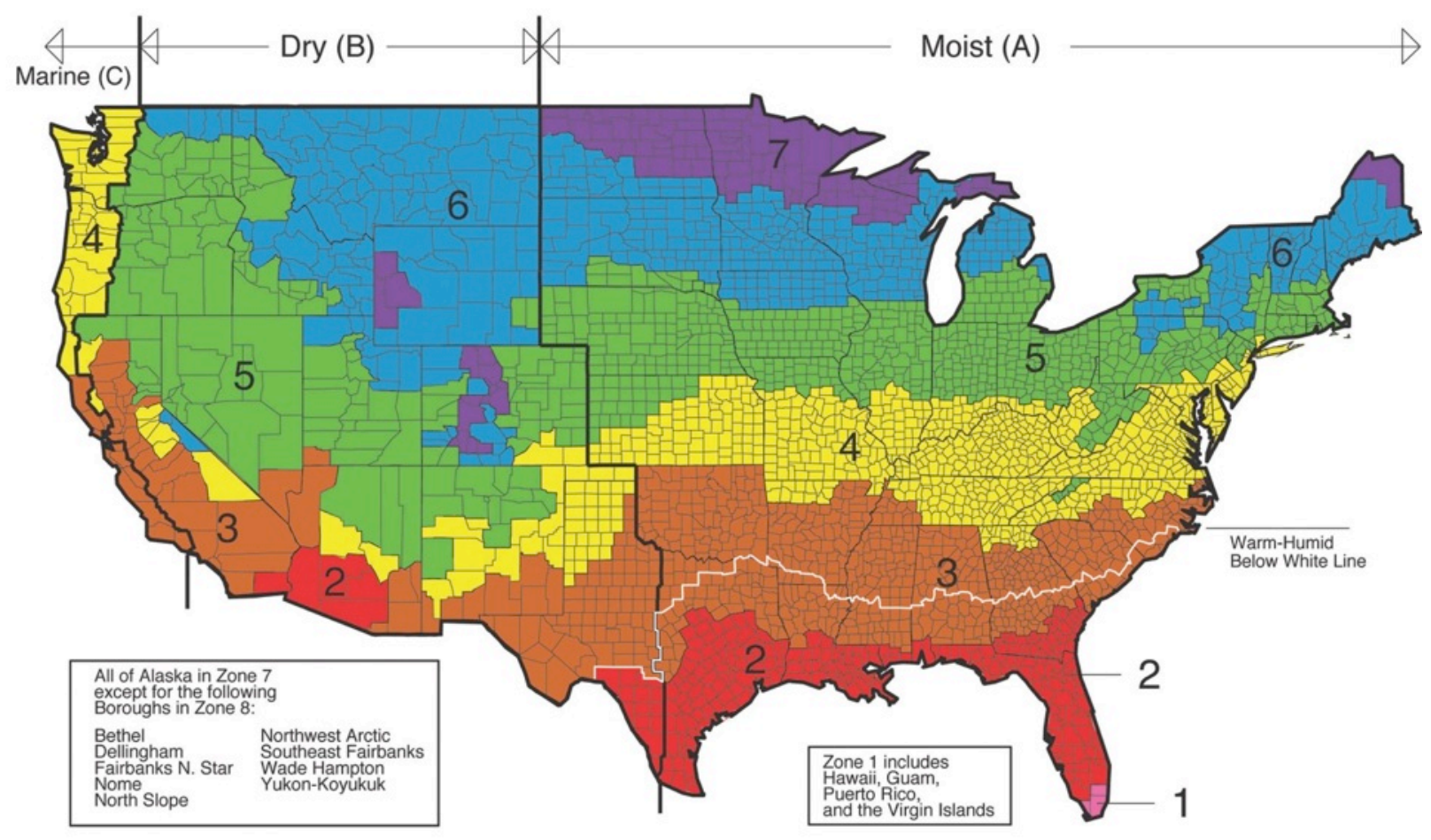

Figure 7. U.S. Department of Energy and IECC climate zones

Table 6. Framed Wall Minimum R-Values

\begin{tabular}{c|c|c}
\hline Climate Zone & 2009 IECC & 2012 IECC \\
\hline $\mathbf{1}$ & 13 & 13 \\
$\mathbf{3}$ & 13 & 13 \\
\hline $\mathbf{4}$ Except Marine & 13 & 20 or $13+5$ \\
\hline $\mathbf{5}$ and Marine $\mathbf{4}$ & 13 & 20 or $13+5$ \\
\hline $\mathbf{6}$ & 20 or $13+5$ & 20 or $13+5$ \\
\hline $\mathbf{7}$ and $\mathbf{8}$ & 20 or $13+5$ & $20+5$ or $13+10$ \\
\hline
\end{tabular}

\subsection{Design}

Section 3.3.1 covers recommended designs for wood-framed wall assemblies insulated with exterior rigid insulation.

\subsubsection{Water Control Layer}

Walls that are oversheathed with rigid insulation have several water control layer options. The water control layer is placed at the discretion of the designer, typically behind (Figure 8) or in front of (Figure 9 and Figure 10) the rigid insulation. It may also be placed between two layers of insulation (Figure 11), but this can lead to significant confusion and coordination problems during construction and is, for the most part, not recommended. The location affects many other 
enclosure connection details. The strategy should be clear and consistent throughout the project and detailed for continuity at all penetrations and intersections where joints occur.

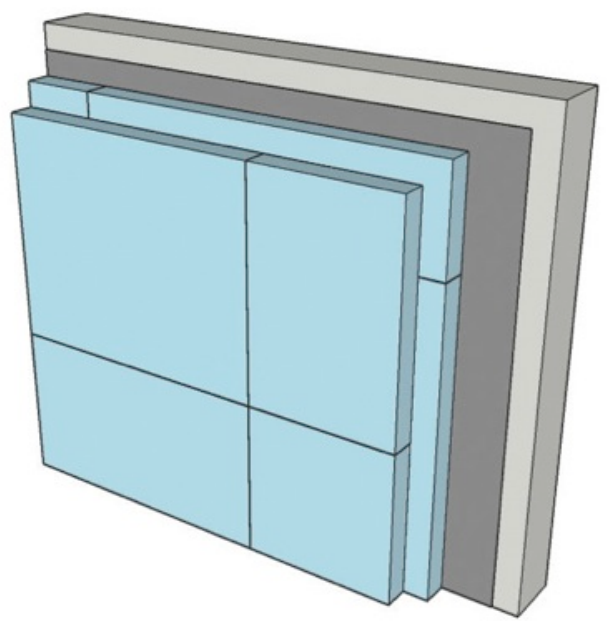

Figure 8. Water control layer behind the insulation

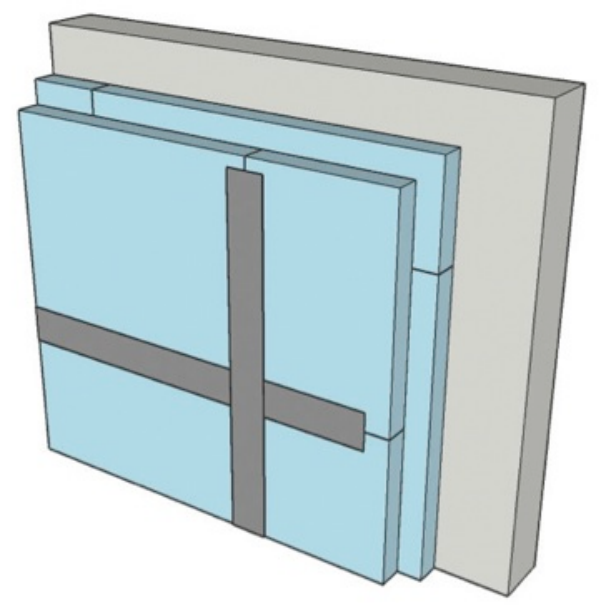

Figure 10. Water control layer using the face of the foam with taped joints

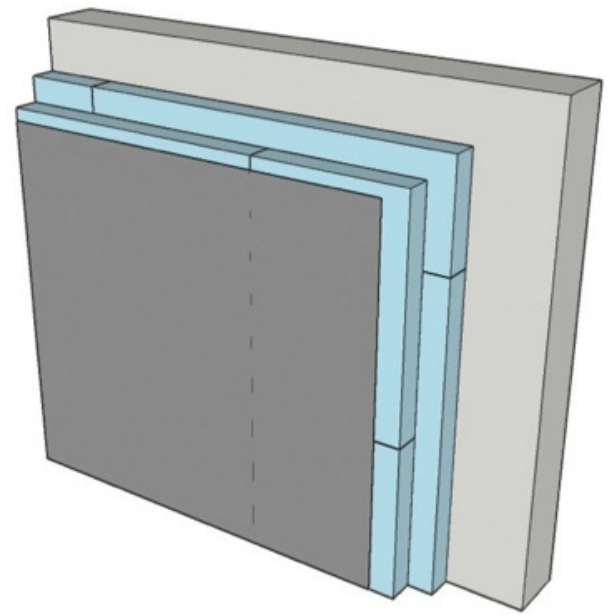

Figure 9. Water control layer in front of the insulation

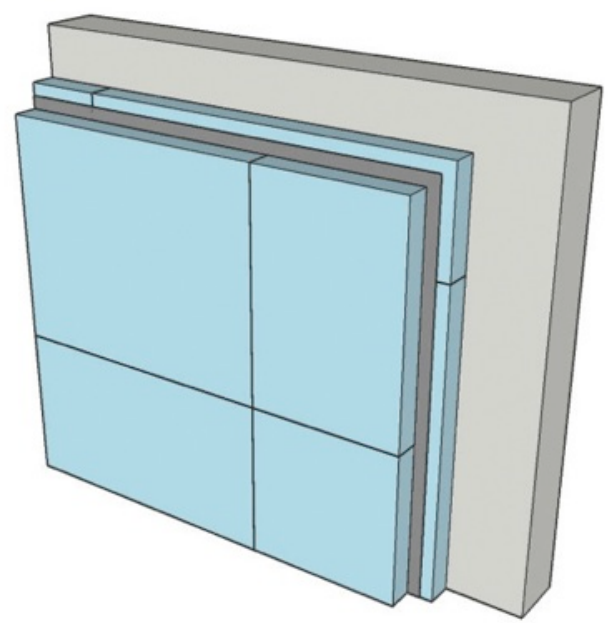

Figure 11. Water control layer in between the layers of insulation

\subsubsection{Air Control Layer}

Walls with exterior rigid insulation require only a single air control layer. It is often located at the structural sheathing or can be the exterior rigid insulation. Airflow control at the exterior structural sheathing can be provided via several methods:

- Tape or seal all the joints in the exterior structural sheathing. This provides very good overall building airtightness because many complicated details at partition walls and floor separations are eliminated - the work is all completed from the exterior. This air control layer can - but is not required to be - part of the water control layer (taped and 
sealed building wraps, fully adhered sheet membranes, or liquid-applied membranes, or taped structural sheathings with integral waterresistant surfacing).

- Seal the structural sheathing from the interior with sealants or spray polyurethane foams. This approach can also work well, but more attention to detail is usually required at interior partition walls, rim boards, band joints, and doubled or tripled framing members.

If a sheet product is used as the air control layer in lieu of the interior gypsum, we recommend a class III vapor retarder (1.0 to 10.0 perms) and at most should be a class II vapor retarder (0.1 to 1.0 perm). We do not recommend a class I vapor retarder (less than 0.1 perms) because it will prevent drying of the wall assembly to the interior. See Section 3.3.2 for additional information.

- Provide airflow control at the interior finish surfaces. The recommended strategy is to caulk and seal the interior gypsum board to the wood structural framing. Penetrations such as electrical boxes should be sealed or gasketed.

- Use the rigid insulation to provide an air control layer for the wall assembly. This approach can be effective in the field of the wall, but may require more complicated detailing at interfaces with other building elements. This is impractical if the water control layer is behind the rigid insulation.

\subsubsection{Vapor Control Layer}

Vapor control for assemblies with exterior rigid insulation mainly controls the condensing surface temperature of the exterior structural sheathing. This is arguably the most effective means of condensation control from both air transported vapor (air leakage) and vapor diffusion. The amount of exterior rigid insulation needed is a function of the climate and the amount of insulation added to the interior of the wall cavities. Multiple methods can be used to determine the appropriate amount of insulation for condensation control; however, analysis is not required for most common wall assemblies. The 2009 IRC and 2012 IRC provide guidance for the most common wall framing dimensions and cavity insulation (Table 7).

Table 7. Minimum Exterior Insulation Required for Common Wall Framing Dimensions

\begin{tabular}{c|c|c}
\hline Climate Zone & $\begin{array}{c}\text { Framing and Insulating } \\
\text { Sheathing }\end{array}$ & $\begin{array}{c}\text { Minimum } \\
\text { R-Value }\end{array}$ \\
\hline \multirow{2}{*}{ 4C } & $2 \times 4$ & 2.5 \\
& $2 \times 6$ & 3.75 \\
5 & $2 \times 4$ & 5 \\
& $2 \times 6$ & 7.5 \\
6 & $2 \times 4$ & 7.5 \\
\hline
\end{tabular}

Assemblies that have higher levels of cavity insulation $(2 \times 8$ walls or double-stud walls $)$ may require additional analysis. Hygrothermal computer modeling provides the most refined risk analysis, but at this level is seldom required for residential construction. Other
Dew point calculations that use design temperatures inevitably result in ultra-conservative answers, and should not be used as a means to assess assembly risks. 
methods, such as a dew point calculation that seeks to limit the sheathing temperature to no lower than $45^{\circ} \mathrm{F}$ based on the average temperature over the coldest 3 months of the year (assumed interior conditions of $35 \%$ relative humidity and $70^{\circ} \mathrm{F}$ ), have also been used as a reasonable check against condensation risks.

\subsubsection{Thermal Control Layer}

Exterior rigid insulation can significantly improve the wall assembly thermal performance because it provides a continuous insulation layer that diminishes the impact of thermal bridges caused by framing. Table 8 lists typical manufacturers' reported thermal resistance values for common rigid insulation materials.

\section{Table 8. Typical Thermal Resistance of Common Rigid Insulation Materials}

\begin{tabular}{c|c}
\hline Insulation Material & R-Value/in. \\
\hline PIC & $6.5^{2}$ \\
XPS & 5.0 \\
EPS & 4.0 \\
MF & 4.0 \\
\hline
\end{tabular}

The amount of exterior thermal rigid insulation added to the assembly will depend on the climate zone and design goals for the project. The minimum levels should be based on the minimum requirements for vapor control (see Section 3.3.3) and minimum requirements based on the current adopted building code and energy code,

With vapor-impermeable rigid insulation materials, a class I vapor retarder on the interior side of the assembly should be avoided because it will not permit the wall assembly to dry to the interior. respectively, for the project. More insulation can be added above these minimums to create high R-value wall assemblies, which commonly add 4 in. or more exterior rigid insulation.

Table 9 and Table 10 provide the prescriptive code requirements for wall insulation for both the 2009 IECC and the 2012 IECC. The effective thermal resistance has also been calculated for a convenient reference so that the total wall thermal performance can be compared.

\footnotetext{
${ }^{2}$ New test methods for PIC roofing products have resulted in a lowered long-term thermal resistance value from R6.0/in. down to R-5.7/in. Wall insulation products are currently not required to be tested to these same standards, and the manufacturers listed values are remaining the same.
} 
Table 9. 2009 IECC Compliance Minimum Insulation and Vapor Retarder Requirements*

\begin{tabular}{c|c|c|c|c}
\hline \multirow{2}{*}{$\begin{array}{c}\text { Climate } \\
\text { Zone }\end{array}$} & \multicolumn{2}{|c|}{$\mathbf{2 \times 4}$ Construction } & \multicolumn{2}{|c}{$\mathbf{2 \times 6 \text { Construction }}$} \\
\cline { 2 - 5 } & $\begin{array}{c}\text { Class III Vapor } \\
\text { Retarder }\end{array}$ & $\begin{array}{c}\text { Class I, II Vapor } \\
\text { Retarder }\end{array}$ & $\begin{array}{c}\text { Class III Vapor } \\
\text { Retarder }\end{array}$ & $\begin{array}{c}\text { Class I, II Vapor } \\
\text { Retarder }\end{array}$ \\
\hline $\begin{array}{c}\text { 1-4 (except } \\
\text { Marine) }\end{array}$ & $13(\mathrm{R}-11)$ & $13(\mathrm{R}-11)$ & $13(\mathrm{R}-13)$ & $13(\mathrm{R}-13)$ \\
\hline Marine 4 & $13+5(\mathrm{R}-17)$ & $13+5(\mathrm{R}-17)$ & $20+3.75(\mathrm{R}-21)$ & $20(\mathrm{R}-16)$ \\
$\mathbf{5}$ & $13+5(\mathrm{R}-17)$ & $13+5(\mathrm{R}-17)$ & $20+7.5(\mathrm{R}-25)$ & $20(\mathrm{R}-16)$ \\
$\mathbf{6}$ & $13+7.5(\mathrm{R}-19)$ & $13+5(\mathrm{R}-17)$ & $20+11.25(\mathrm{R}-29)$ & $20(\mathrm{R}-16)$ \\
$\mathbf{7}$ and $\mathbf{8}$ & $13+10(\mathrm{R}-22)$ & $13+5(\mathrm{R}-17)$ & $21+15(\mathrm{R}-33)$ & $21(\mathrm{R}-16)$ \\
\hline
\end{tabular}

* Effective R-values in parentheses

Table 10. 2012 IECC Compliance Minimum Insulation and Vapor Retarder Requirements*

\begin{tabular}{c|c|c|c|c}
\hline \multirow{2}{*}{$\begin{array}{c}\text { Climate } \\
\text { Zone }\end{array}$} & \multicolumn{2}{|c|}{$\mathbf{2 \times 4}$ Construction } & \multicolumn{2}{c}{$\mathbf{2 \times 6}$ Construction } \\
\cline { 2 - 5 } & $\begin{array}{c}\text { Class III } \\
\text { Vapor Retarder }\end{array}$ & $\begin{array}{c}\text { Class I, II } \\
\text { Vapor Retarder }\end{array}$ & $\begin{array}{c}\text { Class III Vapor } \\
\text { Retarder }\end{array}$ & $\begin{array}{c}\text { Class I, II Vapor } \\
\text { Retarder }\end{array}$ \\
\hline $\begin{array}{c}\mathbf{1 , 2} \\
\mathbf{3} \mathbf{4} \text { (except } \\
\text { Marine) }\end{array}$ & $13(\mathrm{R}-11)$ & $13(\mathrm{R}-11)$ & $13(\mathrm{R}-13)$ & $13(\mathrm{R}-13)$ \\
Marine 4 & $13+5(\mathrm{R}-17)$ & $13+5(\mathrm{R}-17)$ & $20(\mathrm{R}-16)$ & $20(\mathrm{R}-16)$ \\
\hline $\mathbf{5}$ & $13+5(\mathrm{R}-17)$ & $13+5(\mathrm{R}-17)$ & $20+7.5$ & $20(\mathrm{R}-16)$ \\
$\mathbf{6}$ & $13+7.5(\mathrm{R}-19)$ & $13+10(\mathrm{R}-22)$ & $20+11.25(\mathrm{R}-29)$ & $20+5(\mathrm{R}-22)$ \\
\hline $\mathbf{7}$ and $\mathbf{8}$ & $13+10(\mathrm{R}-22)$ & $13+5(\mathrm{R}-17)$ & $20+15(\mathrm{R}-33)$ & $20+5(\mathrm{R}-22)$ \\
\hline
\end{tabular}

* Effective R-values in parentheses 


\section{Measure Implementation}

The location of the water control layer for the assemblies has many implications on the construction detailing. To address this, the measure implementation section of this guideline is separated into two sections:

Option 1: Water control layer in front of the rigid insulation

Option 2: Water control layer behind the rigid

In general, placing the water control layer to the exterior of the rigid insulation can provide the most straightforward installation, because most integration details with other enclosure elements will follow standard construction practices. These details occur at the face of the insulation rather than at the face of the structural sheathing. insulation

The intent is to group all associated details into a single section for easier reference and consistency of design details. As such, some information is repeated; however, this should provide easier reference for designers and builders who are attempting to incorporate exterior continuous rigid insulation in their projects.

\subsection{Option 1: Water Control Layer in Front of the Rigid Insulation \\ 4.1.1 Structure}

No fundamental changes are required to the building's structural design to accommodate the exterior rigid insulation.

Continuous wood structural sheathing provides a simple and robust means of wall bracing and wind resistance for a variety of home styles and design conditions, and is the standard practice for most of the residential building industry. The continuous exterior rigid insulation can be simply added to any home with a codecompliant structural design.

Alternatively, the wood structural sheathing can be CODE REQUIREMENTS FOR WALL BRACING ARE AVAILABLE IN SECTION 602.10 OF THE 2009 IRC AND 2012 IRC. VARIOUS OTHER RESOURCES ARE AVAILABLE TO ASSIST IN ACHIEVING CODE-COMPLIANT WALL BRACING: - AMERICAN PLYWOOD ASSOCIATION SIMPLIFIED BRACING GUIDE - INTERNATIONAL CODE COUNCIL WALL BRACING GUIDE - FOAM SHEATHING COALITION applied only as required for structural bracing, allowing WALL BRACING GUIDE the exterior rigid insulation to function as the primary sheathing. This second approach does incorporate additional changes for builders from standard construction practice; however, the departure is minimal and is relatively easy to implement. It can reduce project costs, because much of the exterior wood structural sheathing can often be omitted.

\subsubsection{Attaching the Insulation}

Attaching the insulation has no specific requirements because the insulation will be ultimately held in place by the wood furring strips. The rigid insulation attachment is a temporary measure to hold the insulation onto the wall until the furring strips are installed. We recommend attaching the furring strips as soon as practical after the insulation is installed to prevent damage to the 
insulation from wind loading. We recommend cap nails, screws with washers or plates, or other larger head fasteners to prevent overdriving through the outer face of the insulation materials.

The exterior rigid insulation can be installed in either a single layer (Figure 12), or in multiple layers (Figure 13). For multilayer applications, we recommend offseting all the joints in the insulation boards.

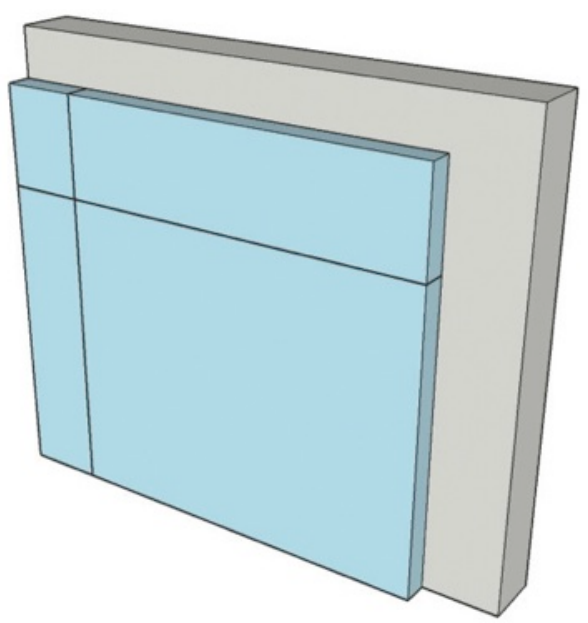

Figure 12. Single layer of rigid insulation

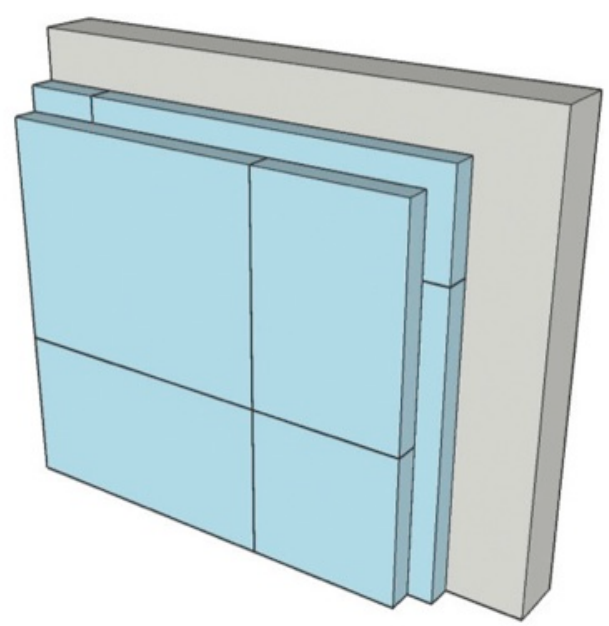

Figure 13. Multiple layers of rigid insulation with offset joints

\subsubsection{Water-Resistive Barriers}

When the water control layer is located in front of the rigid insulation, in concept, two water control layer approaches can be used:

- Install building paper or house wrap over the top of the rigid insulation (Figure 14).

- Tape or seal the joints of the rigid insulation to act as the water control layer (Figure 15).

Option 1 has a practical limit of 1-1/2-in. thick rigid insulation. Finding common cap nails or staples that are typically used to install thicker building paper or house wrap is difficult. Therefore, to install rigid insulation thicker than $1-1 / 2$ in., we recommend taping and sealing the face of the rigid insulation. All flashing and other water control interfaces of the building must connect to the wall water control layer. 


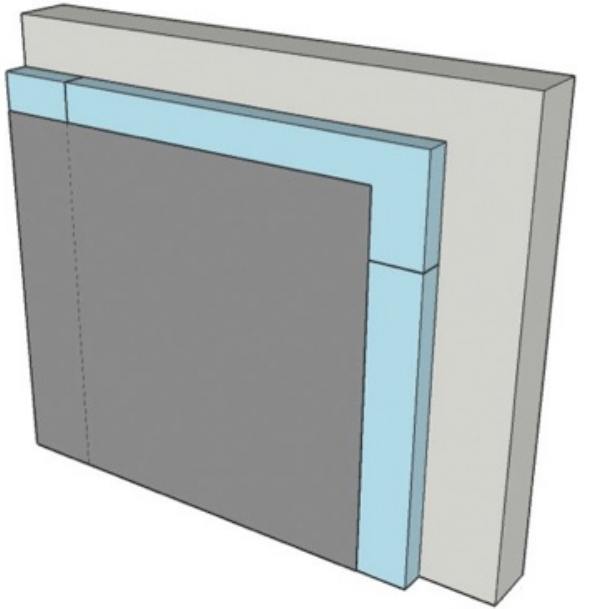

Figure 14. Sheet water control layer over insulation

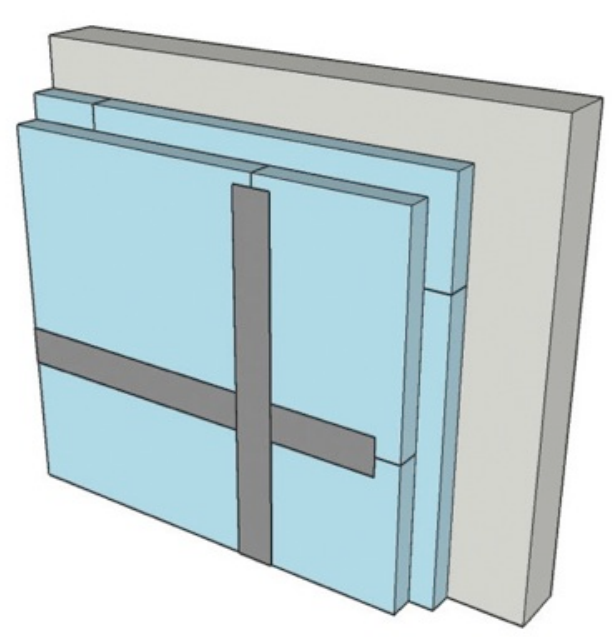

Figure 15. Taped rigid insulation water control layer

\subsubsection{Integrating the Window}

With the water control layer positioned at the face of the insulation, the best location for installing the window is at the face of the rigid insulation. Windows installed at the plane of the rigid insulation follow industry standards for integration with the wall water control layer. We recommend installing all windows in a pan flashed and drained opening with the jambs and the head of the frame taped or sealed to the wall water control layer (see sequence in Figure 16 and Figure 17; see also Figure 18 through Figure 20). 

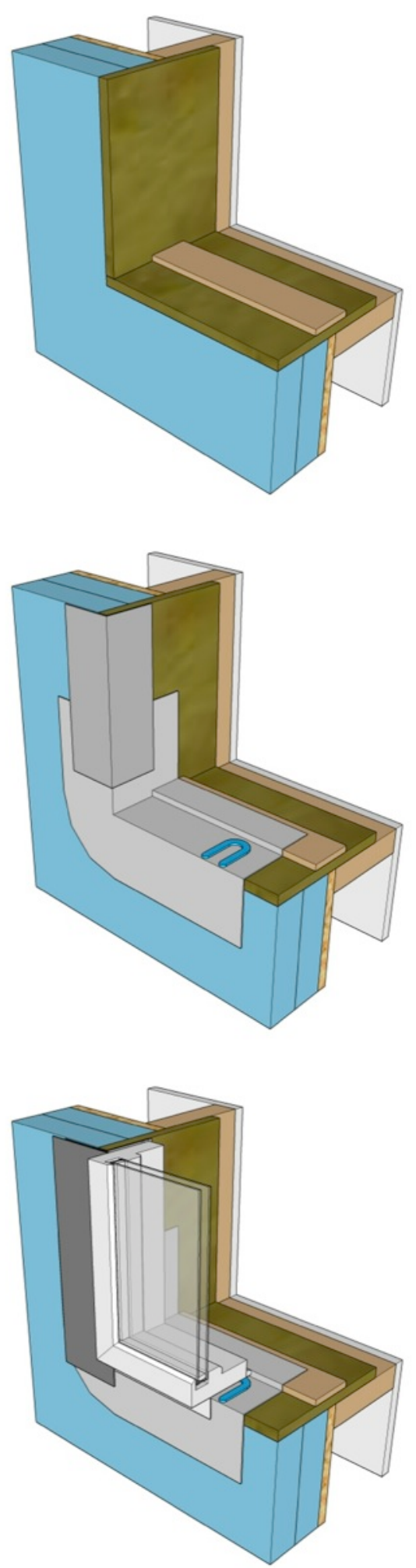

Step 1. Use a wood extension box to support the window in the insulation layer.

Step 2. Seal the membrane pan flashing and jamb flashing to the face of the insulation and return both to the rough opening.

Step 3. Tape the window and jamb flange to the rigid insulation with self-adhered membrane flashing. Do not tape the flange at the sill.

Figure 16. Window flush with the face of the exterior rigid insulation (sill installation sequence) 

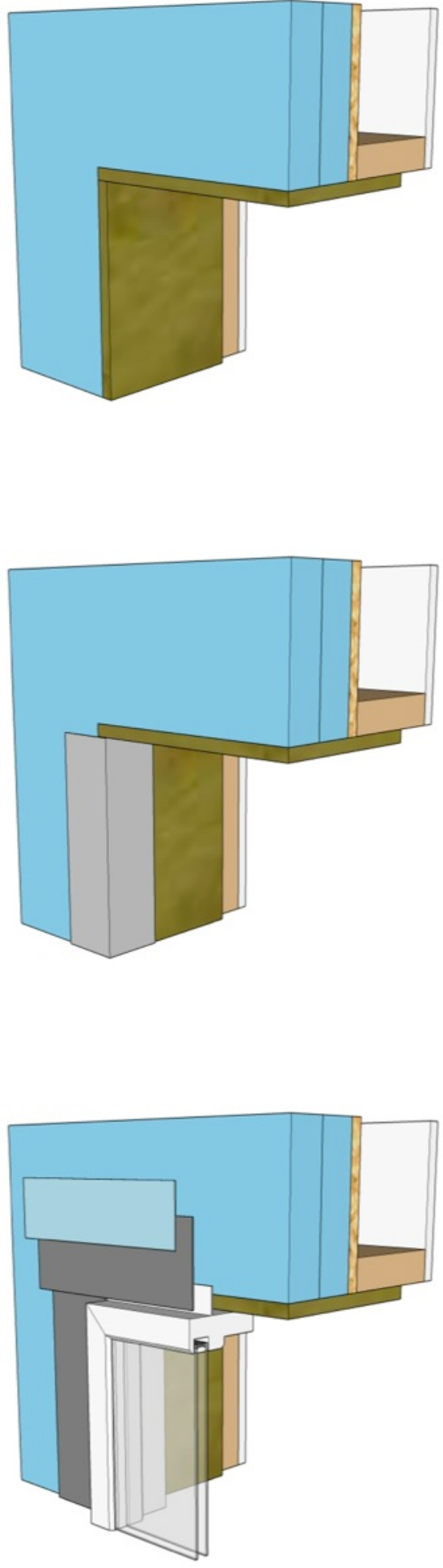

Step 1. Use a wood extension box to support the window in the insulation layer.

Step 2. Seal the membrane jamb flashing to the face of the insulation and return it to the rough opening.
Step 3. Install the window. Tape the head and jamb flanges to the rigid insulation with self-adhered membrane flashing. Adhere the top edge of the head membrane flashing with construction tape.

Figure 17. Window flush with the face of the exterior rigid insulation (head installation sequence) 
Wall air control layer (recommended)

Water control layer positioned at faceof insulation (method of taped insulating sheathing shown in this detail)

Two layers of 2" rigid insulating sheathing; joints offset from underlying layer

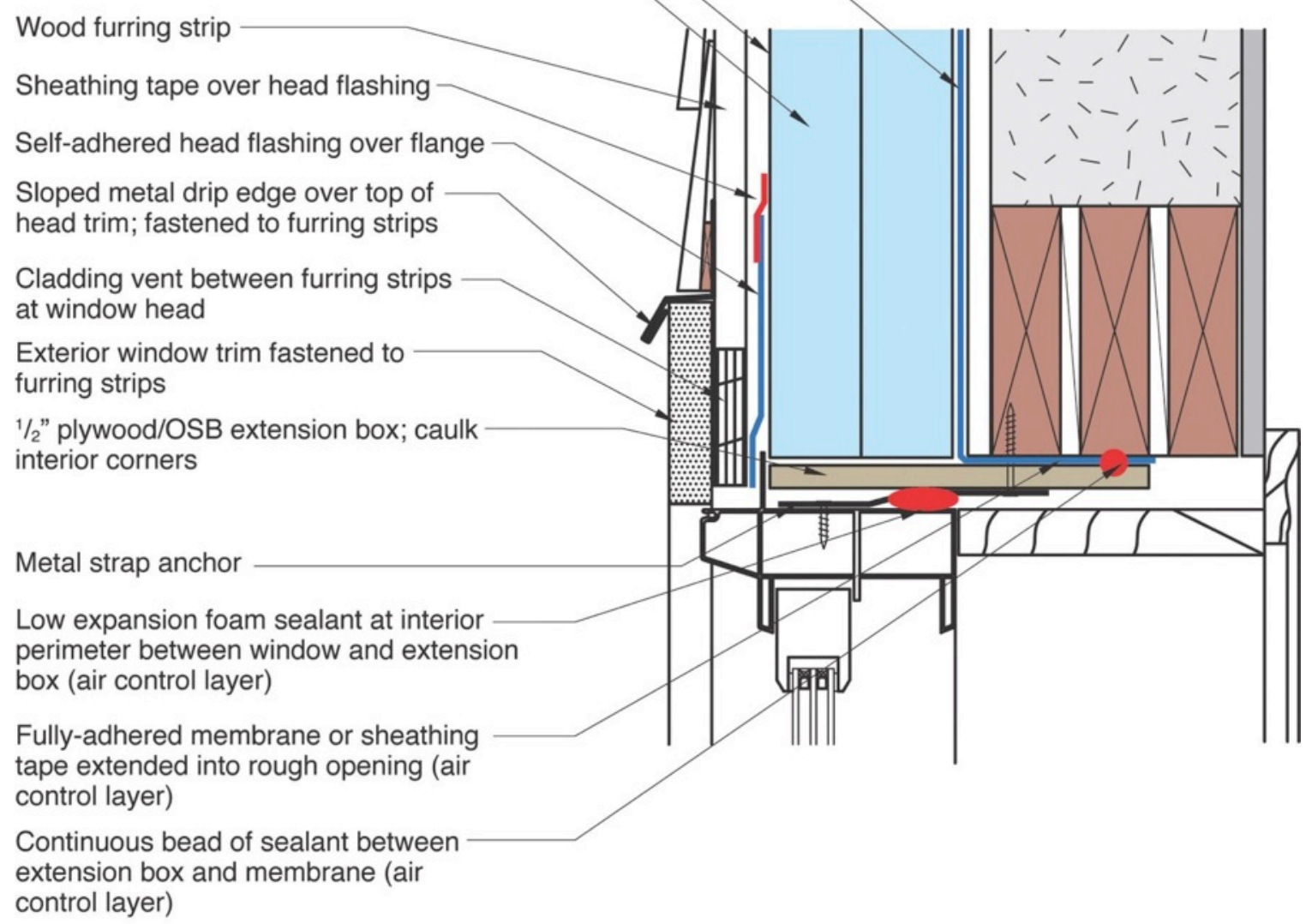

Figure 18. Window head-water control layer in front of the rigid insulation 


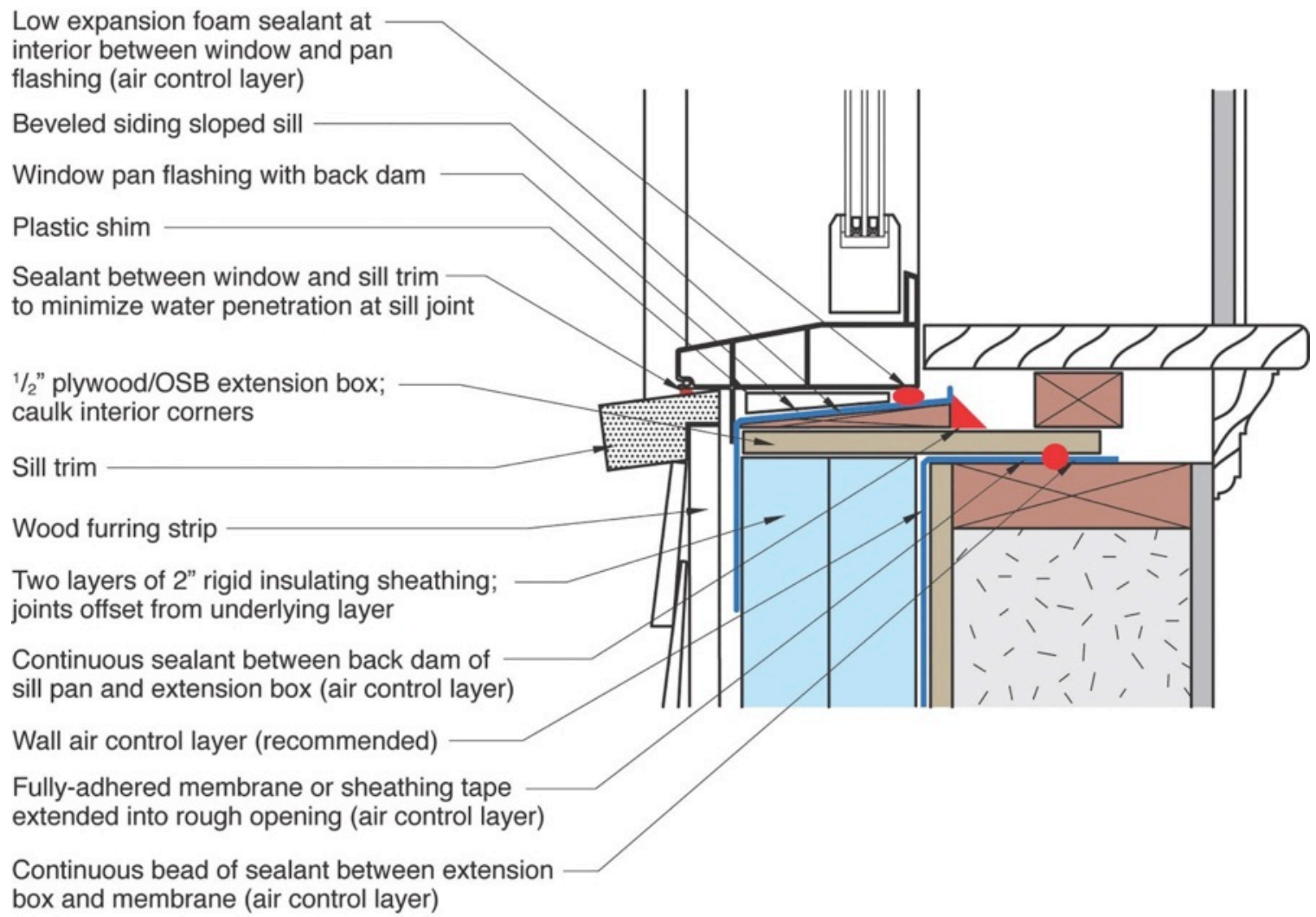

Figure 19. Window sill-water control layer in front of the rigid insulation 
Continuous bead of sealant between extension box and membrane (air control layer)

Wall air control layer (recommended)

Fully-adhered membrane or sheathing tape extended into rough opening (air control layer)

$1 / 2$ " plywood/OSB extension box; caulk interior corners

Metal strap anchor

Low expansion foam sealant at interior perimeter between window and extension box (air control layer)

Fully-adhered jamb flashing wrapped into rough opening

Fully-adhered jamb flashing lapped over window flange

Sealant between window and jamb of trim extension box to minimize water penetration

Two layers of 2" rigid insulating sheathing; joints offset from underlying layer

Wood furring strip attached through insulation to framing

Exterior window trim fastened to wood furring strip

Sealant between trim and cladding to minimize water penetration

Figure 20. Window jamb-water control layer in front of the rigid insulation

Moving the windows further to the interior while maintaining the water control layer at the plane of the rigid insulation requires a recessed opening for flanged windows (see sequences in Figure 21 and Figure 22). For nonflanged windows, the window frame can be placed at any location within the opening provided that the water control layer is wrapped into the rough opening. 

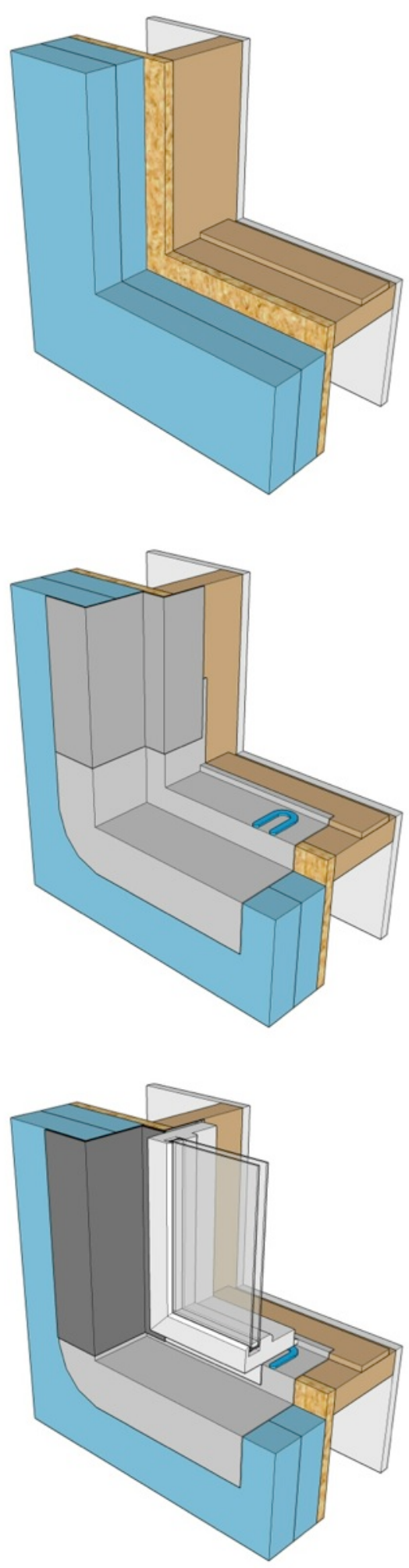

Step 1. Cut back the insulation around the rough opening to accommodate the window flange.

Step 2. Seal the membrane pan flashing and jamb flashing to the face of the insulation and return both to the rough opening.
Step 3. Install the window and tape the jamb flange to the rigid insulation with self-adhered membrane flashing. Do not tape the flange at the sill.

Figure 21. Window recessed from the face of the rigid insulation (sill installation sequence) 

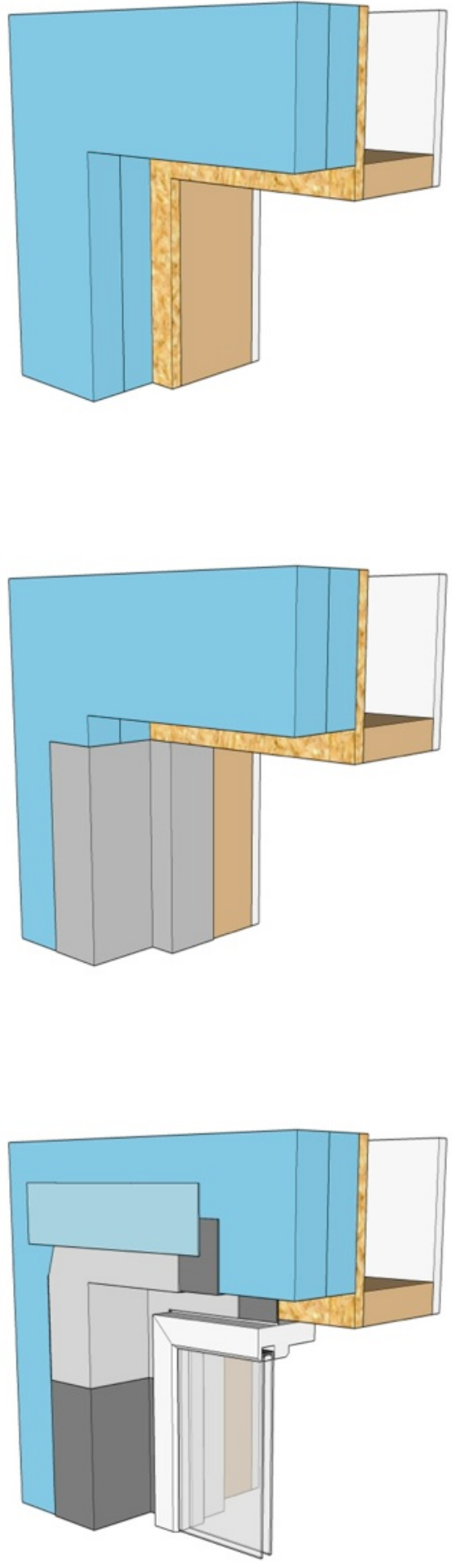

Step 1. Cut back the insulation around the rough opening to accommodate the window flange.

Step 2. Seal the membrane jamb flashing to the face of the insulation and return it to the rough opening.
Step 3. Install the window. Tape the head and jamb flanges to the rigid insulation with self-adhered membrane flashing. A flexible membrane flashing tape is recommended at the corners. Tape the top edge of the head membrane flashing with construction tape.

Figure 22. Window recessed from the face of the rigid insulation (head installation sequence) 


\subsubsection{Roofs}

Where the roof is above the wall, the termination of the exterior insulation does not change significantly regardless of whether the attic is vented or unvented. The differences would mostly be associated with the attic design rather than with the wall design.

For vented attics, the rigid insulation needs to terminate below the level of the roof sheathing to provide a ventilation opening. Extending the rigid insulation up as high as possible (leaving at least a 2-in. gap for attic ventilation) has some additional benefits though, including increased thermal resistance at the roof-to-wall connection, and it can act as an insulation stop and baffle for the attic insulation (see Figure 23). Additional thermal resistance is not needed for gable ends; however, simply maintaining the rigid insulation to the full height to keep the cladding aligned is often practical.

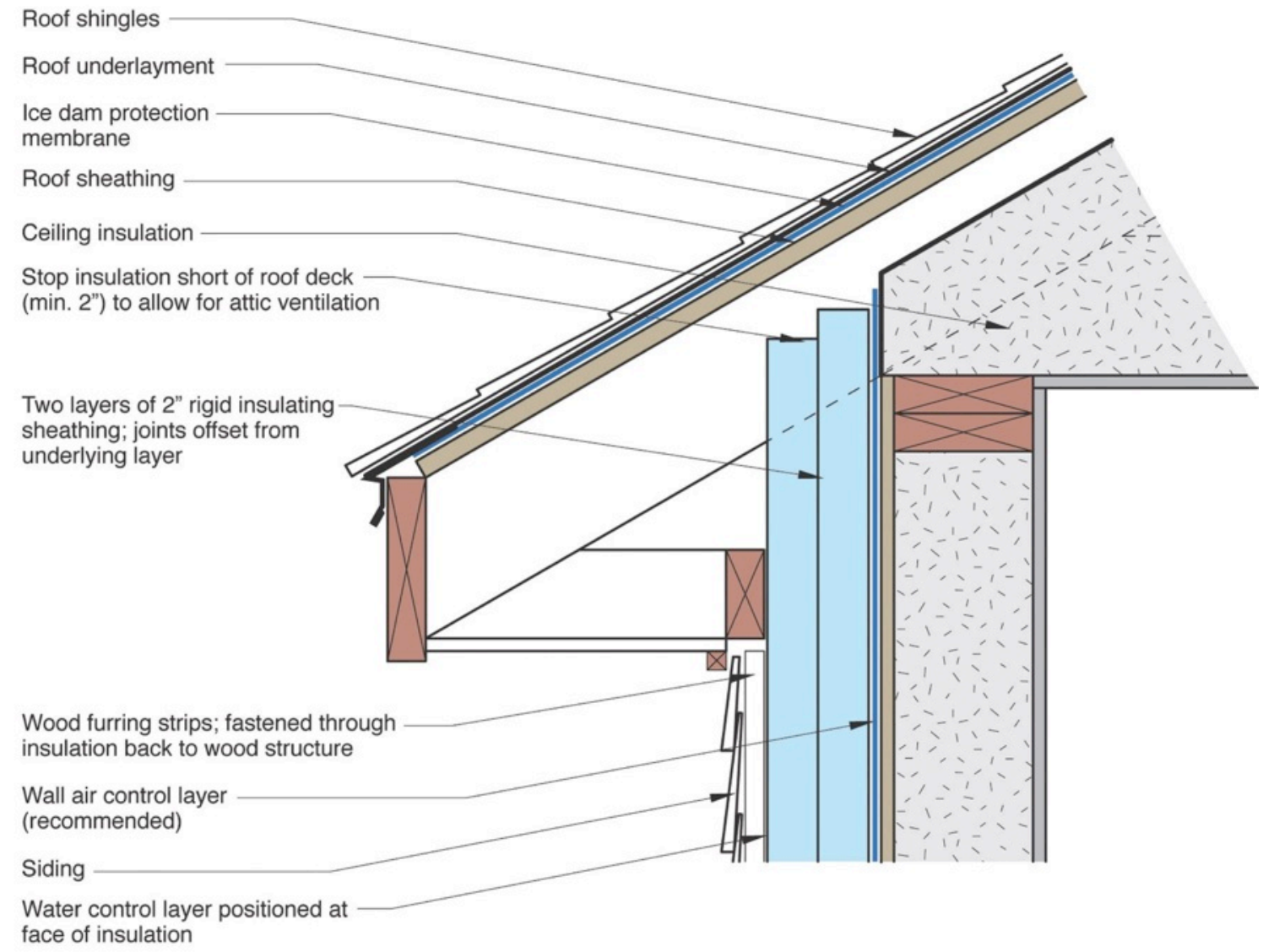

Figure 23. Vented attic water control layer in front of the rigid insulation

For unvented attics, the rigid insulation can be run tight to the underside of the roof sheathing. In this configuration, it can act as an insulation stop for spray polyurethane foam if it is being used (Figure 24). At the gable ends, continuing the rigid insulation up the full height provides additional thermal resistance for the attic assembly. 


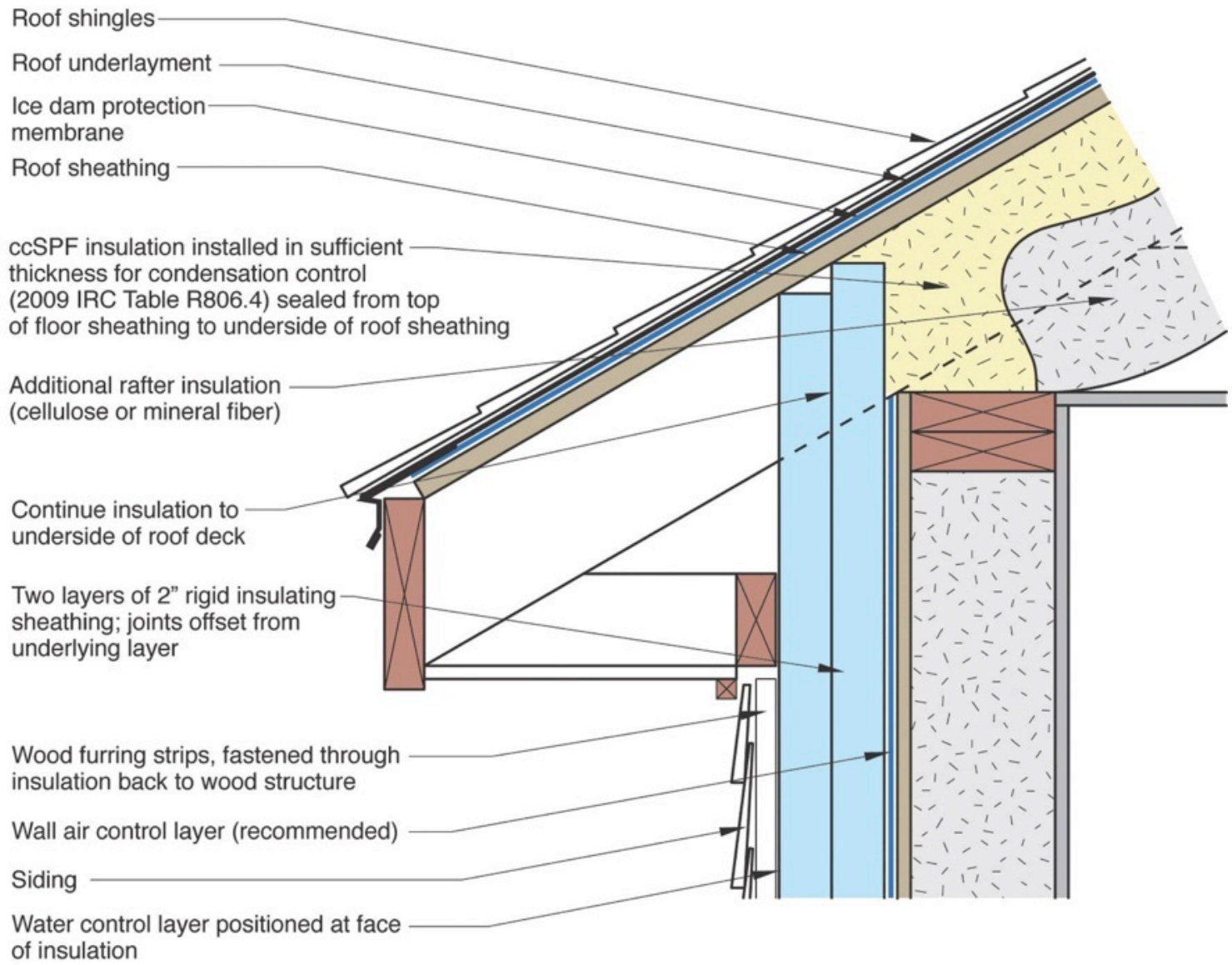

Figure 24. Unvented attic water control layer in front of the rigid insulation

Where the roof is below the wall, the termination details are critical. With the water control layer at the face of the rigid insulation, the step flashing and shingles are installed up to the rigid insulation. Although the installation details are typical, the construction sequence may create a problem because the rigid insulation may not be installed at the same time the roof is installed. If this is the case, a curb of insulation must be installed so that the roofing can be completed. A temporary weather seal at the top of the insulation curb is also required to prevent water infiltration into the structure before the rigid wall insulation is installed. Installing a nail base for the step flashing is helpful so that extra long nails are not required for step flashing attachment (see sequence in Figure 25). 

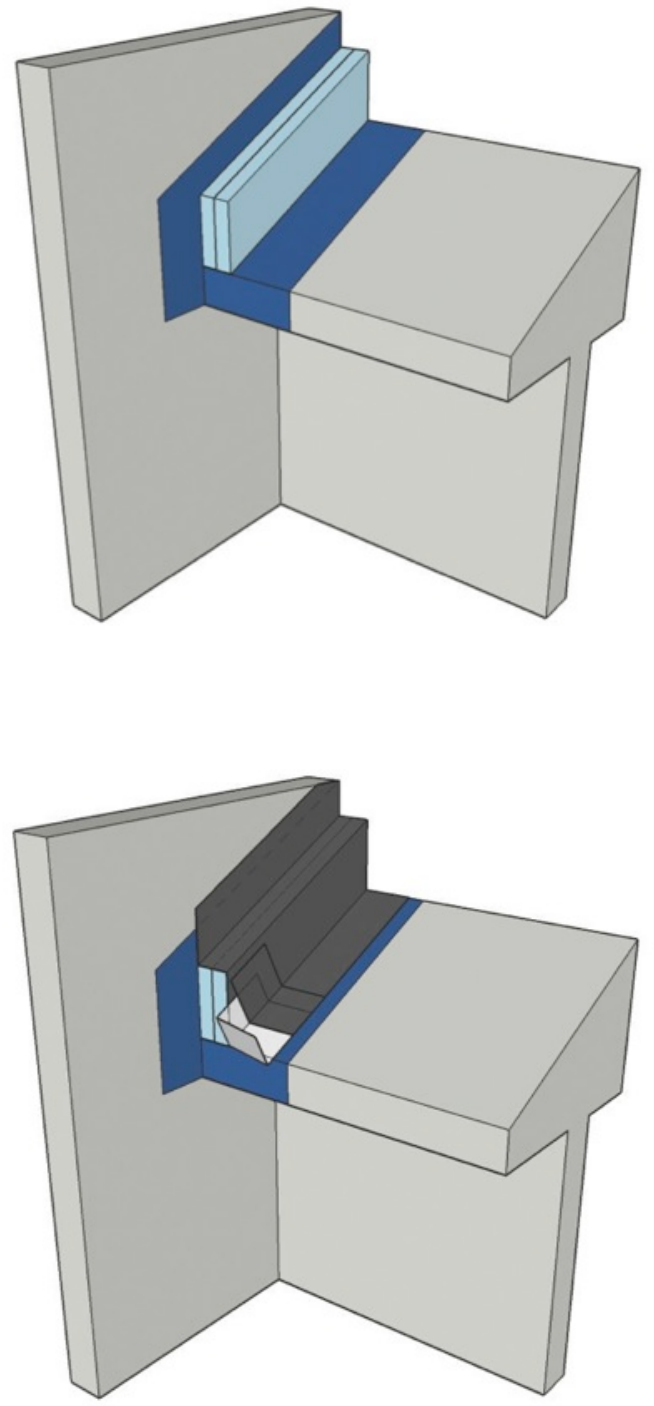

Step 1. Install a fully adhered membrane and insulation curb before installing the roof shingles.

Step 2. Install a fully adhered membrane over the insulation curb to provide temporary waterproofing until the wall insulation is installed. 

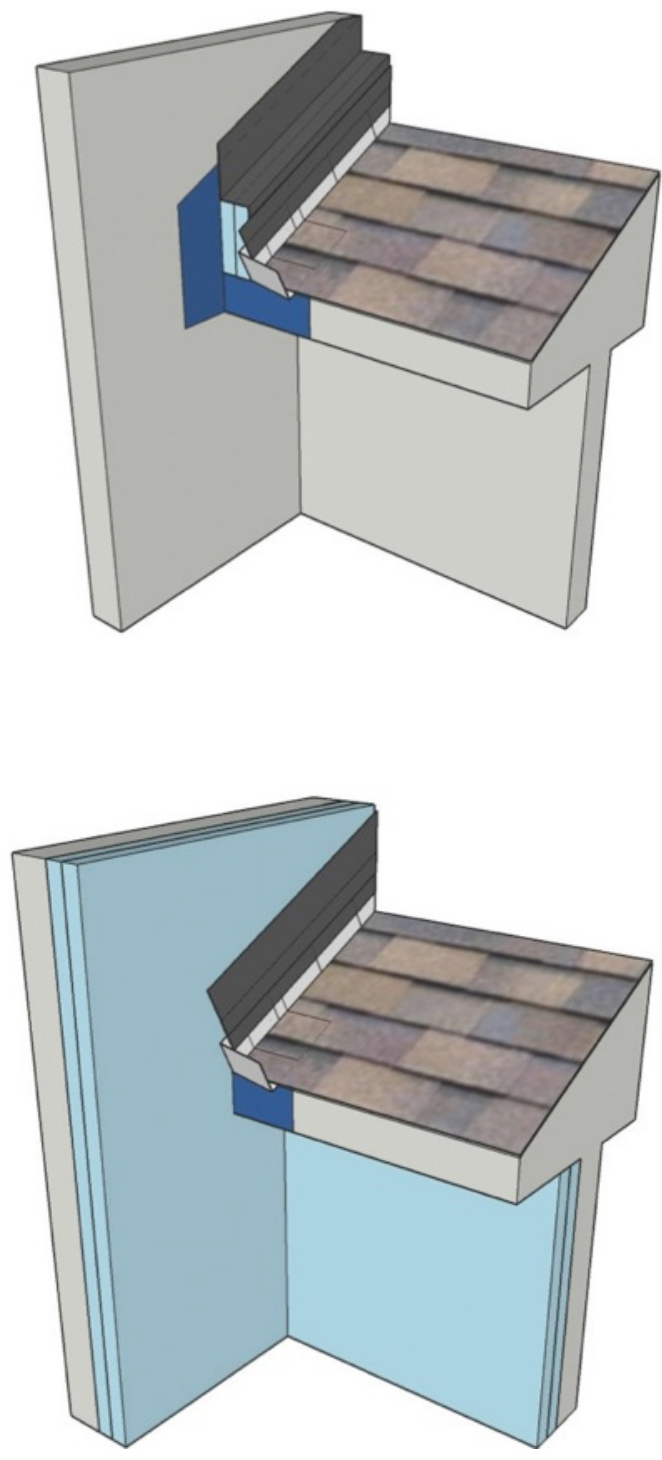

Step 3. Install the roof assembly and step flashing according to industry standard practice.
Step 4. Add insulation to the wall assembly and seal it over the step flashing.

Figure 25. Upper wall to lower roof construction sequence

For vented attics or porch roofs, the intent is to maintain the continuity of the insulation past the roofline to the wall above, and to the wall below the roof, both of which are considered exterior wall assemblies (Figure 26). For unvented attics, the insulation must follow the plane perpendicular to the roof sheathing (Figure 27). 
Wall air control layer (recommended)

Water control layer positioned at face of

insulation (method of taped insulating

sheathing shown in this detail)

Two layers of 2" rigid insulating

sheathing; joints offset from

underlying layer

Wood furring strips; fastened through insulation back to wood structure

Fully-adhered transition membrane to provide for temporary waterproofing of roof to wall interface prior to

installation of insulation

Metal flashing

Sheathing tape at joints in insulation

Installation of $1 / 2$ " plywood or OSB

layer to allow for step flashing attachment

Removable trim at base of wall

Roof sheathing

Step flashing (top edge taped with sheathing tape or shingle-lapped with water control layer)

Insulation installed at time of roof to accommodate construction sequence

Fully-adhered membrane at roof to wall interface to provide continuity of air control layer

Sealant to maintain continuity of air control layer

Wall air control layer (recommended)
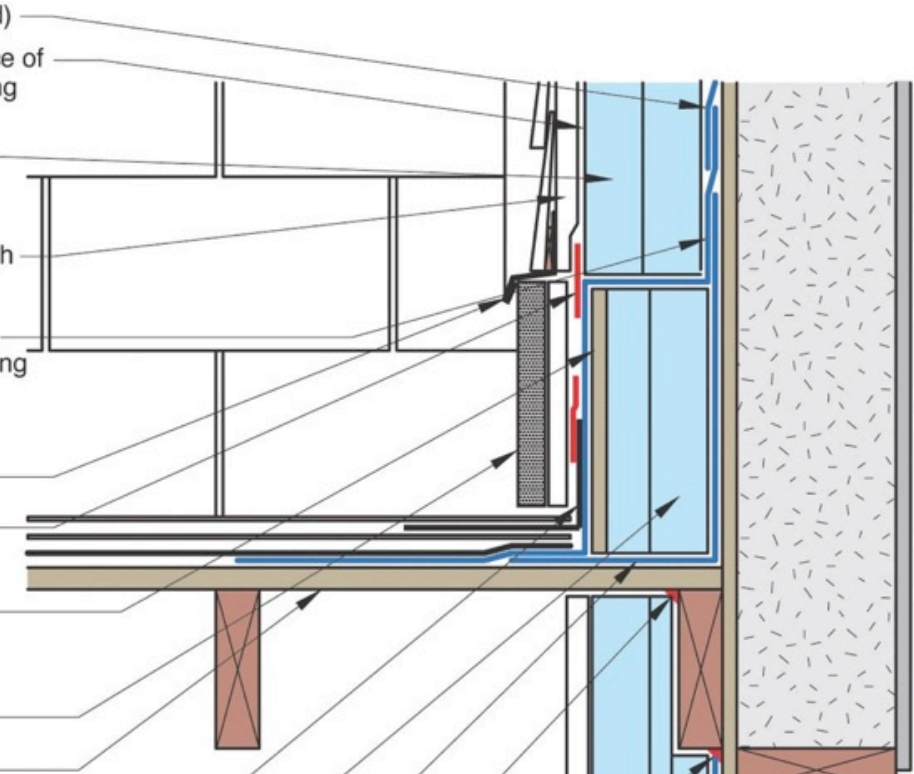

Figure 26. Vented attic or porch water control layer in front of the rigid insulation 


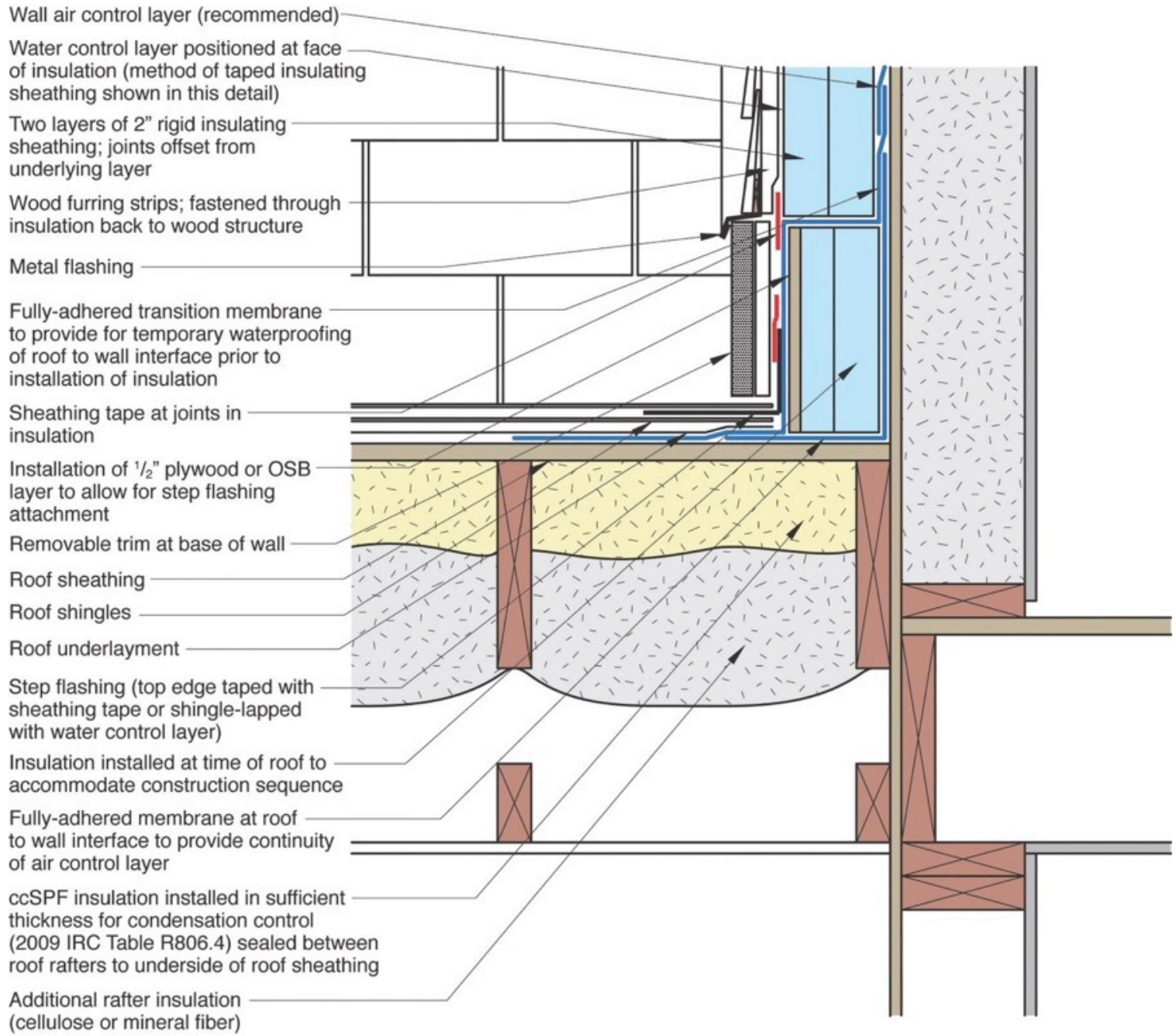

Figure 27. Unvented attic water control layer in front of the rigid insulation

\subsubsection{Balconies}

Balcony interfaces need to be addressed similarly to walls above lower roofs. Because the water control layer is in front of the rigid insulation, all deck waterproofing should be returned up the face of the rigid insulation (see Figure 28 and Figure 29). These details would also be used for low-slope membrane roof assemblies. 
Wall air control layer (recommended)

Water control layer positioned at face of insulation

(method of taped insulating sheathing shown in this detail)

Two layers of 2" rigid insulating sheathing;

joints offset from underlying layer

Wood furring strips; fastened through

insulation back to wood structure

Fully-adhered transition membrane to provide for temporary waterproofing of roof to wall interface

prior to installation of insulation

Metal flashing

Sheathing tape at joints in insulation

Removable trim at base of wall

Deck structure over balcony membrane

Decking sleepers

Balcony sheathing

Fully-adhered membrane at balcony to wall interface

Insulation installed at time of roof to accommodate construction sequence

Fully-adhered membrane at roof to wall interface to provide continuity of air control layer

Sealant to maintain continuity of air control layer

Wall air control layer (recommended)
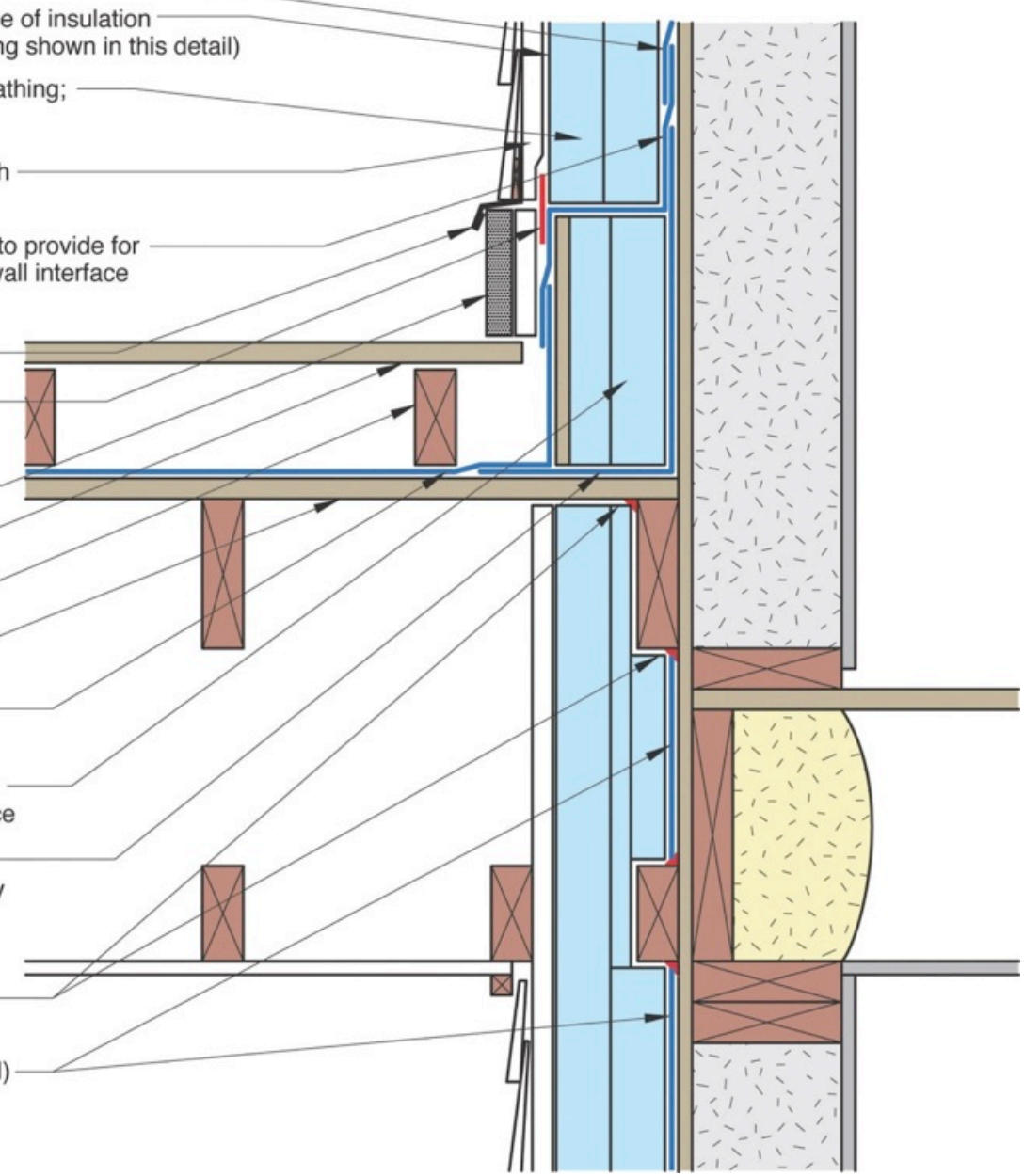

Figure 28. Balcony water control layer in front of the rigid insulation 


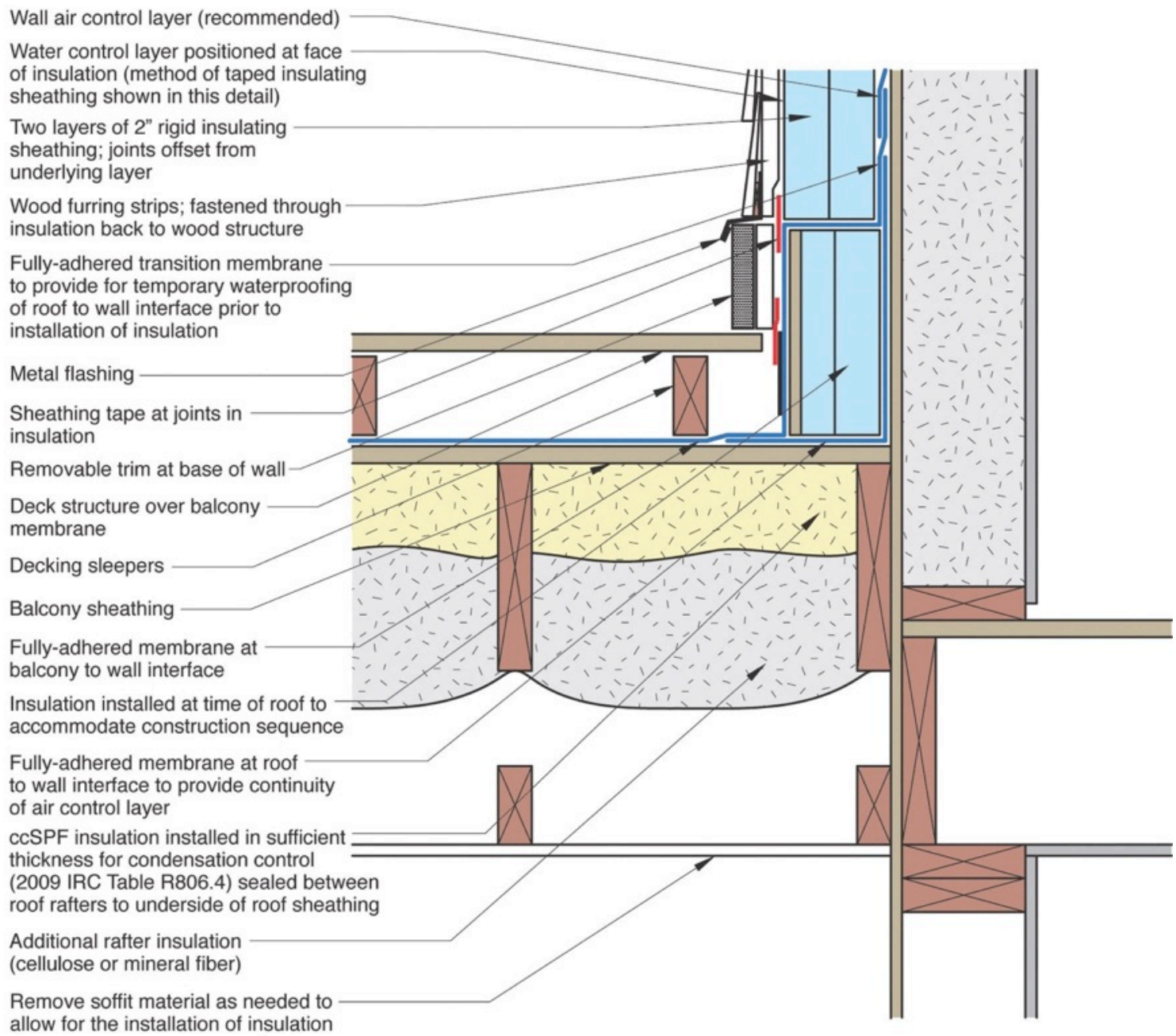

\section{Figure 29. Balcony water control layer in front of the rigid insulation}

\subsubsection{Decks}

Attaching framed decks can be a little complicated where the water control layer is in front of the rigid insulation. The best approach is to support the deck independently with the ledger attachment used to pin the deck to the house rather than to allow it to take any significant vertical load. The recommended location for the ledger is outboard of the rigid insulation, though it can also be installed inboard of the insulation if the deck has heavy loads. (See construction sequences in Figure 30 and Figure 31.) 

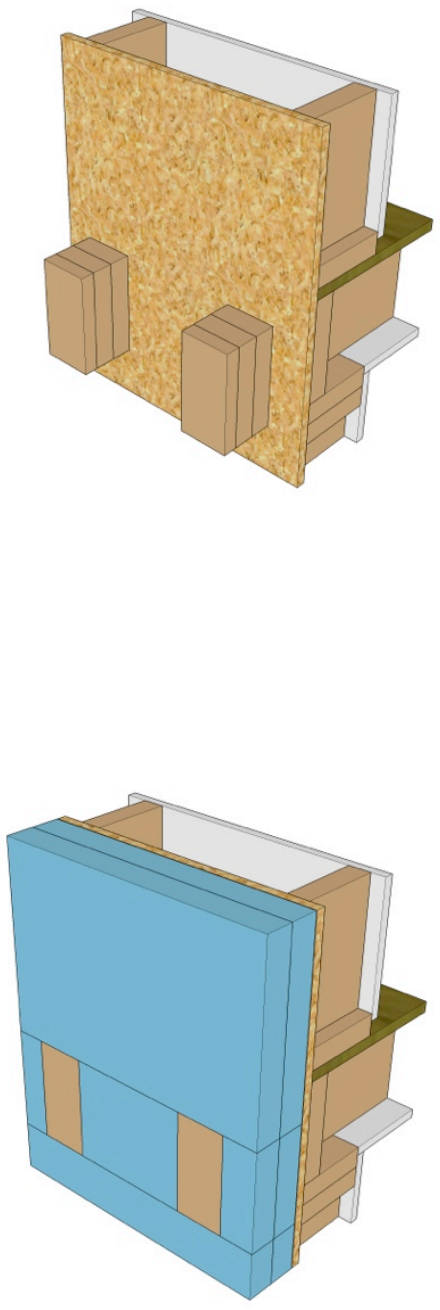

Step 1. Use ledger support blocking as required to accommodate the deck's structural load. If the deck is self-supporting, the blocking can be omitted.
Step 2. Cut and fit the exterior rigid insulation around the deck support blocking. 

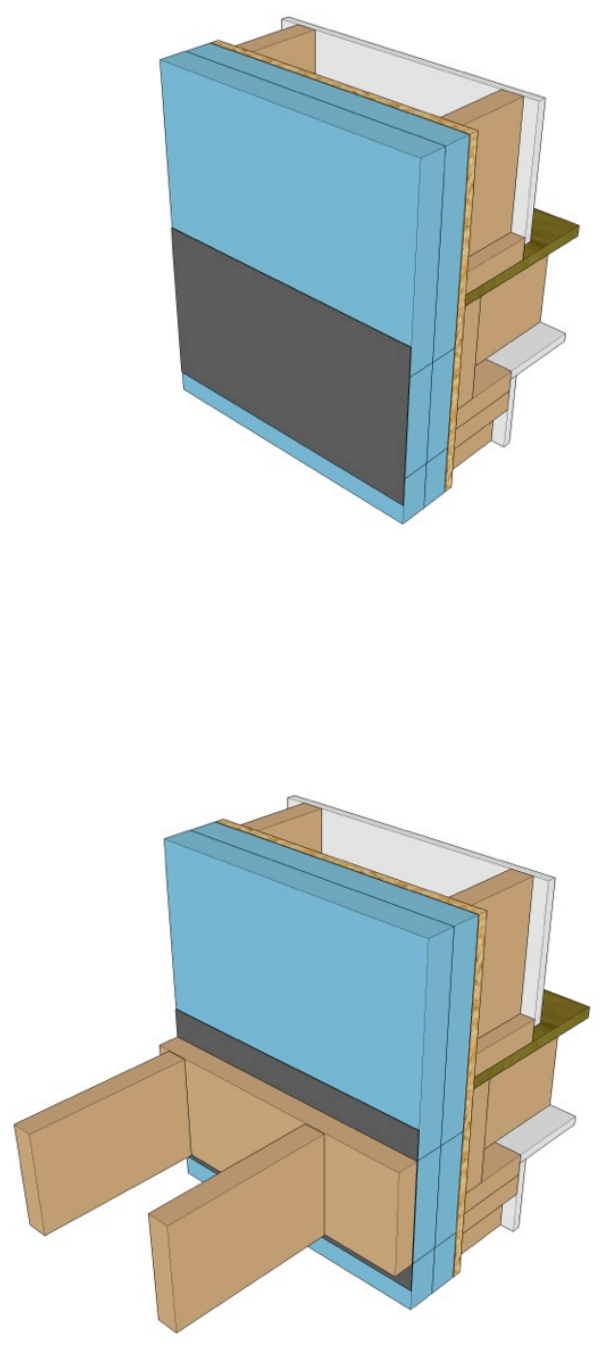

Step 3. Install the fully adhered membrane flashing behind the deck ledger.

Step 4. Attach the deck ledger and framing to the structure. 


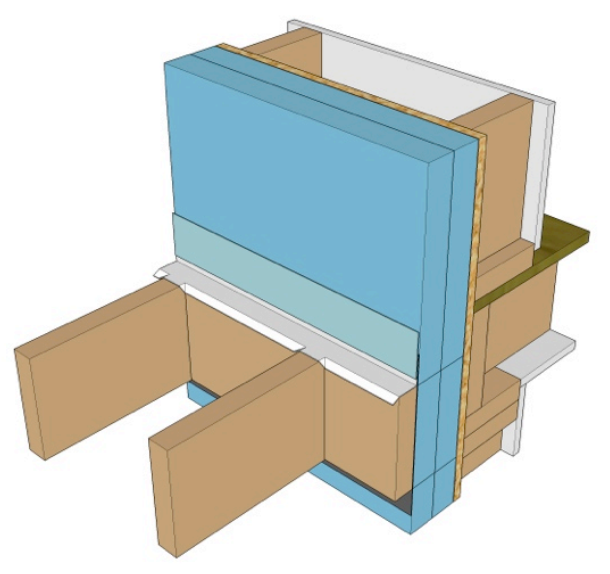

Step 5. Adhere the metal ledger flashing to the exterior rigid insulation with construction tape.

Figure 30. Ledger outboard of rigid insulation construction sequence 

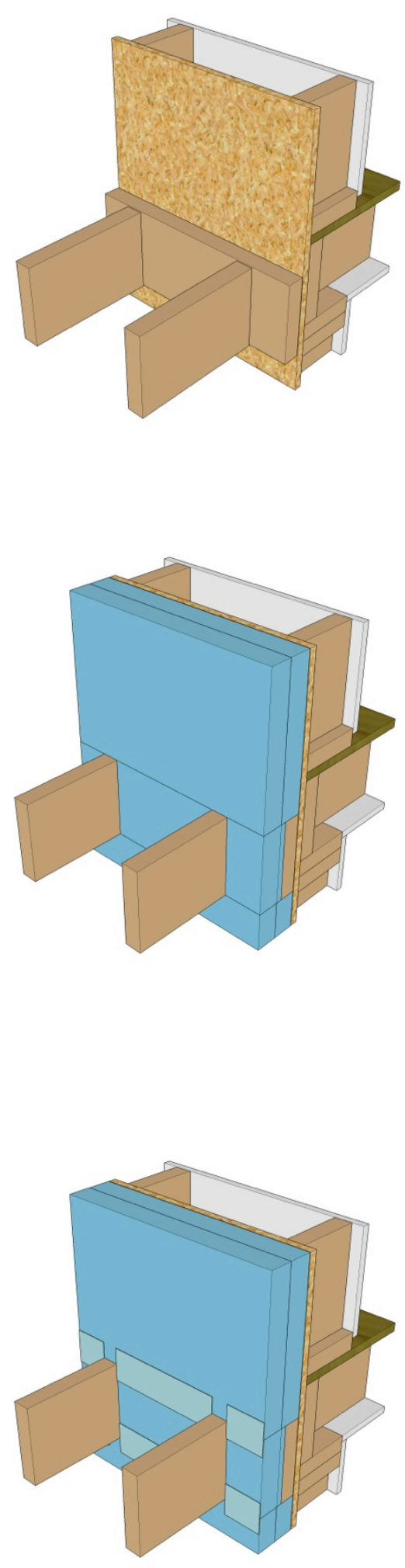

Step 1. Attach the ledger to the structure.

Step 2. Cut and fit the exterior rigid insulation around the deck joists.

Step 3. Adhere all joints in the exterior rigid insulation with construction tape. 

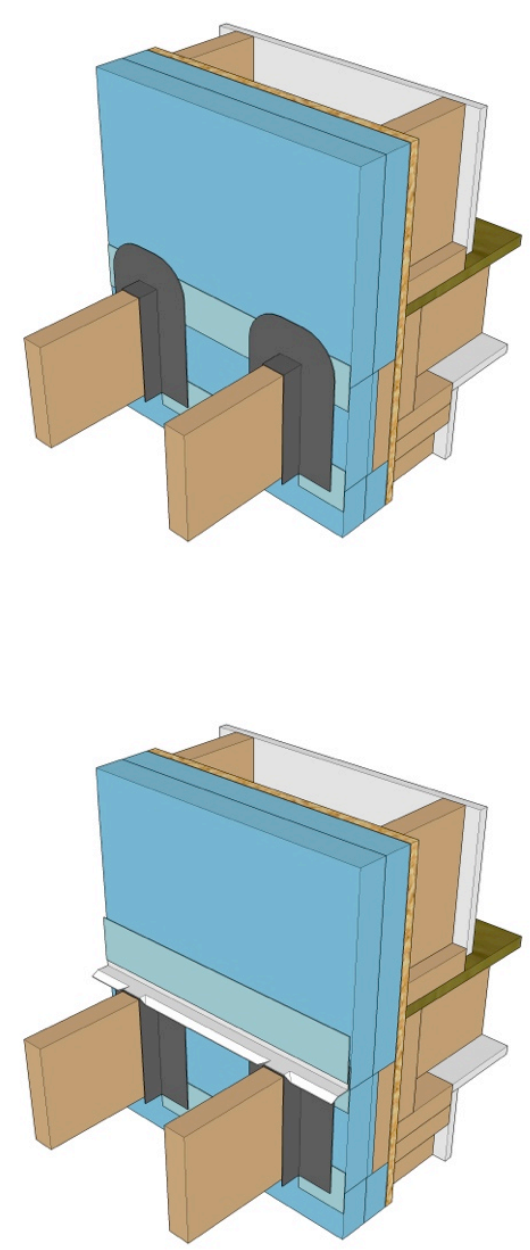

Figure 31. Ledger inboard of rigid insulation construction sequence

\subsubsection{Penetrations}

Mechanical and electrical penetrations should be sealed at the location of the water control layer. The sealing details are similar to those used with a sheet WRB, so the top edge of any membrane flashing should be adhered with construction tape. (See construction sequence in Figure 32.) 

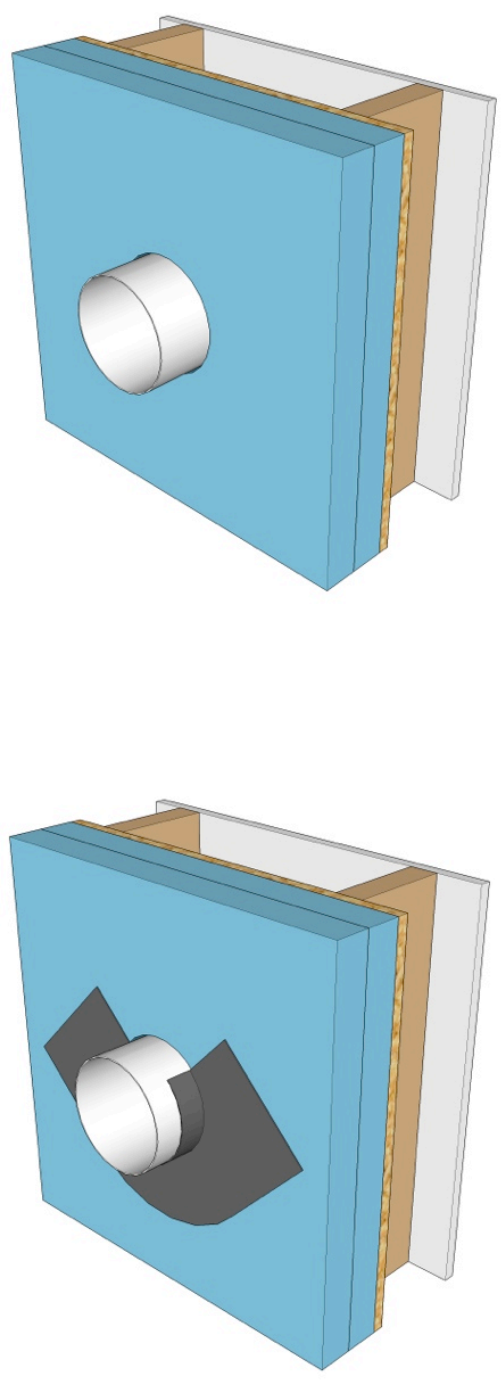

Step 1. Cut a mechanical penetration through the rigid insulation.

Step 2. Seal the flexible membrane flashing around the bottom of the penetration. 


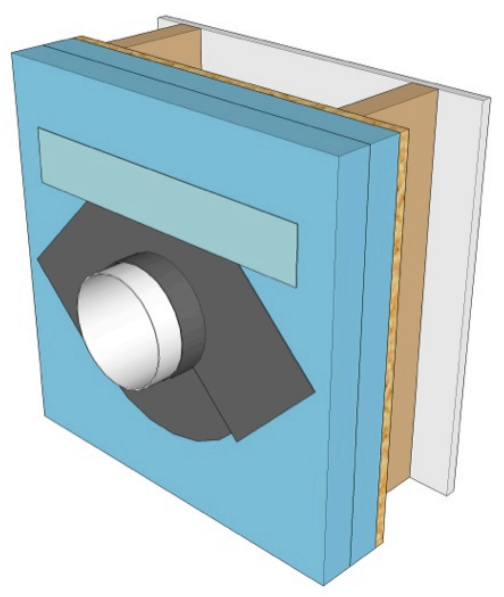

Step 3. Seal the flexible membrane flashing over the top of the penetration. Adhere the top edge of the membrane flashing construction tape.

Figure 32. Mechanical penetration construction sequence

\subsubsection{Attaching the Cladding}

For thinner insulation, the cladding can often be attached directly through the rigid insulation back to the structure. The practical limit of this approach is around $1-1 / 2$ in. of rigid insulation because fastener lengths for many pneumatic nail guns are limited (see Figure 32 and Figure 33).

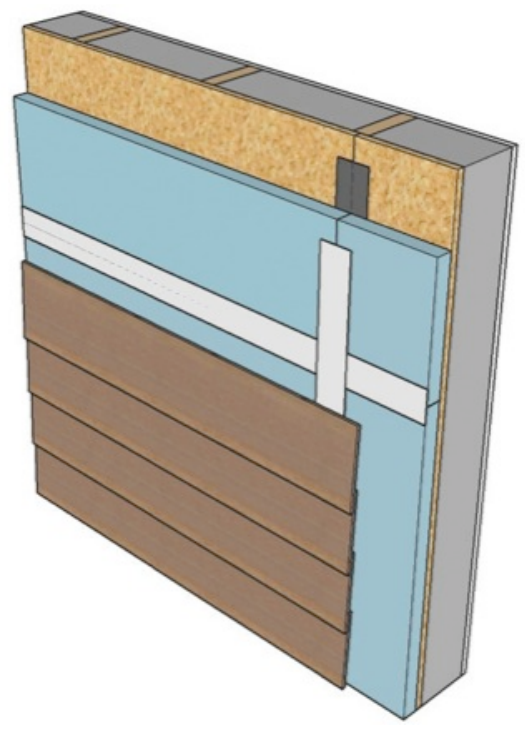

Figure 33. Lap siding attached directly through rigid insulation
CODE REQUIREMENTS FOR

CLADDING ATTACHMENT ARE AVAILABLE IN SECTION R703 OF THE 2009 IRC AND 2012 IRC. TABLE R703.4 PROVIDES GUIDANCE FOR ATTACHING CLADDING DIRECTLY THROUGH EXTERIOR RIGID INSULATION.

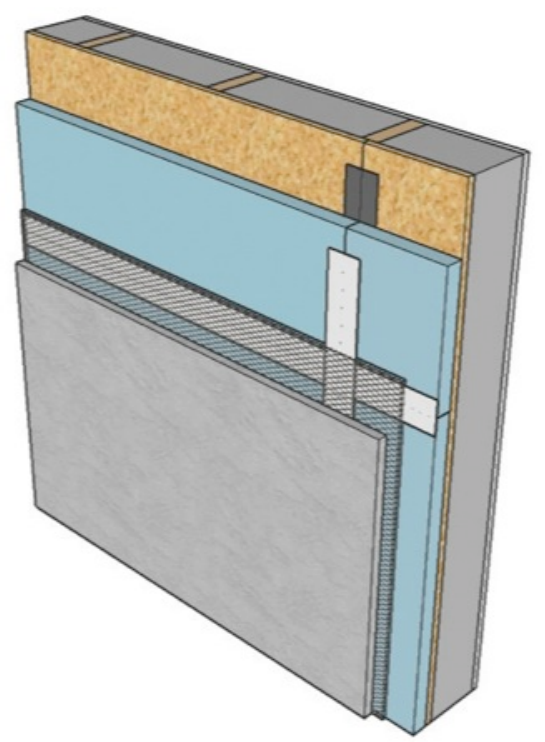

Figure 34. Stucco attached directly through rigid insulation 
For insulation thicker than 1-1/2 in., we recommend vertical wood furring strips to provide a cladding attachment location (see Figure 34). The approach also provides a drainage and ventilation gap behind the cladding, which is beneficial to the water management performance of the wall assembly.

To adequately support the cladding, we recommend attaching the furring strips back to the structure using \#10 or larger wood screws that are sized to maintain a 1-1/4-in. minimum embedment into the structural framing. As an example, a 6-in. long wood screw can be used to attach up to 4 in. of insulation ( 4 in. insulation $+3 / 4$ in. of furring $+1-1 / 4$ in. of embedment $=6$ in. total). A 4 -in. screw would be adequate for 2 in. of rigid insulation ( $2 \mathrm{in}$. of insulation $+3 / 4$ in. of furring $+1-1 / 4$ in. of embedment $=4 \mathrm{in}$.). With the furring strips attached directly back to the wood framing, the horizontal spacing will generally either be 24 in. o.c. or 16 in. o.c. Table 11 provides a quick reference of recommended vertical screw spacings based on framing spacing and cladding type for up to 4 in. of exterior rigid insulation.

Table 11. Vertical Screw Spacings for Attaching Wood Furring Strips to the Structure for up to 4 in. of Rigid Insulation

\begin{tabular}{|c|c|c|}
\hline Cladding & $\begin{array}{c}16 \text { in. o.c. } \\
\text { Stud Spacing }\end{array}$ & $\begin{array}{c}24 \text { in. o.c. } \\
\text { Stud Spacing }\end{array}$ \\
\hline Wood, Vinyl, and Fiber Cement (up to $5 \mathrm{lb} / \mathrm{ft}^{2}$ ) & 24 in. & 18 in. \\
\hline Stucco (up to $\left.10 \mathrm{lb} / \mathbf{f t}^{2}\right)$ & $12 \mathrm{in.}$ & 9 in. \\
\hline Adhered Stone Veneer (up to $20 \mathrm{lb} / \mathrm{ft}^{2}$ ) & 6 in. & 4 in. \\
\hline
\end{tabular}

Larger spacing can be used if less insulation is used. We recommend additional design for claddings that exceeed $20 \mathrm{psf}$. For additional options for fastener type, spacing, and thickness of insulation, see Appendix B.

Bridging the insulation with additional wood framing members in order to provide a cladding attachment location is generally not recommended because thermal resistance is lost.

Some claddings (such as stucco and adhered stone veneer) may require additional support between the structural furring strips to facilitate the installation. In these cases, additional structural furring or nonstructural spacer strips can be added (see Figure 35). 


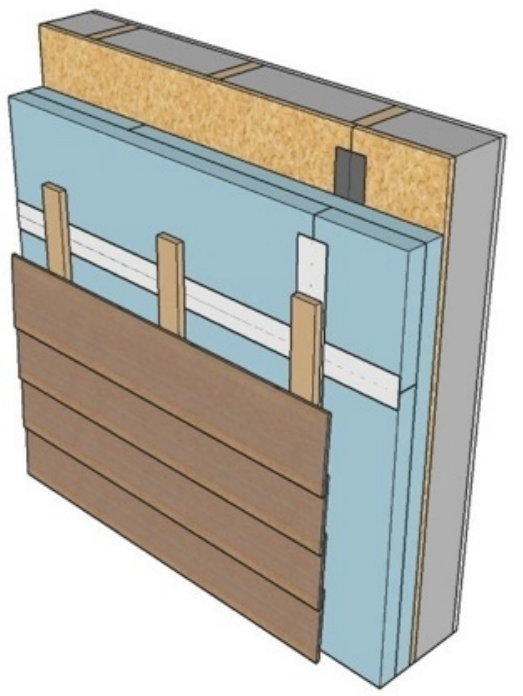

Figure 35. Furring strips attachment location for lap siding

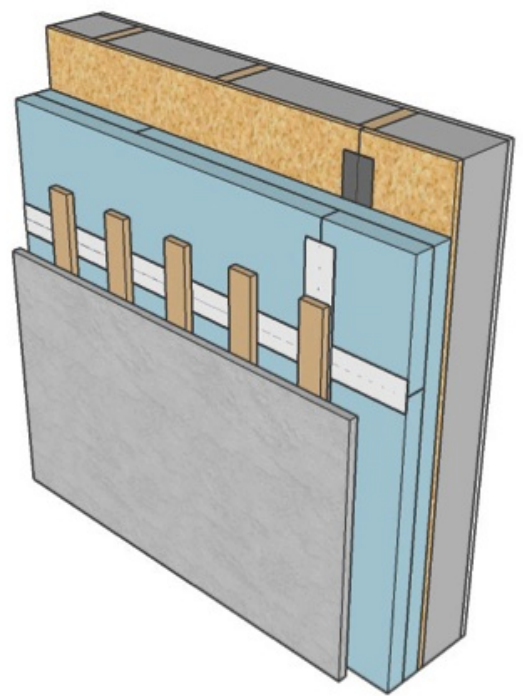

Figure 36. Additional intermediate furring used to facilitate the installation of stucco and adhered stone veneer

Wood shingles require a continuous nail base, which is best provided by installing another layer of structural sheathing directly over the insulation in place of wood furring strips. For this configuration, the new sheathing becomes analogous to the wood structural sheathing of the wall assembly, so water management details can now be managed exactly per standard construction (i.e., the new sheathing needs to be protected from rainwater absorption with either a building paper or a house wrap that is integrated with the windows). With this configuration, the assembly will dry little or not at all to the interior, so ventilation drying to the exterior is recommended. A drainage mat must be installed behind the wood shingles to provide cladding drainage and ventilation.

At openings such as windows and doors, the details for trim attachment can differ slightly from standard construction practice. At the head and sill, the furring strips that are already in the field of the wall are generally sufficient to attach those elements; however, additional furring strips at the jambs are generally required to attach the jamb trim and support the abutting cladding (see sequences in Figure 36 through Figure 39). 

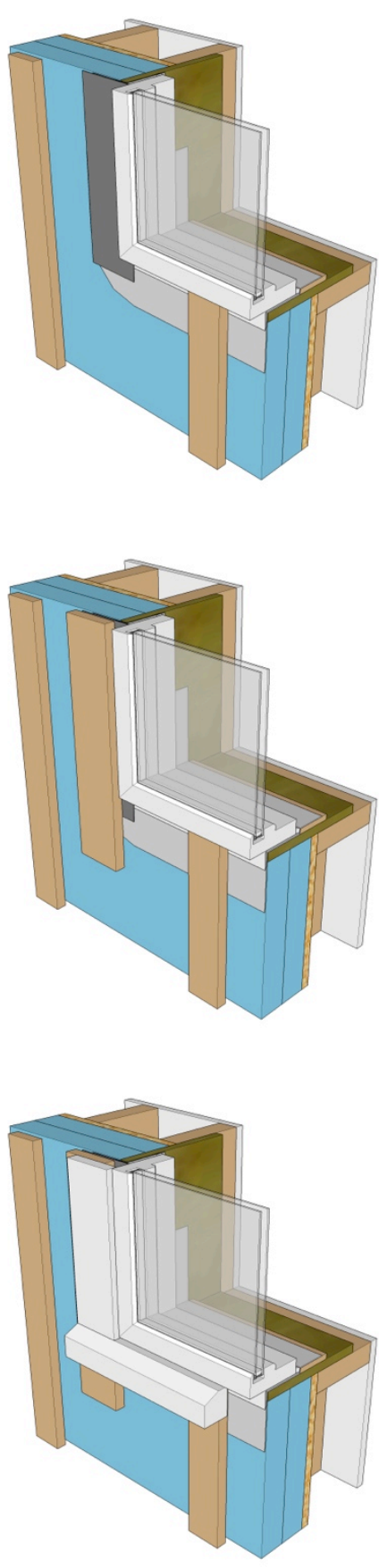

Step 1. Install the furring strips back to the stud framing.

Step 2. Install the jamb furring strips. These should extend about 6 in. past the head and the sill.

Step 3. Install the trim fastened back to the furring strips. 


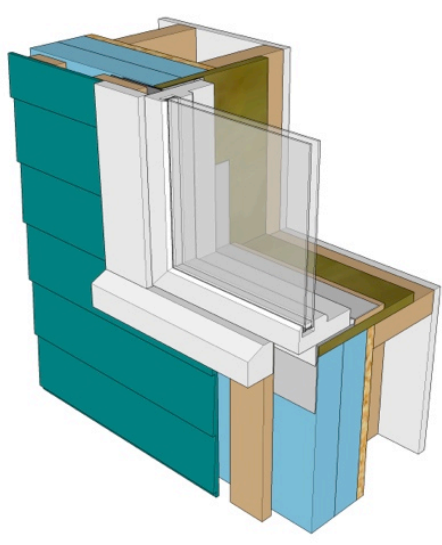

Figure 37. Cladding and trim attachment around a window (sill condition)
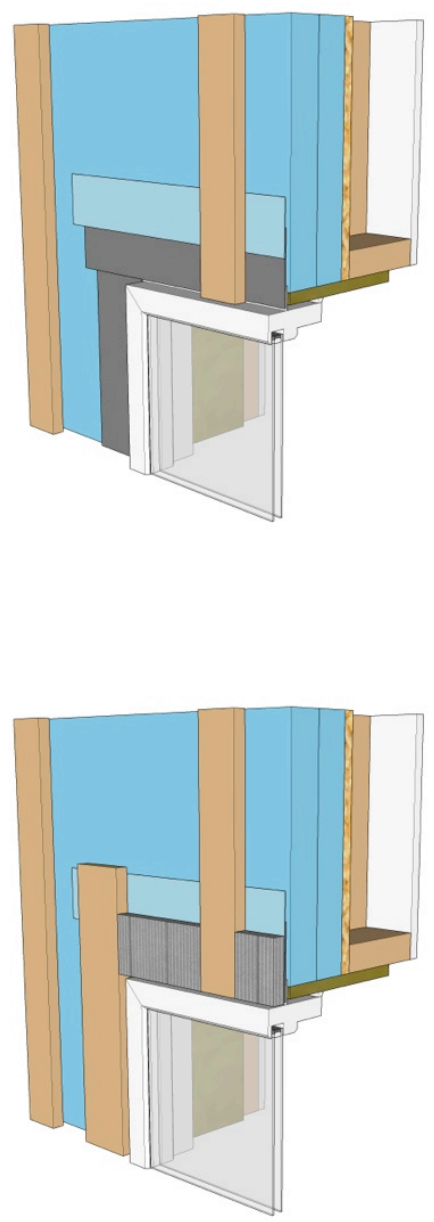

Step 4. Install the siding attached to the furring according to the siding manufacturer's installation recommendations.
Step 1. Install the furring strips back to the stud framing.

Step 2. Install the jamb furring strips. These should extend about 6 in. past the head and the sill. 

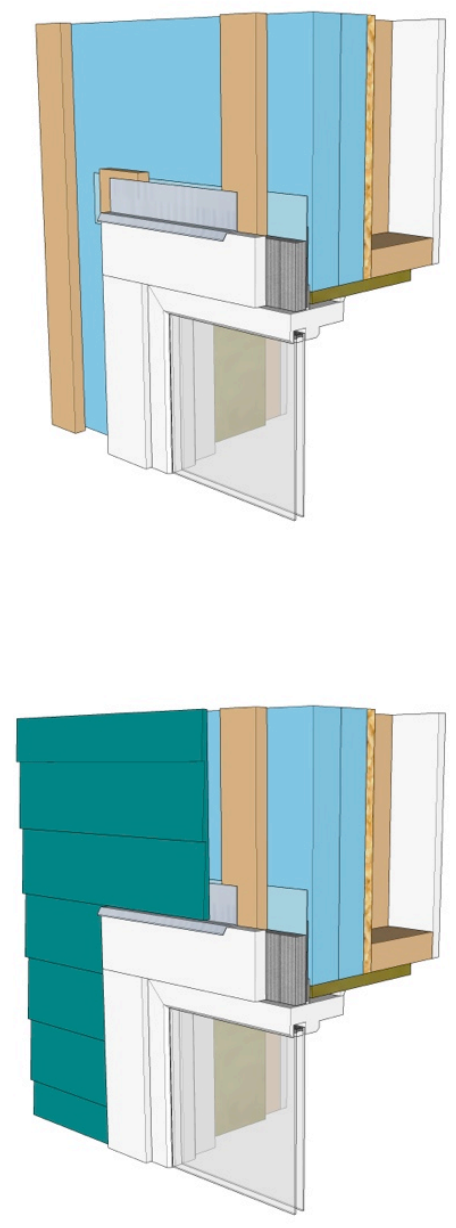

Figure 38. Cladding and trim attachment around a window (head condition)

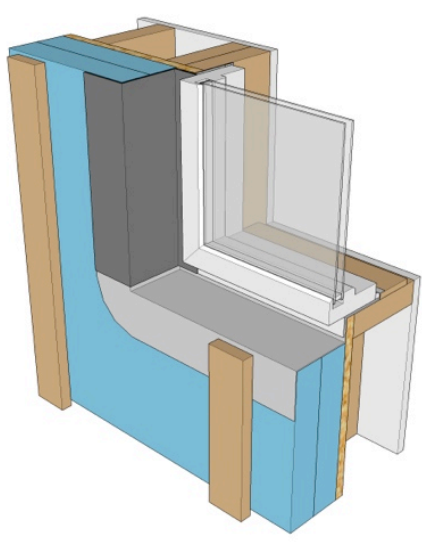

Step 1. Install the furring strips back to the stud framing.
Step 3. Install the trim fastened back to the furring strips. At the head, install a head flashing over the head trim to maintain the shingle lap effect with the siding.

Step 4. Install the siding attached to the furring according to the siding manufacturer's installation recommendations. 

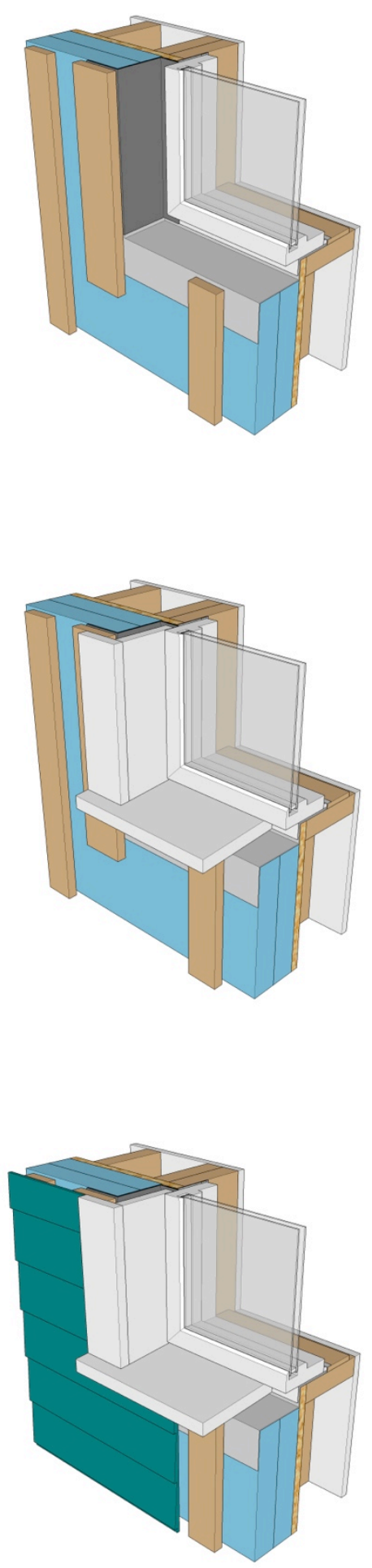

Step 2. Install the jamb furring strips. The furring strips should extend about 6 in. past the head and the sill.
Step 3. Install the trim fastened back to the furring strips. For the recessed condition, the trim may need to be assembled as a frame before it is attached to the structure.

Figure 39. Cladding and trim attachment around a window (recessed sill condition) 

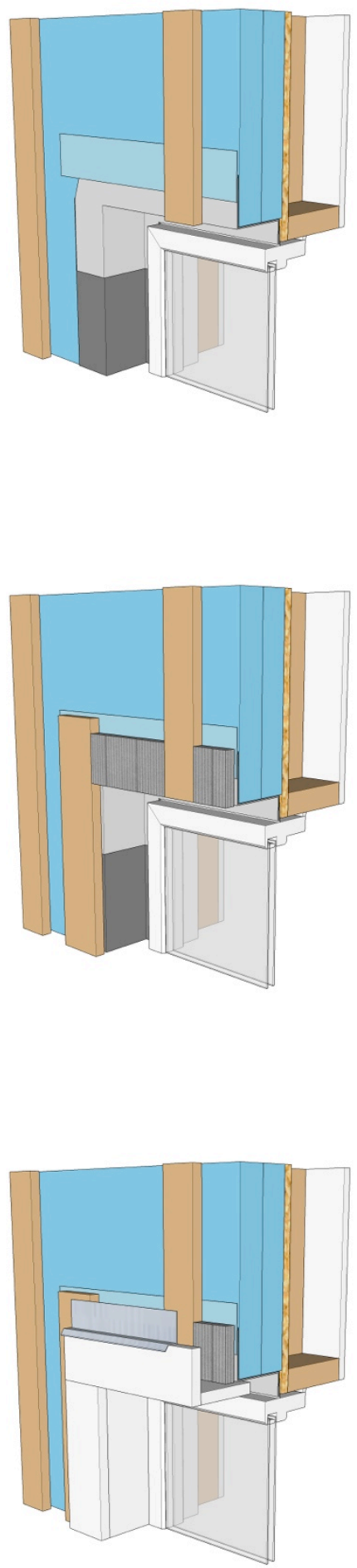

Step 1. Install the furring strips back to the stud framing.

Step 2. Install the jamb furring strips. These should extend about 6 in. past the head and the sill.

Step 3. Install trim fastened back to the furring strips. For the recessed condition, the trim may need to be assembled as a frame before it is attached to the structure. At the head, install a head flashing over the head trim to maintain the shingle lap effect with the siding. 


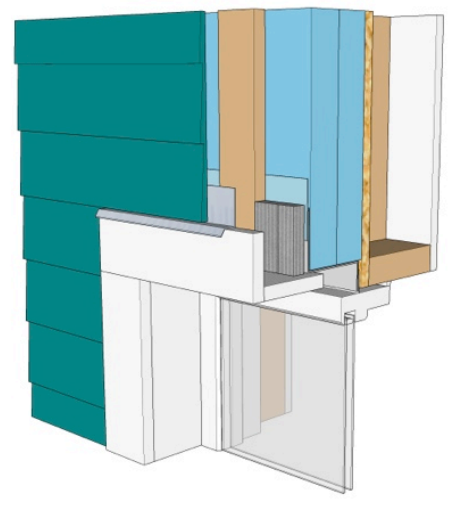

Step 4. Install the siding attached to the furring according to the siding manufacturer's installation recommendations.

Figure 40. Cladding and trim attachment around a window (recessed head condition)

If the sill profile is similar to a traditional sill, attaching it through the front face of the trim is often impractical. In this case, small segments of furring strips can be preattached to the back of the sill and the furring can be attached back to the structure to attach the trim. The head flashing above the head trim does not need to be installed all the way back to the water control layer. In reality, that flashing principally maintains the shingle lapping of the siding with the trim. It can thus be installed over the top of the furring.
CODE REQUIREMENTS FOR WALL BRACING ARE AVAILABLE IN SECTION 602.10 OF THE 2009 IRC AND 2012 IRC. THERE ARE OTHER RESOURCES TO ASSIST IN ACHIEVING CODE-COMPLIANT WALL BRACING:

- AMERICAN PLYWOOD ASSOCIATION SIMPLIFIED BRACING GUIDE - INTERNATIONAL CODE COUNCIL WALL BRACING GUIDE - FOAM SHEATHING COALITION WALL BRACING GUIDE

\subsection{Option 2: Water Control Layer Behind the Rigid Insulation}

\subsubsection{Structure}

No fundamental changes are required to the building's structural design to accommodate exterior rigid insulation.

Continuous wood structural sheathing provides a simple and robust means for wall bracing and wind resistance for a variety of home styles and design conditions, and is the standard practice for most of the residential building industry. Continuous exterior rigid insulation can be simply added to any home with a code-compliant structural design.

Alternatively, the wood structural sheathing can be applied only as required for structural bracing, allowing the exterior rigid insulation to function as the primary sheathing. This second approach does incorporate additional changes for builders from standard construction practice; however, the departure is minimal and is relatively easy to implement. It can reduce project costs because much of the exterior wood structural sheathing can often be omitted.

\subsubsection{Attaching the Insulation}

Attaching the insulation has no specific requirements because the insulation will ultimately be held in place by the wood furring strips. Attaching the rigid insulation is a temporary measure to 
hold the insulation onto the wall until the furring strips are installed. We recommend attaching the furring strips as soon as practical after the insulation is installed to prevent damage to the insulation from wind loads. For the temporary attachment, we recommend cap nails, screws with washers or plates, or other larger head fasteners to prevent overdriving through the outer face of the insulation materials.

The exterior rigid insulation can be installed in either a single layer (Figure 40) or in multiple layers (Figure 41). For multilayer applications, we recommend offseting all the joints in the insulation boards.

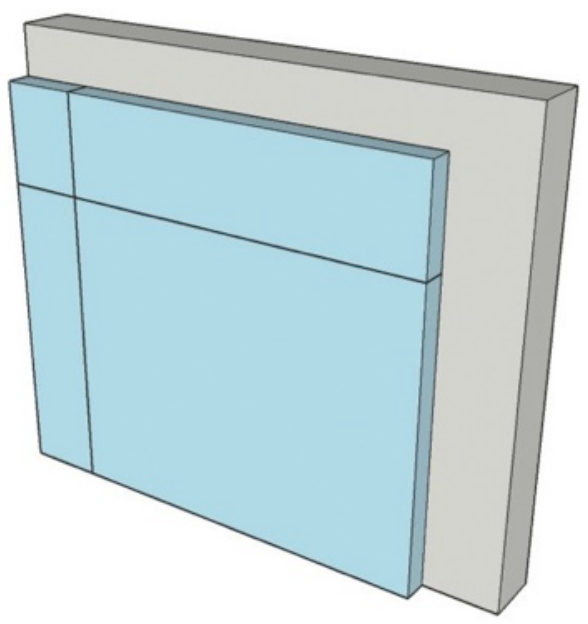

Figure 41. Single layer of rigid insulation

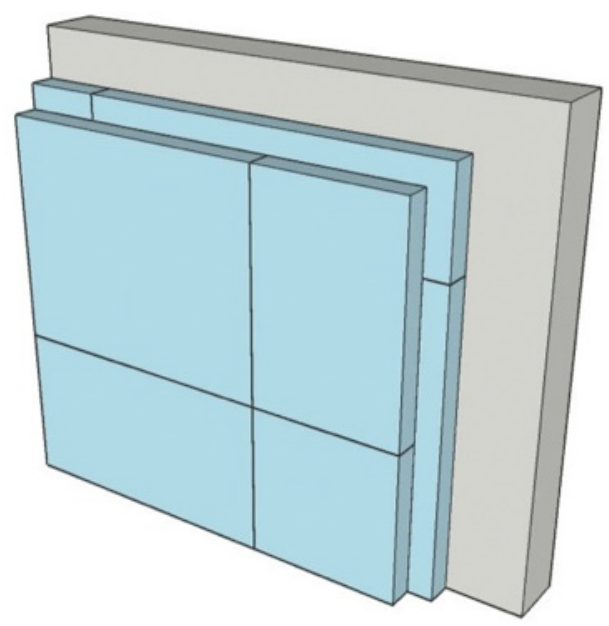

Figure 42. Multiple layers of rigid insulation with offset joints

\subsubsection{Water-Resistive Barriers}

When the water control layer is located behind the rigid insulation, any number of products or systems can be used. Most common are building paper and house wrap (Figure 42). Other options include fully adhered membranes, liquid-applied membranes, and taped and sealed joints of faced structural panels (Figure 43). These products should be installed according to industry standard practice and are independent of installing the rigid insulation. All flashing and other water control interfaces must connect to the wall water control layer. 


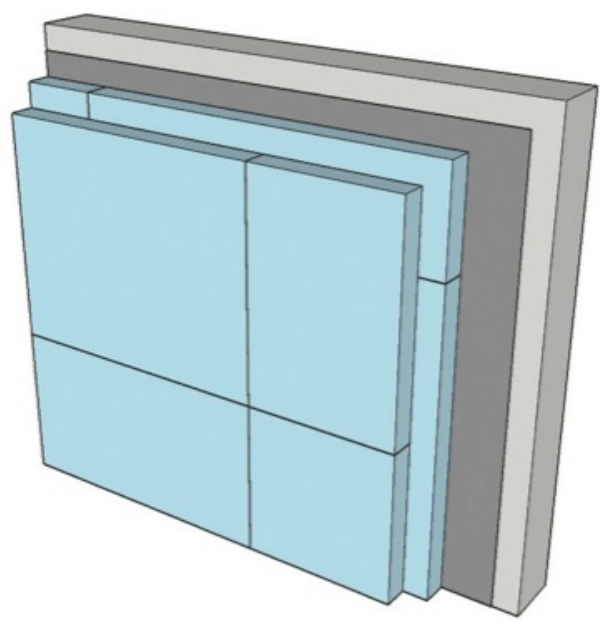

Figure 43. Sheet water control layer behind insulation

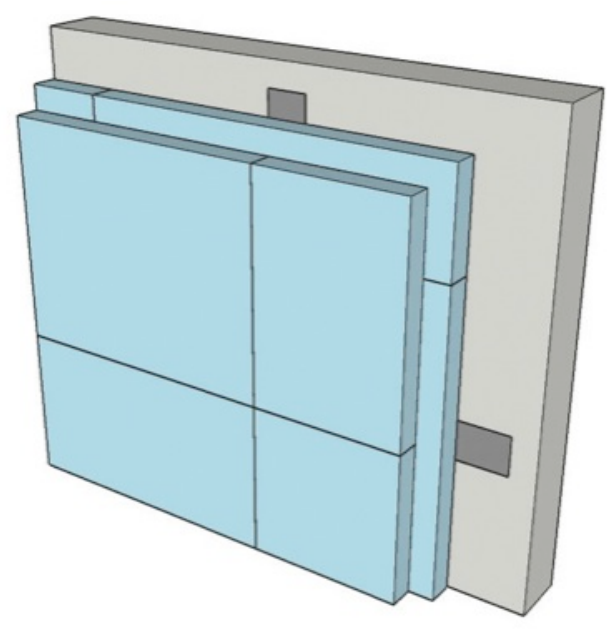

Figure 44. Taped water control layer behind insulation

\subsubsection{Integrating the Window}

Windows installed at the plane of the structural sheathing follow industry standards for integration with the wall water control layer. We recommend installing all windows in a pan flashed and drained opening with the jambs and the head of the frame taped or sealed to the wall water control layer. The exterior rigid insulation is added after all the water management details are completed (see sequence in Figure 44 and Figure 45; see also Figure 46, Figure 47, and Figure 48).

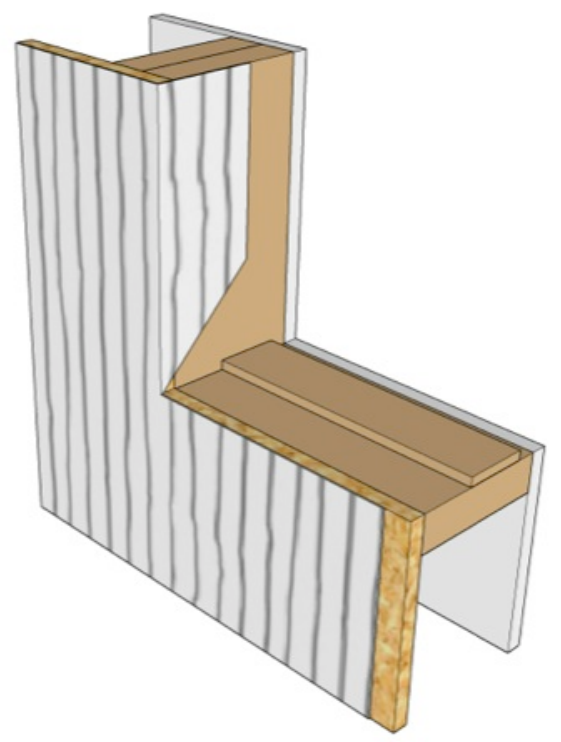

Step 1. Apply the water control layer to the exterior of the wall framing. 


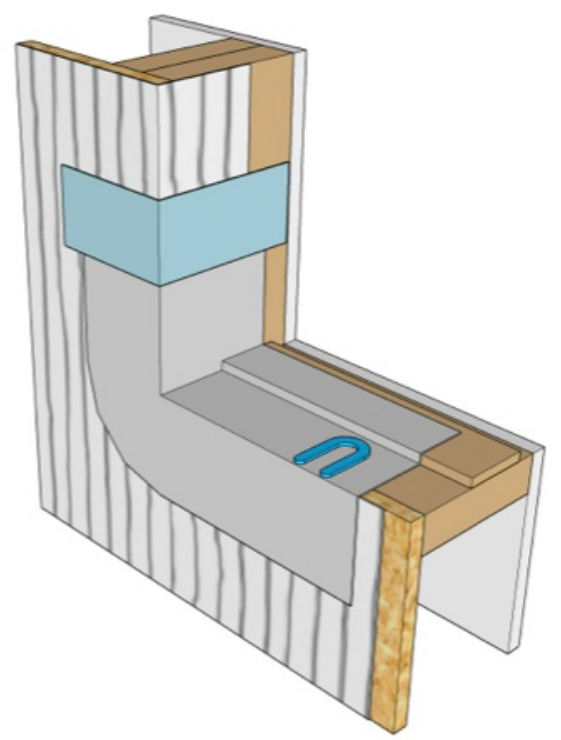

Step 2. Install the membrane pan flashing in the rough opening.

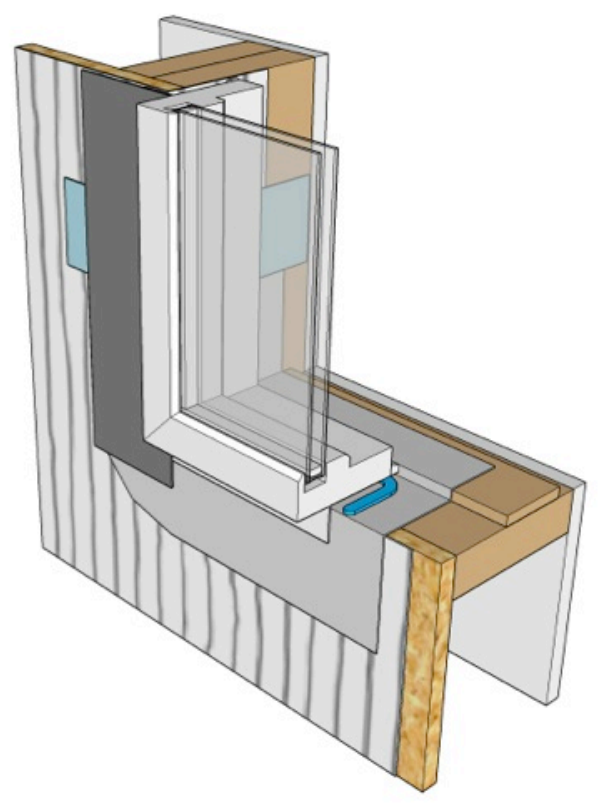

Step 3. Install the window and tape the jamb flange to the water control layer with a self-adhered membrane flashing. Do not tape the flange at the sill. 


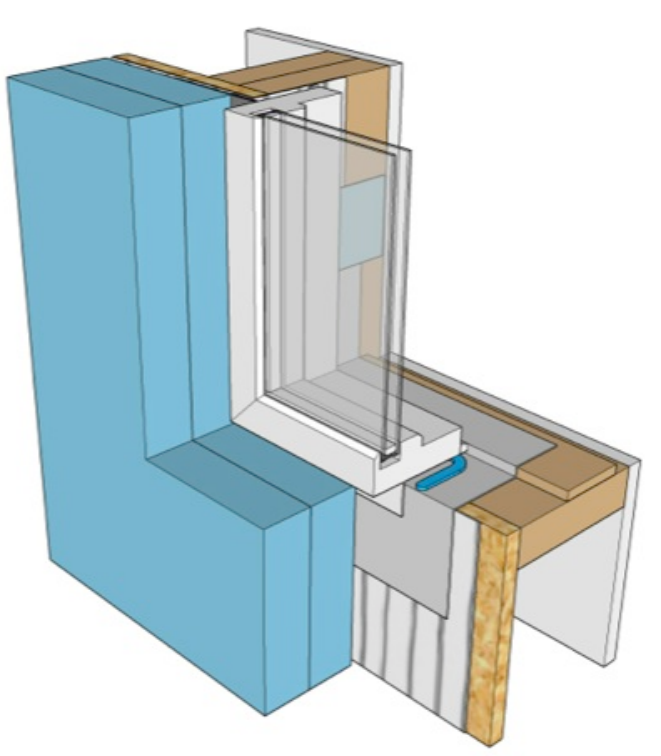

Step 4. Install the insulation.

Figure 45. Window recessed from the face of the rigid insulation (sill installation sequence)

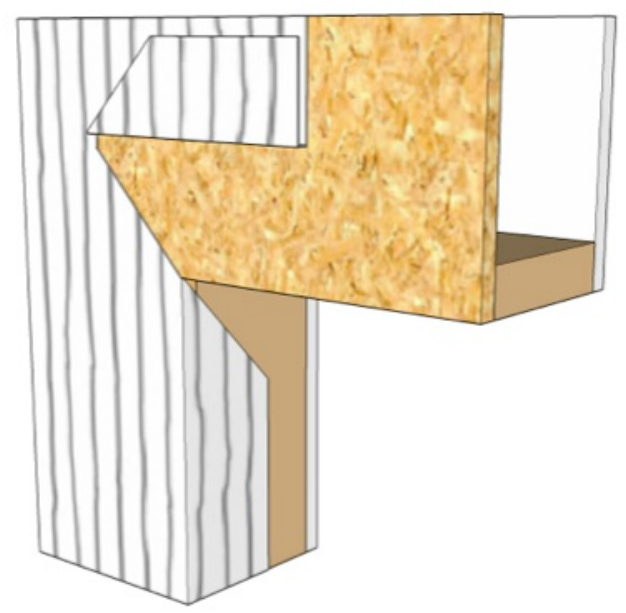

Step 1. Apply the water control layer to the exterior of the wall framing. 

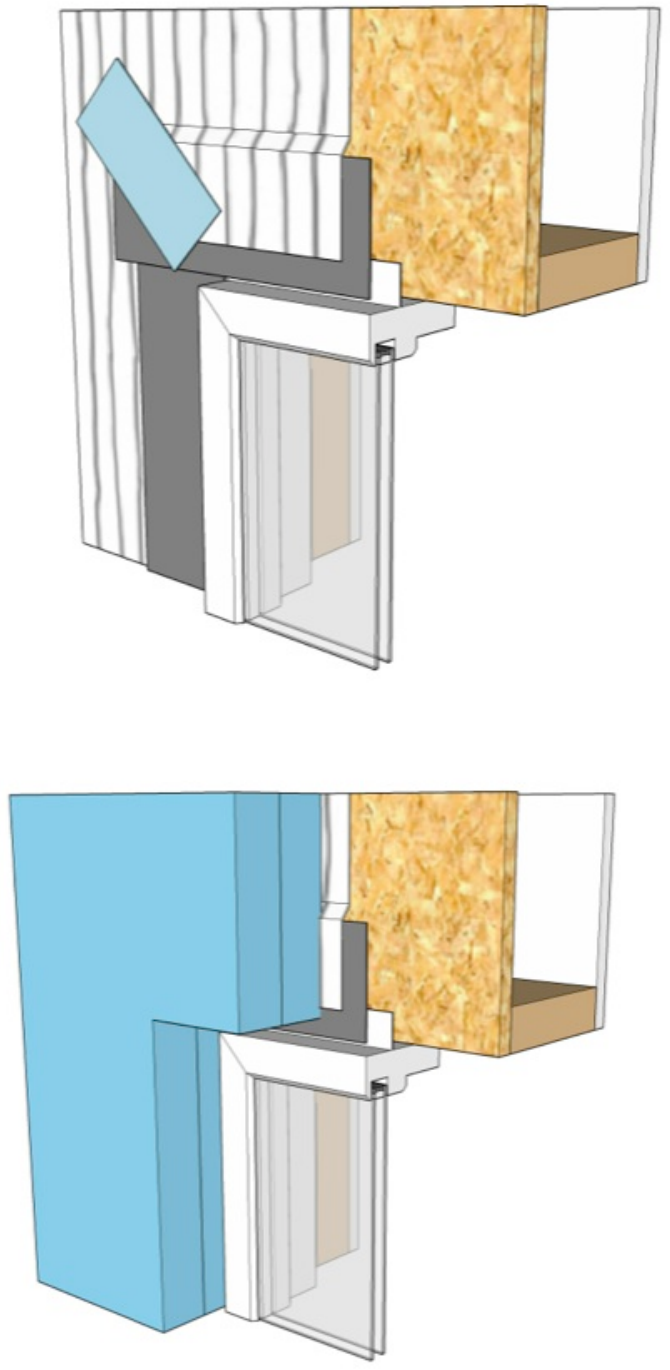

Step 3. Install the window and tape the jamb and head flange to the water control layer with selfadhered membrane flashing. Do not tape the flange at the sill.

Step 4. Install the insulation.

Figure 46. Window recessed from the face of the rigid insulation (head installation sequence) 
Water control layer positioned behind rigid insulation (can be combined with air control layer as shown in this detail)

Two layers of 2" rigid insulating sheathing; joints offset from underlying layer

Wood furring strip

Self-adhered head flashing; tape top edge of head flashing with compatible sheathing tape

Sloped metal drip edge over top of head trim; fastened to furring strips

Blocking as needed to allow for trim attachment

Cladding vent between furring strips window head

Exterior window trim fastened to furring strips

Head of trim extension box; leave $1 / 8$ " gap to allow drainage

Do not caulk trim extension box to window head

Fully-adhered membrane or sheathing tape extended into rough opening (air control layer)

Low expansion foam sealant at interior perimeter between window and rough opening framing (air control layer)

Figure 47. Window head-water control layer behind rigid insulation

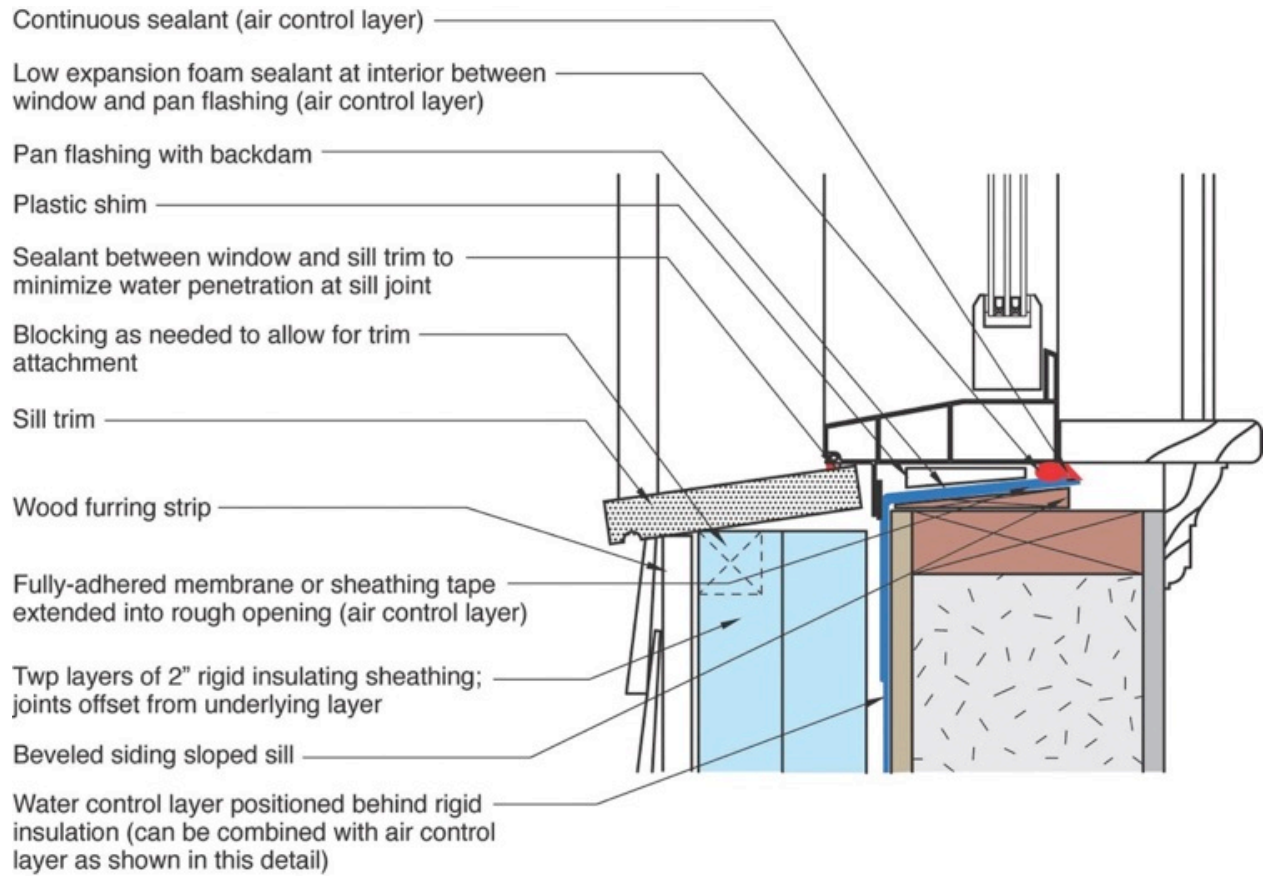

Figure 48. Window sill-water control layer behind rigid insulation 


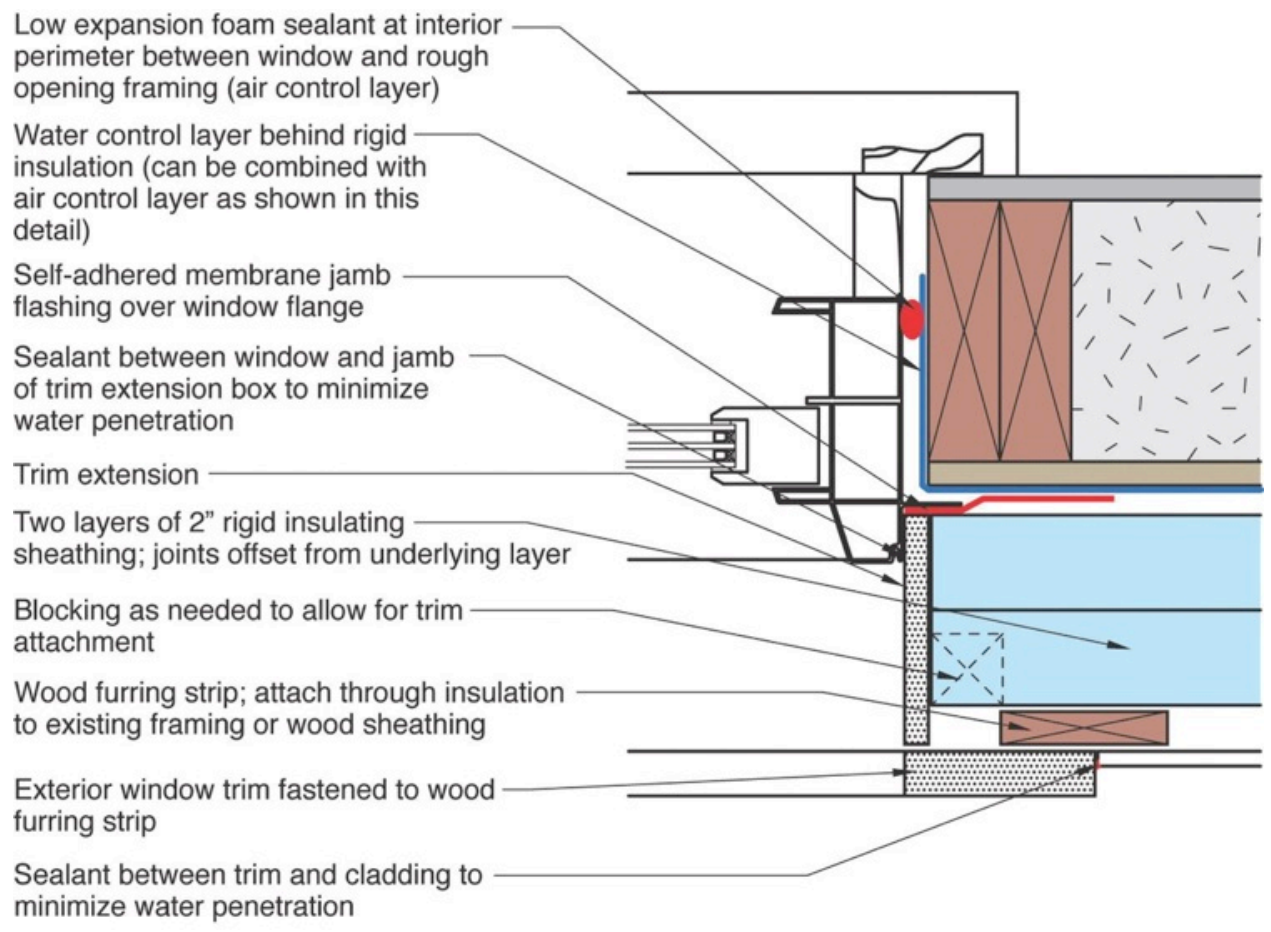

Figure 49. Window jamb-water control layer behind rigid insulation

Moving the windows further to the exterior while maintaining the water control layer at the structural sheathing plane requires that extension bucks be installed in the window rough opening. At the head, we recommend sloping the top surface to the exterior. The extension bucks need to be covered with a waterproof membrane; liquid-applied membranes are particularly well suited for this application. Then flash the window into the rough opening with fully adhered flashing membranes (see sequences in Figure 49 and Figure 50). 

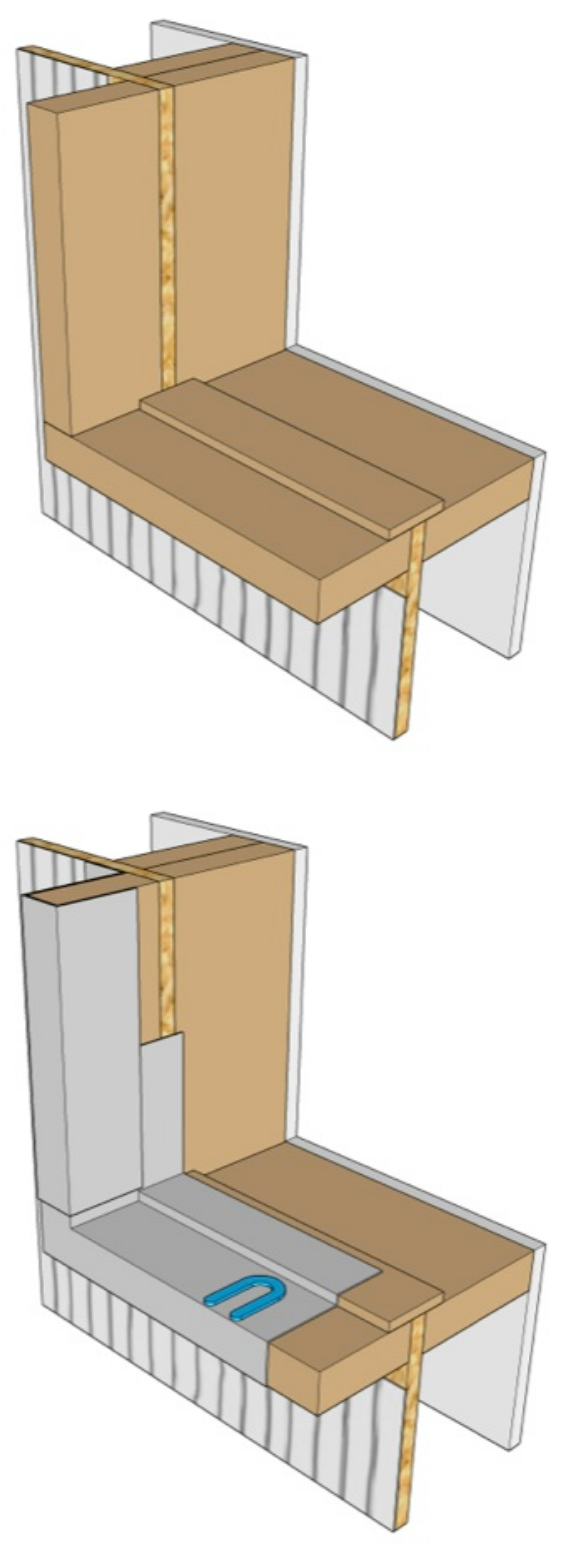

Step 1. Apply the water control layer to the exterior of the wall framing. Add wood buck extensions to the window frame to extend the window out to the face of the insulation.

Step 2. Install the membrane pan flashing and jamb flashing over the wood buck extensions and seal both to the wall water control layer. 


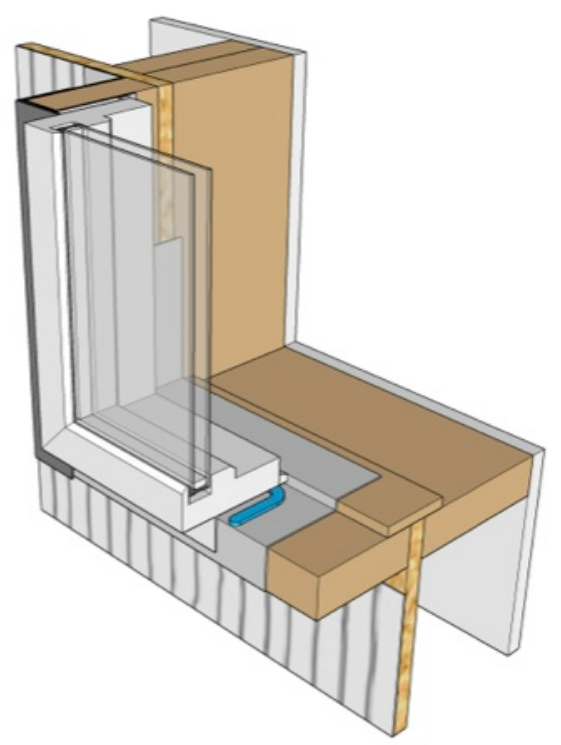

Step 3. Install the window and tape the jamb flange to the water control layer with self-adhered membrane flashing. Do not tape the flange at the sill.

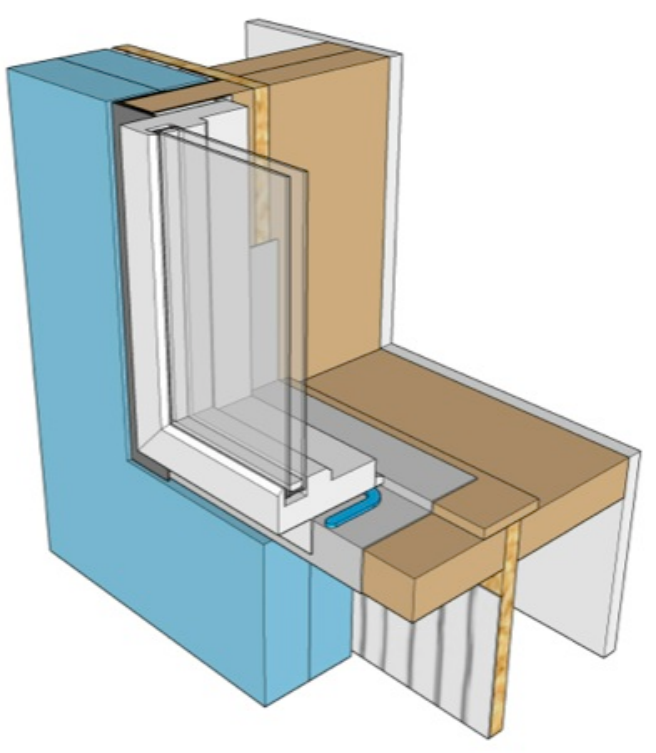

Step 4. Install the insulation.

Figure 50. Window flush with the face of the exterior rigid insulation (sill installation sequence) 

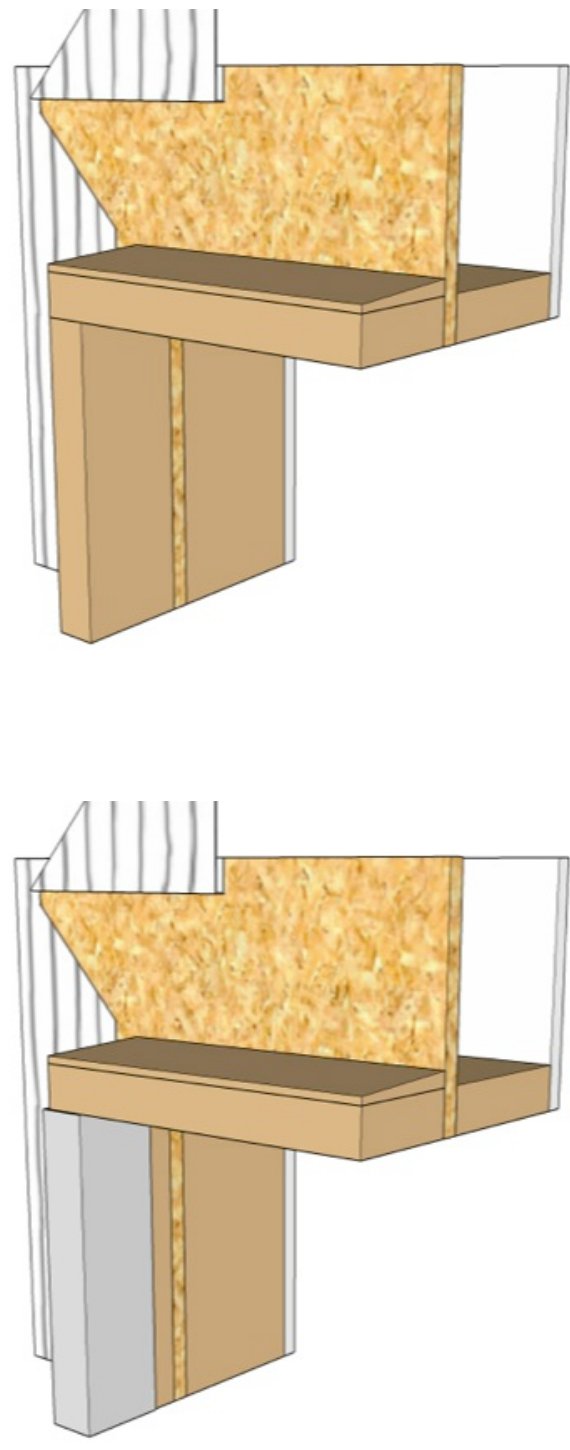

Step 1. Apply the water control layer to the exterior of the wall framing. Add wood buck extensions to the window frame to extend the window out to the face of the insulation.
Step 2. Install the membrane pan flashing and jamb flashing over the wood buck extensions and seal both to the wall water control layer. 

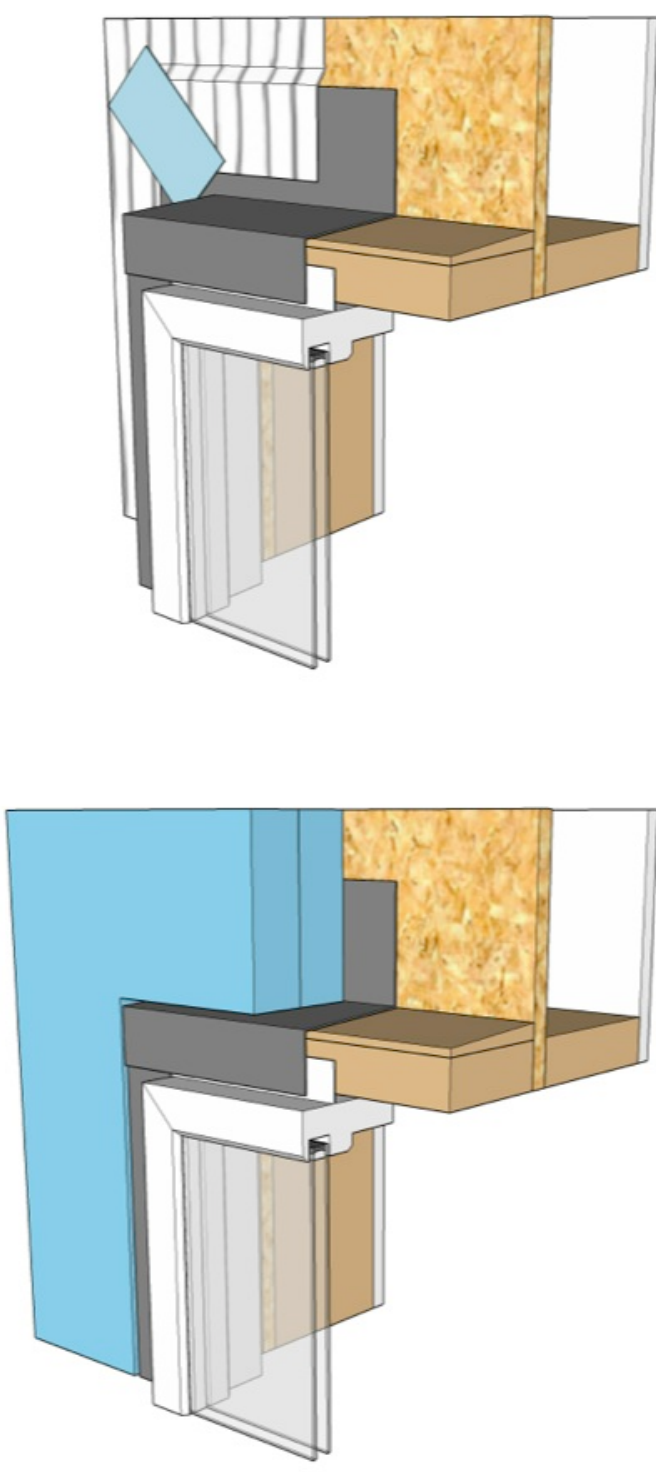

Step 3. Install the window and tape the jamb flange to the water control layer with self-adhered membrane flashing. Do not tape the flange at the sill.

Step 4. Install the insulation.

Figure 51. Window flush with the face of the exterior rigid insulation (head installation sequence)

\subsubsection{Roofs}

Where the roof is above the wall, the termination of the exterior insulation does not change significantly regardless of whether the attic is vented or unvented. The differences are mostly associated with the attic design rather than with the wall design.

For vented attics, the rigid insulation must terminate below the level of the roof sheathing to provide a ventilation opening. Extending the rigid insulation up as high as possible (leaving at least a 2-in. gap for attic ventilation) has some additional benefits though, including increased thermal resistance at the roof-to-wall connection, and it can act as an insulation stop and baffle for the attic insulation (see Figure 51). Gable ends need no additional thermal resistance; 
however, simply maintaining the rigid insulation up the full height is often practical to keep the cladding aligned.

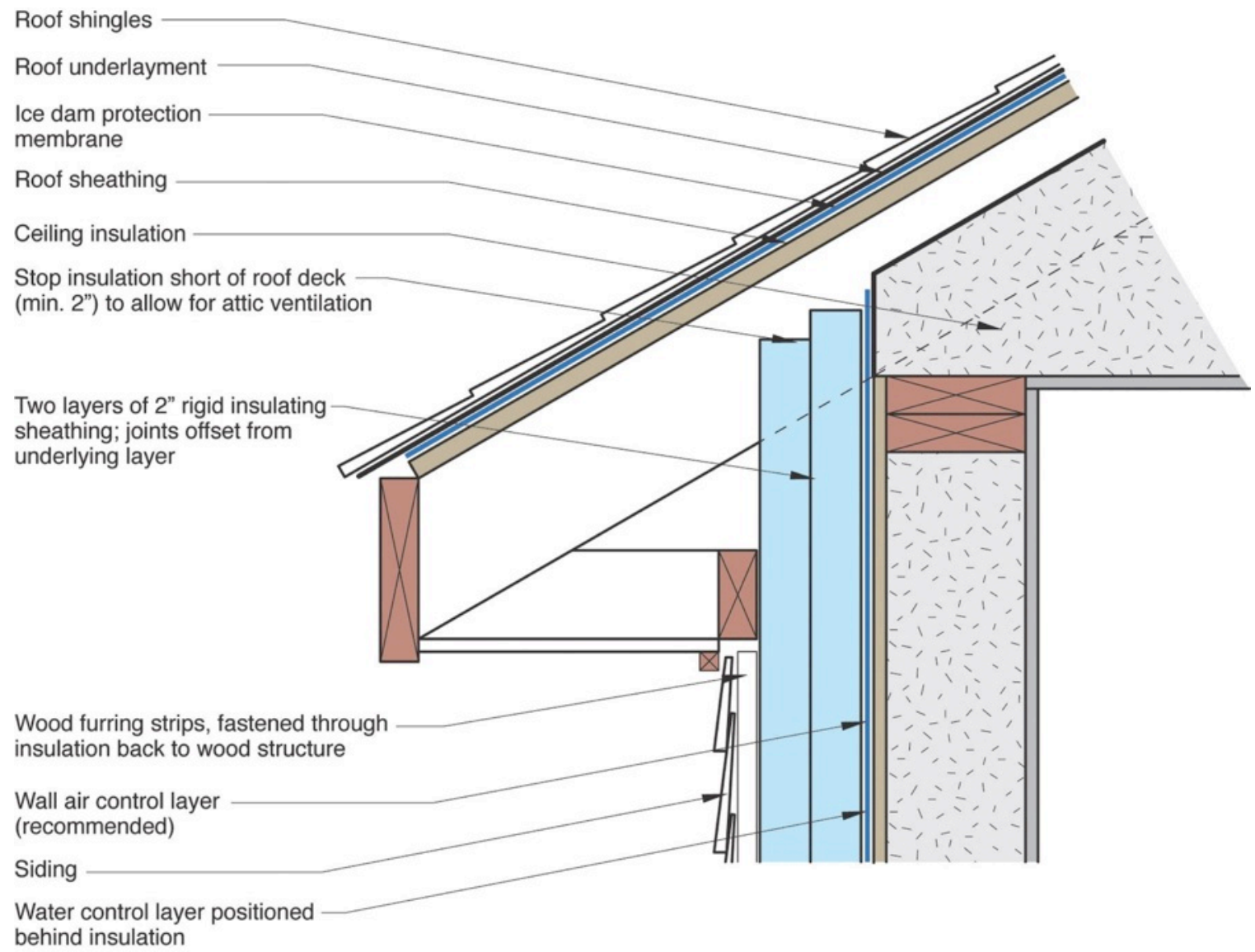

Figure 52. Vented attic water control layer behind rigid insulation

For unvented attics, the rigid insulation can be run tight to the underside of the roof sheathing. In this configuration, it can act as an insulation stop for spray polyurethane foam if it is being used (see Figure 54). At the gable ends, continuing the rigid insulation up the full height provides additional thermal resistance for the attic assembly. 


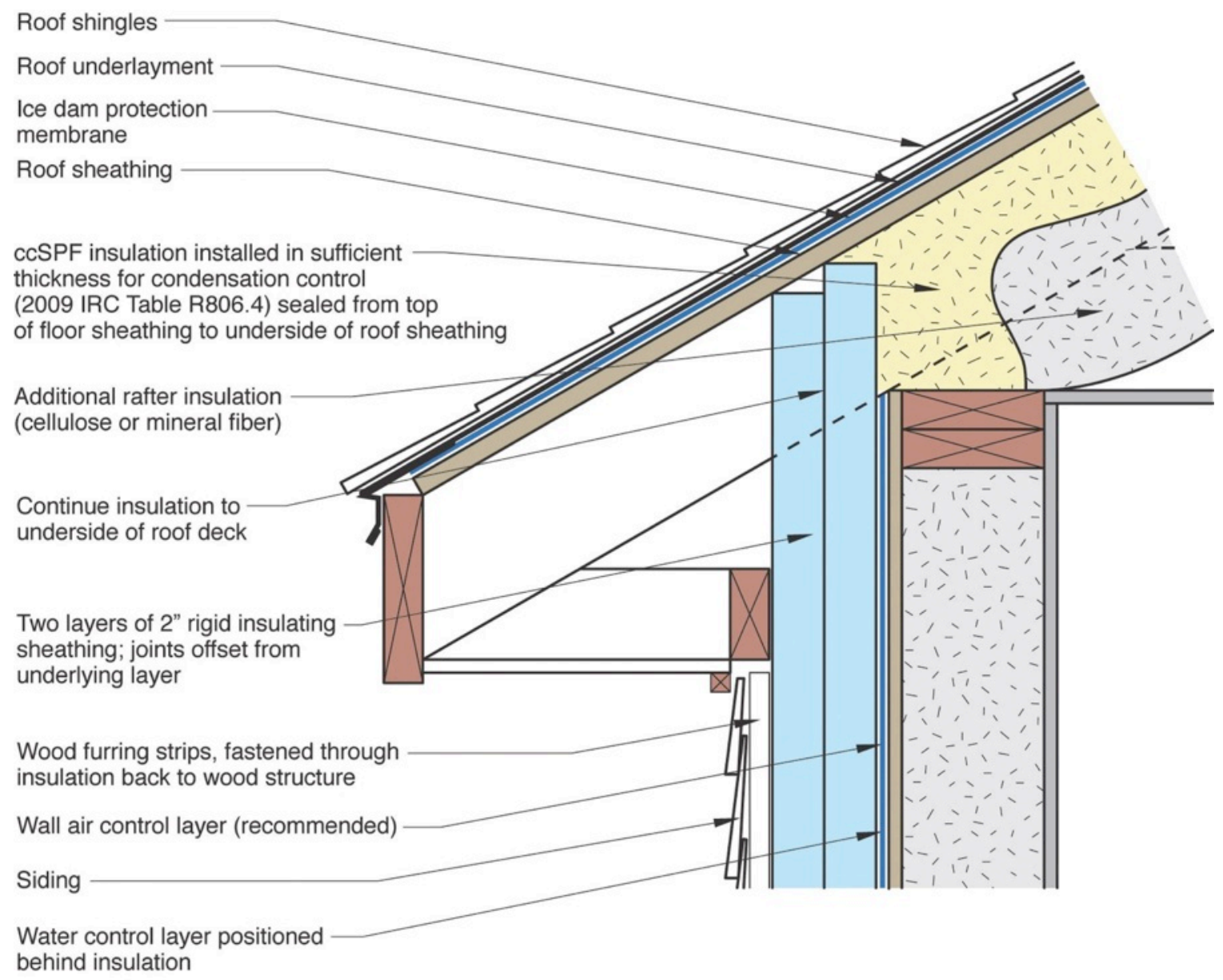

Figure 53. Unvented attic water control layer behind rigid insulation

Where the wall is above a roof, the termination details are critical. With the water control layer behind the insulation, the step flashing and shingles must extend back to the plane of the structural sheathing. A consideration for the detailing of this interface is the future need to reroof the building. The roof covering will undoubtedly have a shorter service life than the wall cladding; thus, a means to access the roof-to-wall interface from behind the exterior insulation should be provided so that future work can be completed without disrupting the primary siding. We recommend installing a minimum 8-in. band of siding and insulation at the roof-to-wall interface to provide a removable termination and allow future access to the flashing at the roofto-wall interface (see sequence in Figure 53). This band also provides an easy detail for the installation of a kick-out flashing should the end of the roof terminate in the field of the wall. 

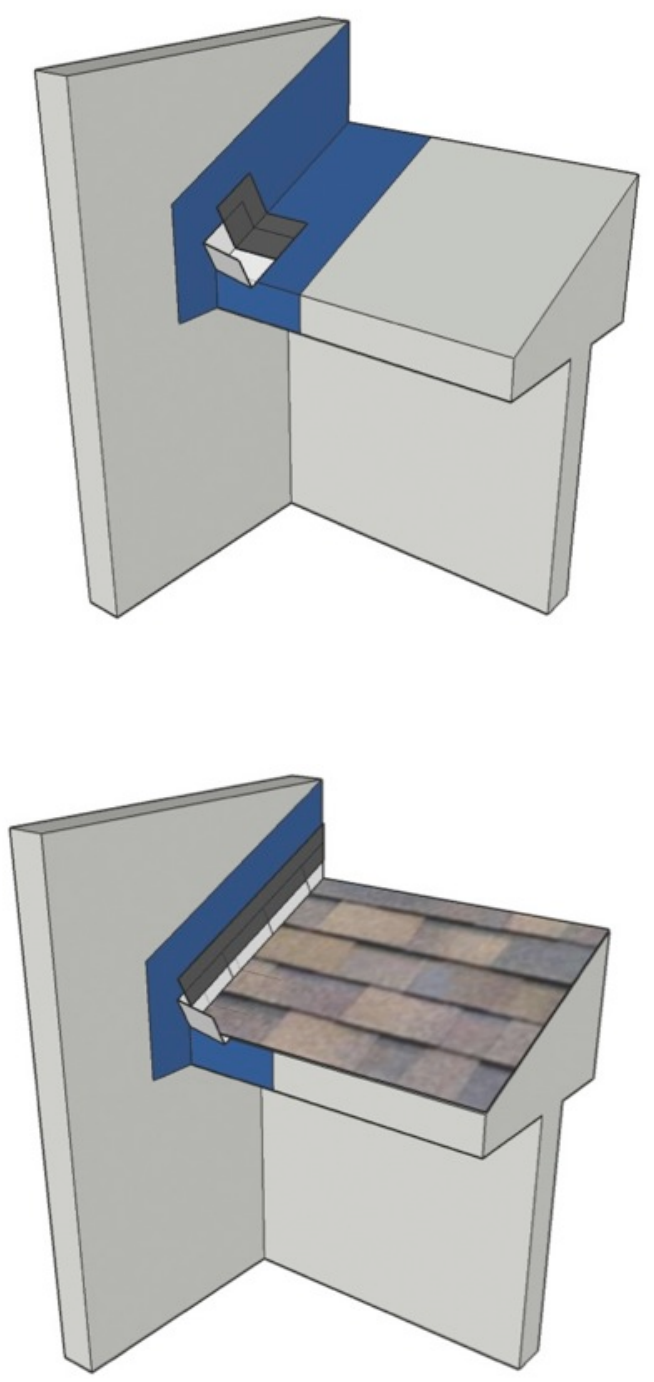

Step 1. Install the fully adhered membrane at the roof-to-wall connection. Strip in the kick-out flashing at the roof termination.

Step 2. Install the roof assembly and step flashing according to industry standard practice. 

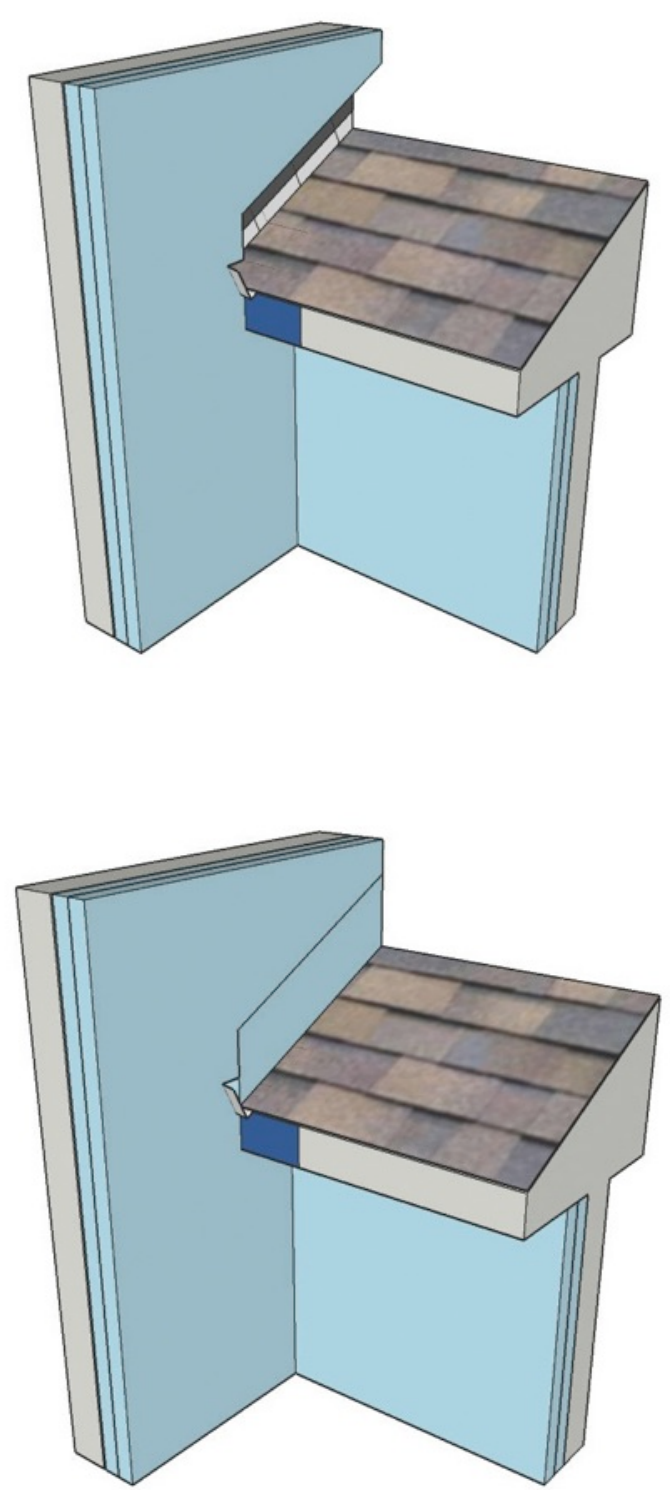

Step 3. Add the insulation to the wall assembly.

Step 4. Install a removable 8-in. strip of insulation to allow for future reroofing of the assembly.

Figure 54. Upper wall to lower roof construction sequence

For vented attics or porch roofs, the intent is to maintain the continuity of the insulation past the roof line to the wall above and to the wall below the roof, both of which are considered exterior wall assemblies (see Figure 54). For unvented attics, the insulation must follow the plane perpendicular to the roof sheathing (see Figure 55). 


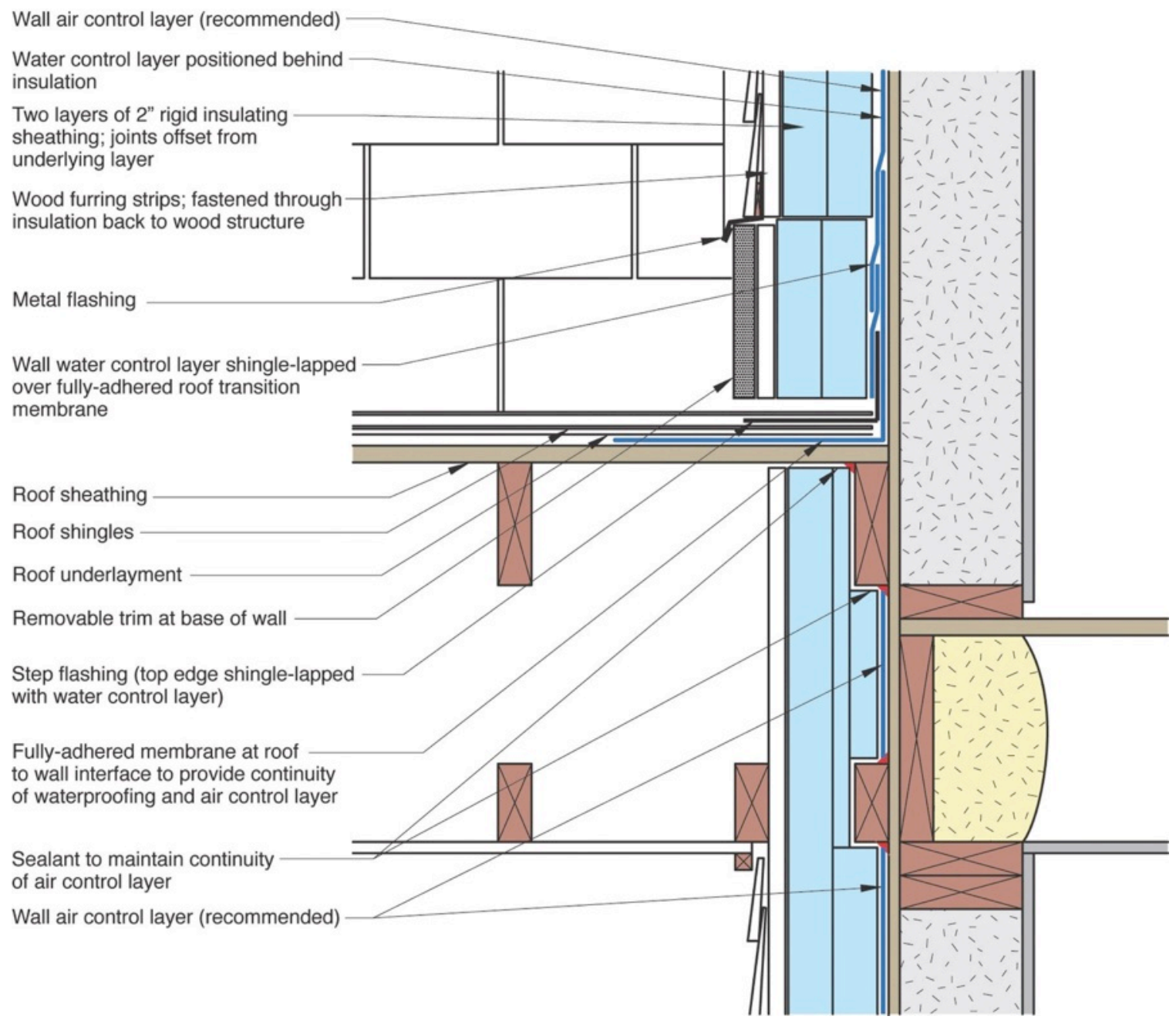

Figure 55. Vented attic or porch water control layer behind the rigid insulation 
Wall air control layer (recommended)

Water control layer positioned behind insulation

Two layers of 2" rigid insulating

sheathing; joints offset from underlying layer

Wood furring strips, fastened through insulation back to wood structure

Metal flashing

Wall water control layer shingle-lapped over fully-adhered roof transition membrane
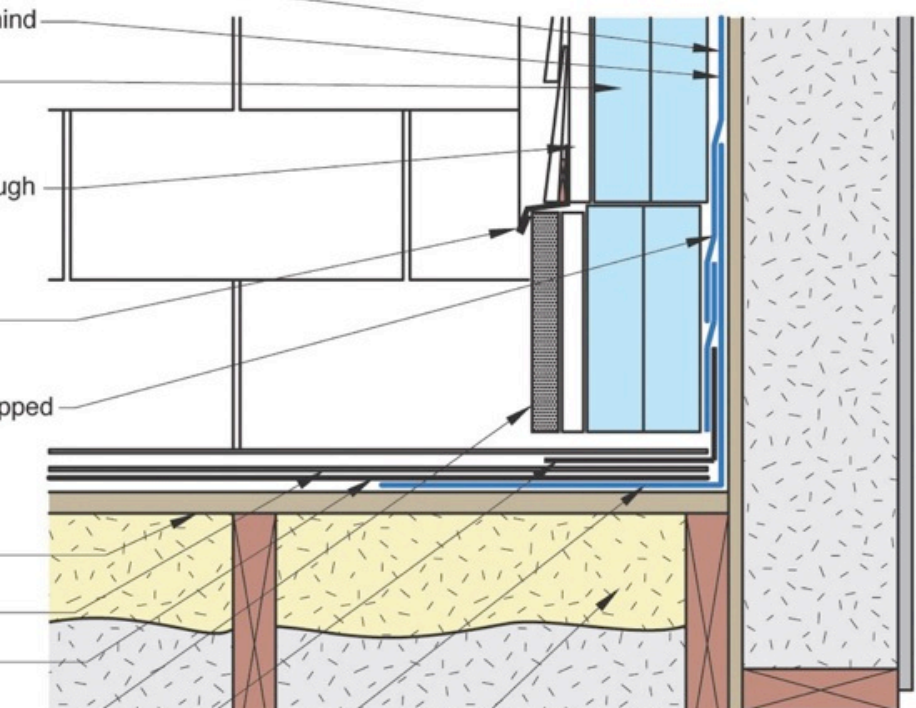

Roof sheathing

Roof shingles

Roof underlayment

Removable trim at base of wall

Step flashing (top edge shinglelapped with water control layer)

Fully-adhered membrane at roof to wall interface to provide continuity of waterproofing and air control layer

ccSPF insulation installed in sufficient thickness for condensation control

(2009 IRC Table R806.4) sealed between roof rafters to underside of roof sheathing

Additional rafter insulation

(cellulose or mineral fiber)
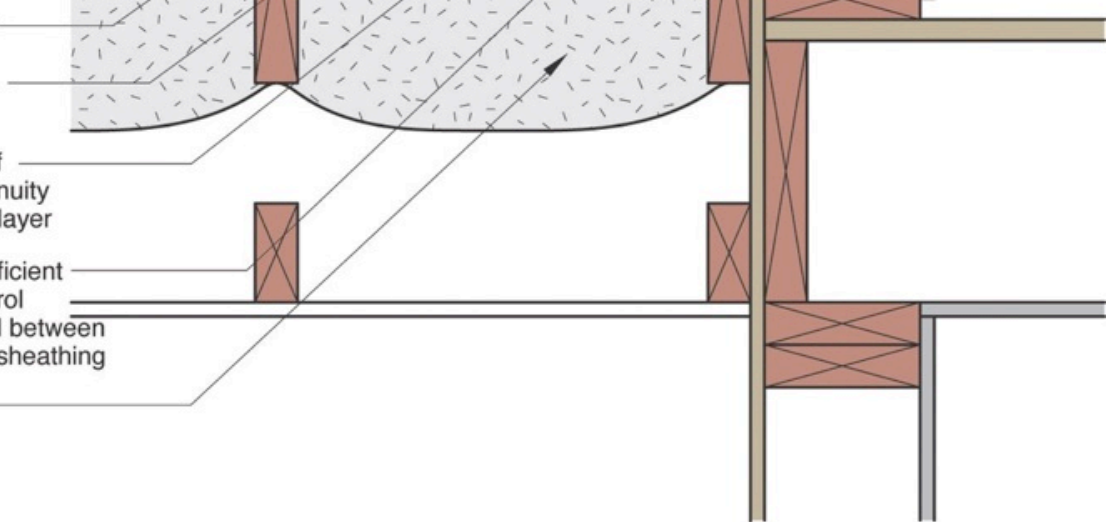

Figure 56. Unvented attic water control layer behind the rigid insulation 


\subsubsection{Balconies}

Balcony interfaces need to be addressed similarly to walls above lower roofs. Again, providing a removable strip of insulation and cladding at the wall to balcony interface allows the balcony waterproofing system to be replaced (see Figure 56 and Figure 57).

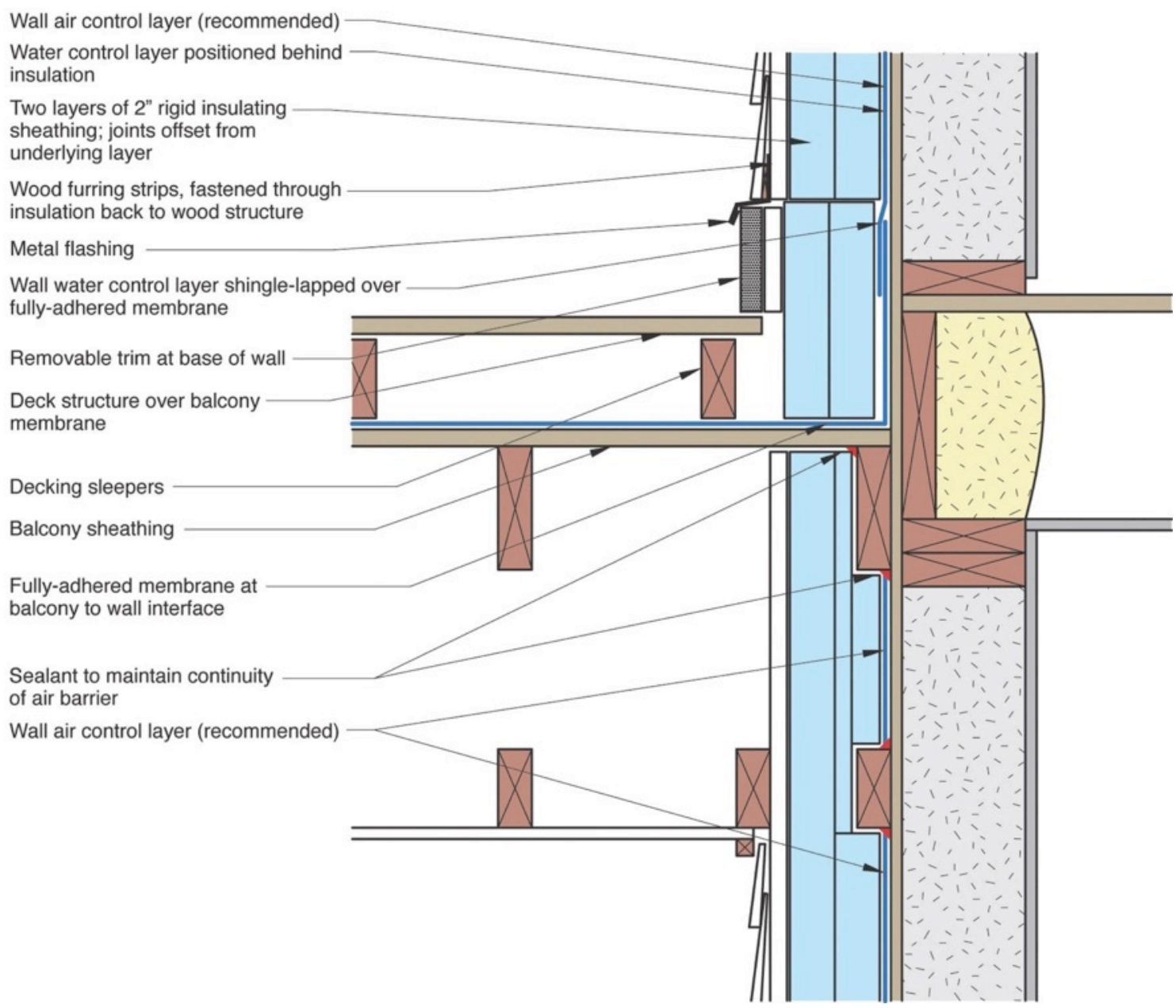

Figure 57. Balcony water control layer behind the rigid insulation 


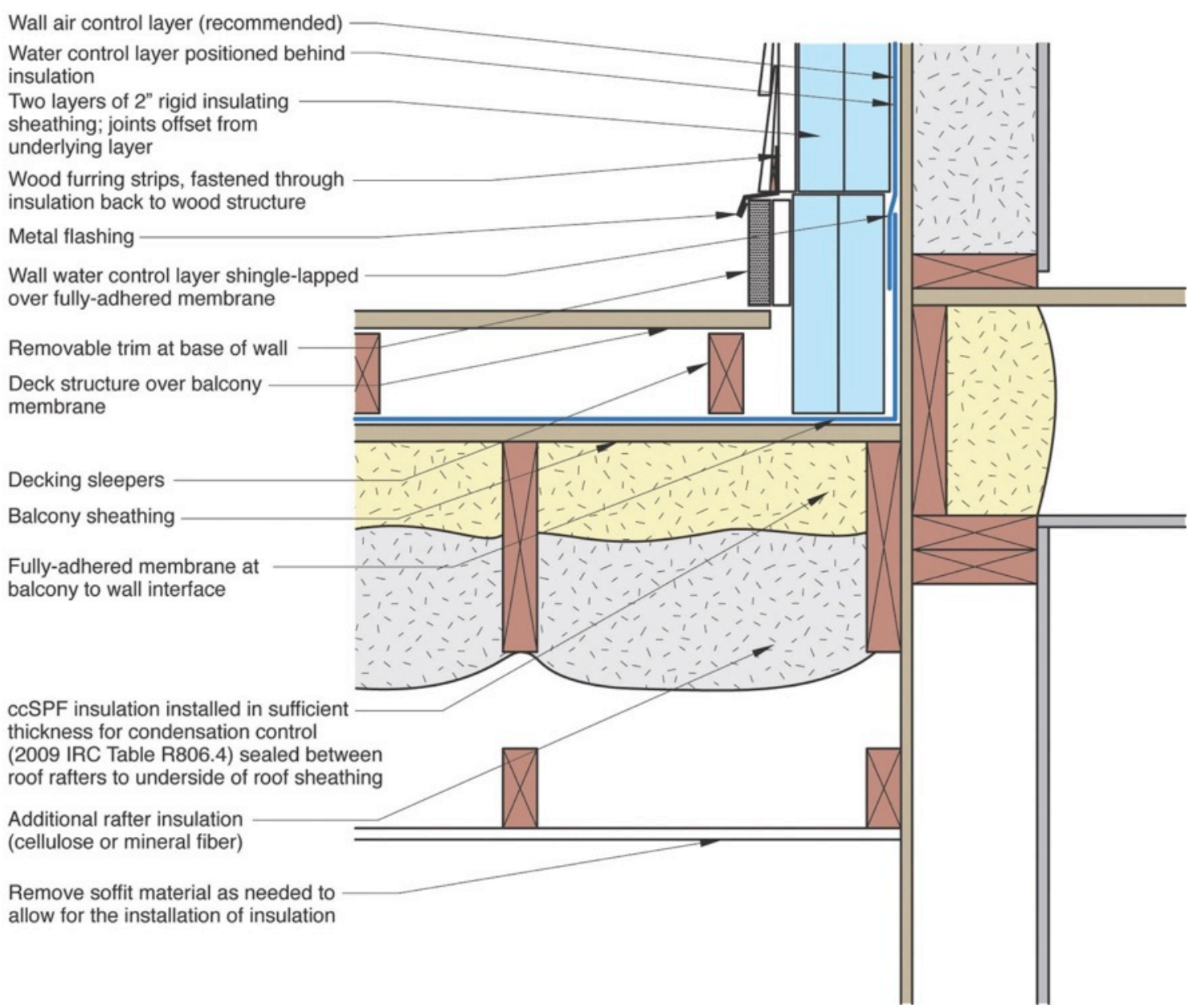

Figure 58. Balcony water control layer behind the rigid insulation

\subsubsection{Decks}

Attaching framed decks can be a little complicated if the water control layer is behind the rigid insulation. The ledger can be installed either outboard or inboard of the rigid insulation depending on loads (see Figure 58 and Figure 59). With heavy loads, an inboard location may be necessary. In general, placing the ledger outboard of the rigid insulation is preferred from a water control perspective. 

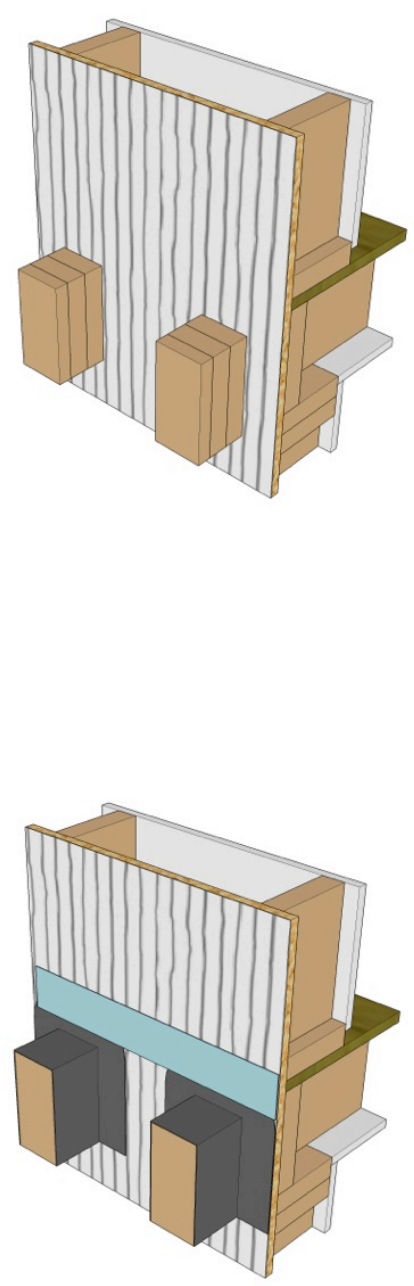

Step 1. Use ledger support blocking as required to accommodate the structural load of the deck. If the deck is self-supporting, the blocking can be omitted.
Step 2. Install the membrane saddle flashings over the ledger support blocking. Adhere the top edge with construction tape. 

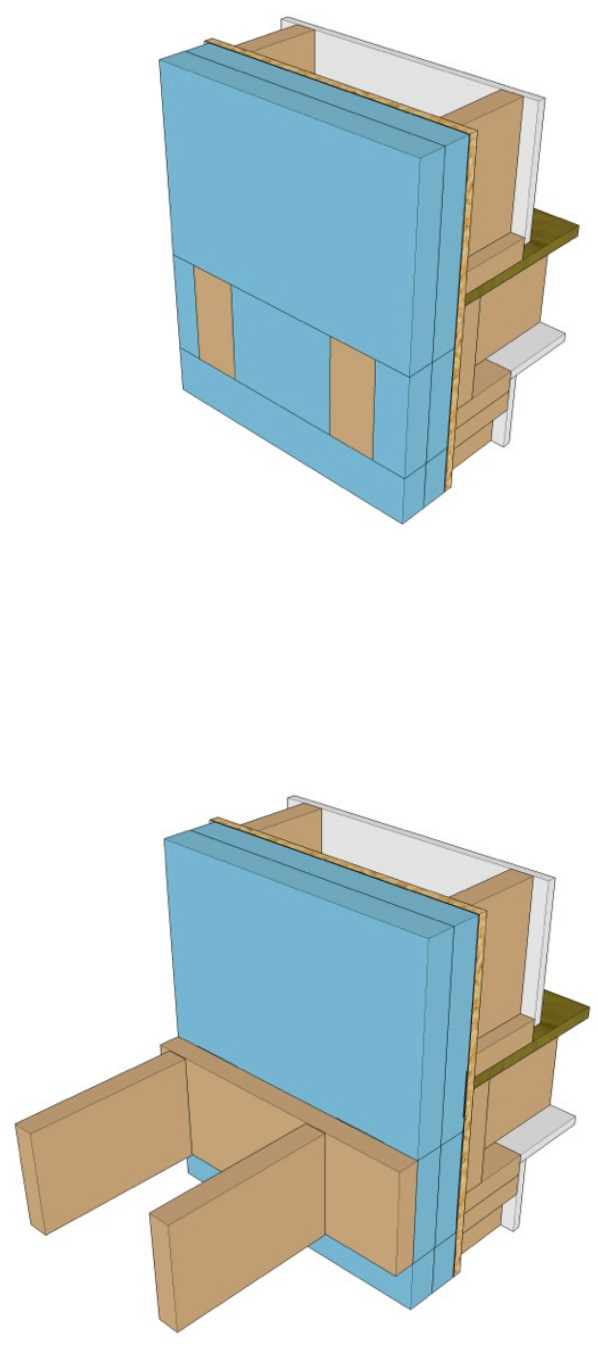

Step 3. Cut and fit the exterior rigid insulation around the deck support blocking.

Step 4. Attach the deck ledger and framing to the structure. 


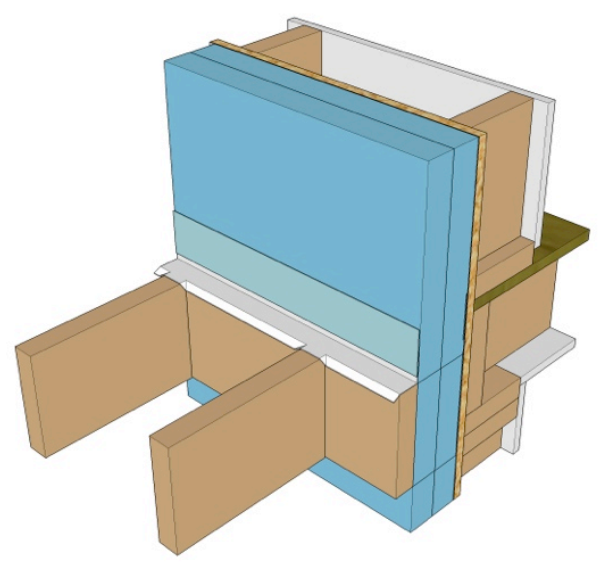

Step 5. Adhere the metal ledger flashing to the exterior rigid insulation with construction tape.

Figure 59. Ledger outboard of rigid insulation construction sequence 

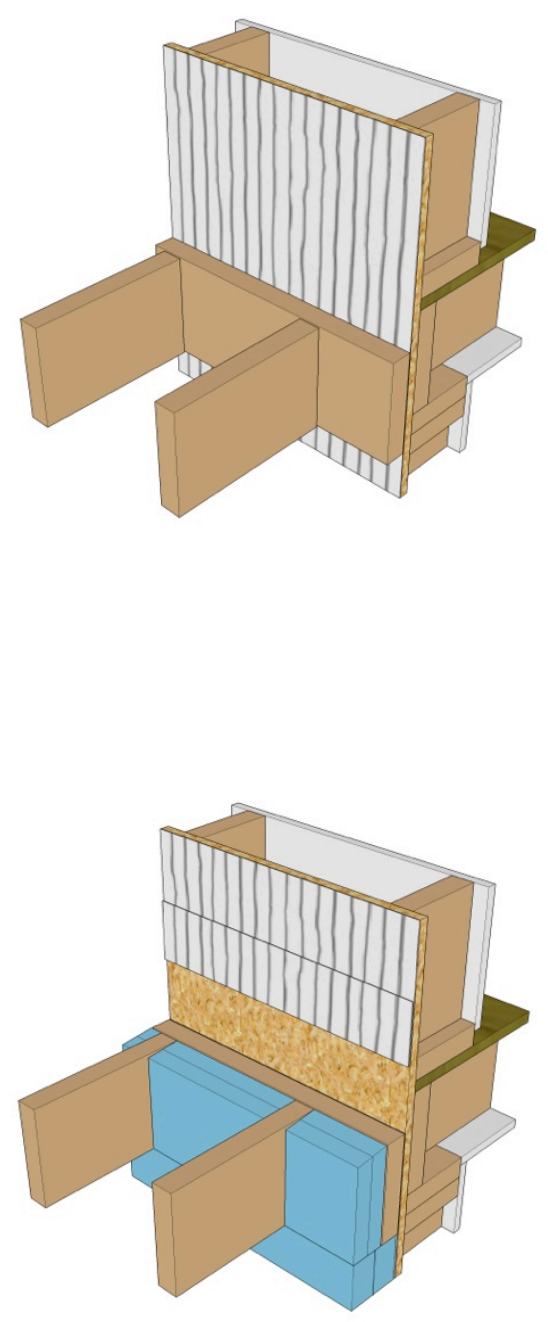

Step 1. Attach the ledger at the structure.

Step 2. Cut and fold the wall WRB at the ledger. Cut and fit the exterior rigid insulation around the deck joists. 

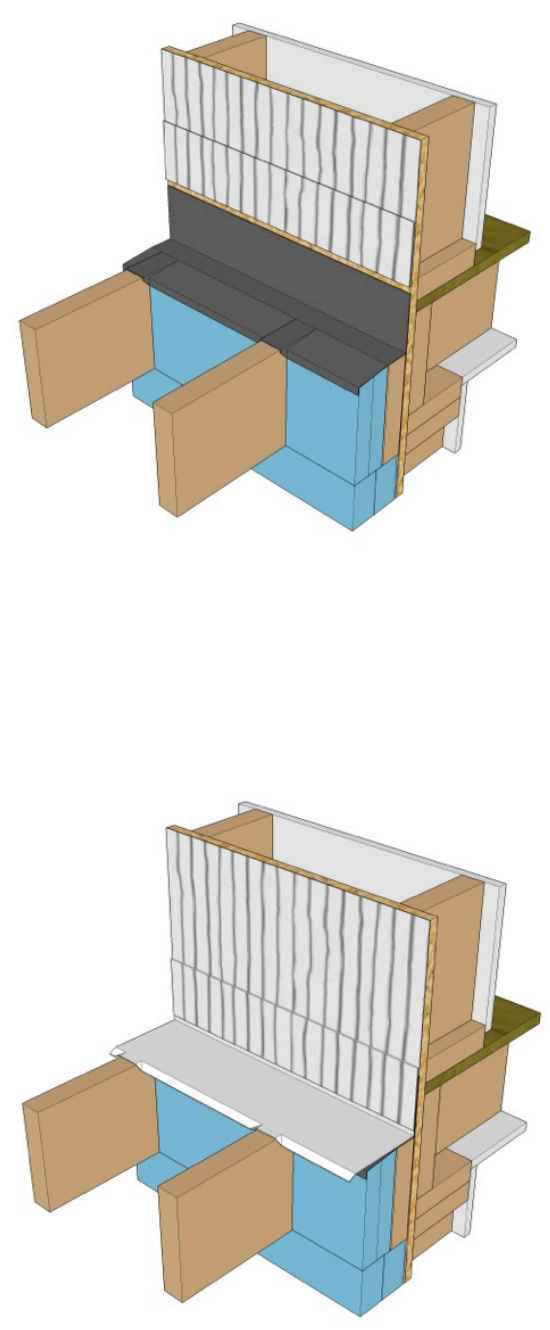

Step 3. Install the fully adhered membrane flashing over the ledger and extend it out over the exterior rigid insulation.

Step 4. Lap the metal flashing shingle with the wall WRB. Extend the flashing out over the exterior rigid insulation. 


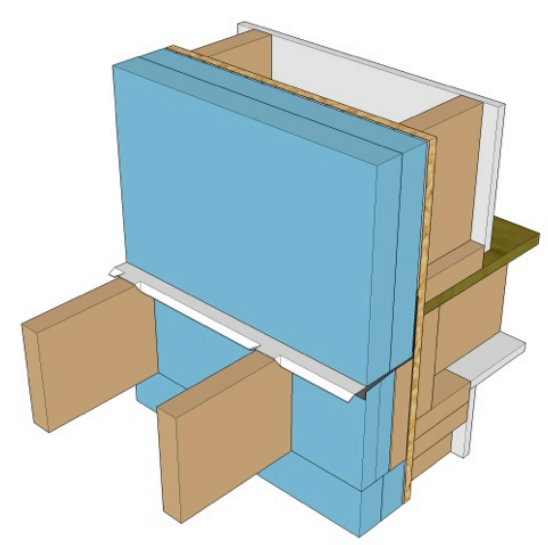

Step 5. Install the exterior rigid insulation above the flashing.

Figure 60. Ledger inboard of rigid insulation construction sequence

\subsubsection{Penetrations}

Mechanical penetrations are treated as they would be for typical construction with a sheetapplied WRB (or whatever water control strategy is being used behind the rigid insulation). The insulation is simply cut and fit around the penetration. (See the construction sequence in Figure 61.) All the penetrations must be installed before the exterior rigid insulation is installed, or a section of the insulation must be left out to allow for a proper tie with the wall water control strategy. 

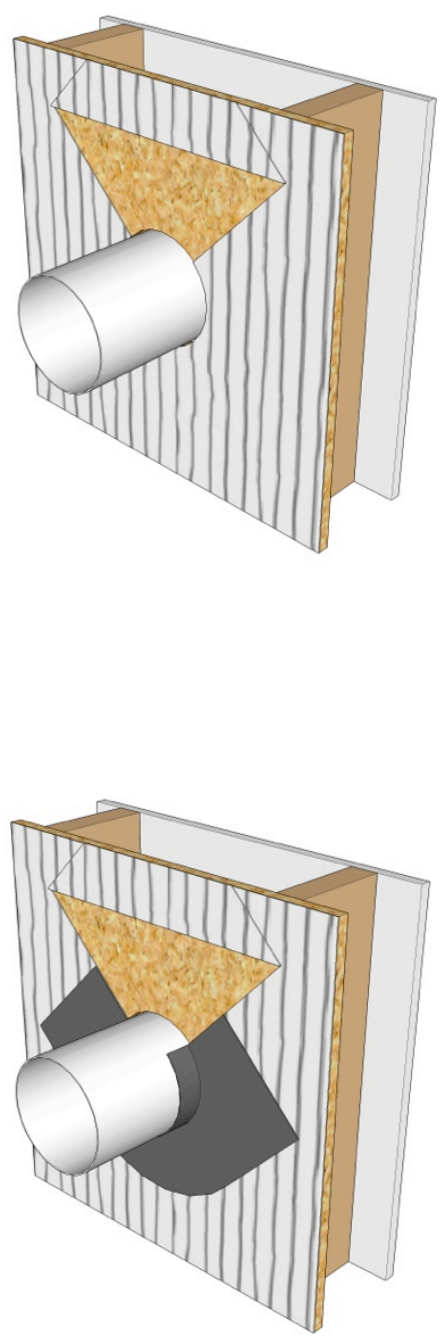

Step 1. Cut a penetration through the wall and WRB.

Step 2. Seal the flexible membrane flashing around the bottom of the penetration. 

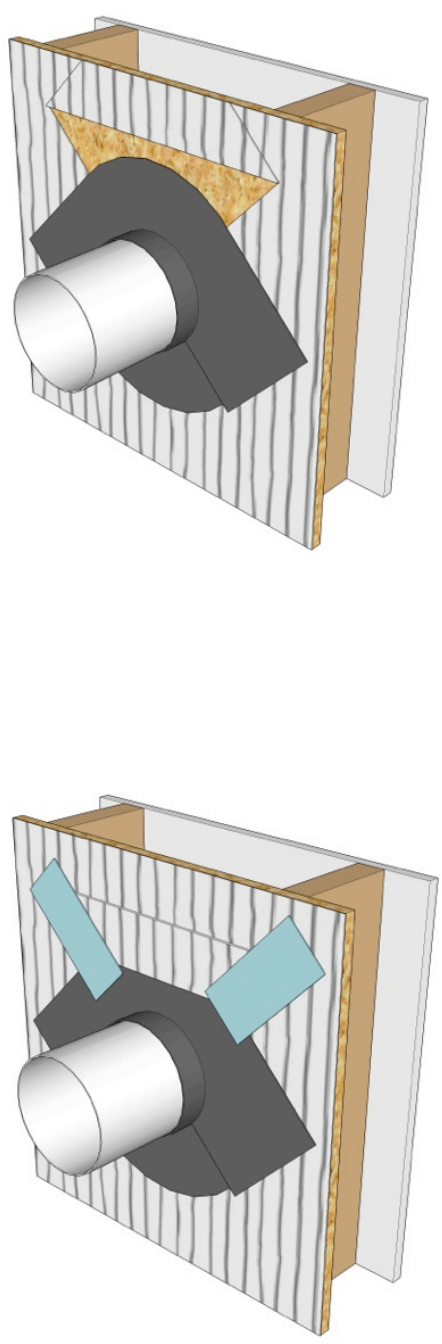

Step 3. Seal the flexible membrane flashing over the top of the penetration.

Step 4. Fold the WRB down over the membrane flashing and adhere the cuts with WRB tape. 


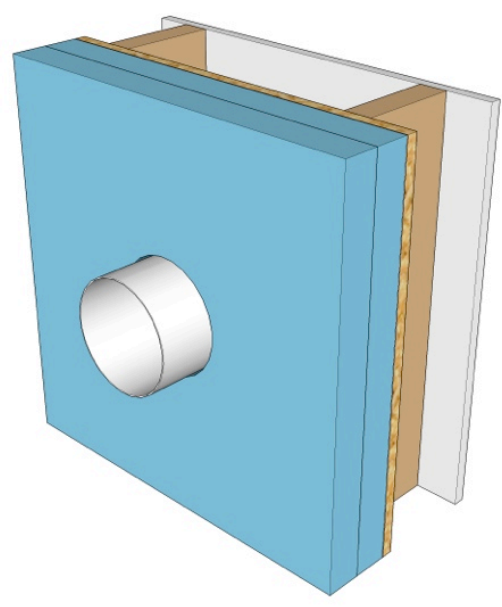

Step 5. Install the rigid insulation around the penetration.

Figure 61. Mechanical penetration construction sequence

\subsubsection{Attaching the Cladding}

For thinner insulation, the cladding can often be attached directly through the rigid insulation back to the structure. The practical limit of this approach is around $1-1 / 2$ in. of rigid insulation because fastener lengths for many pneumatic nail guns are limited (see Figure 60 and Figure 61).

CODE REQUIREMENTS FOR CLADDING ATTACHMENT ARE AVAILABLE IN SECTION R703 OF THE 2009 IRC AND 2012 IRC. TABLE R703.4 PROVIDES GUIDANCE FOR ATTACHING CLADDING DIRECTLY THROUGH EXTERIOR RIGID INSULATION.

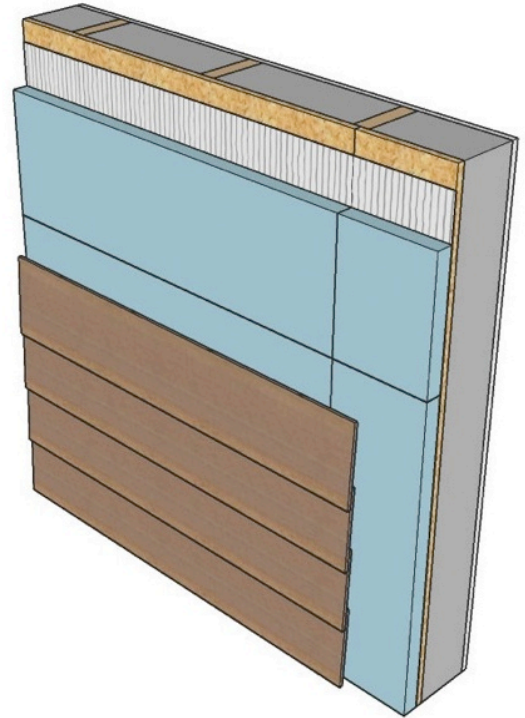

Figure 62. Lap siding attached directly through the rigid insulation

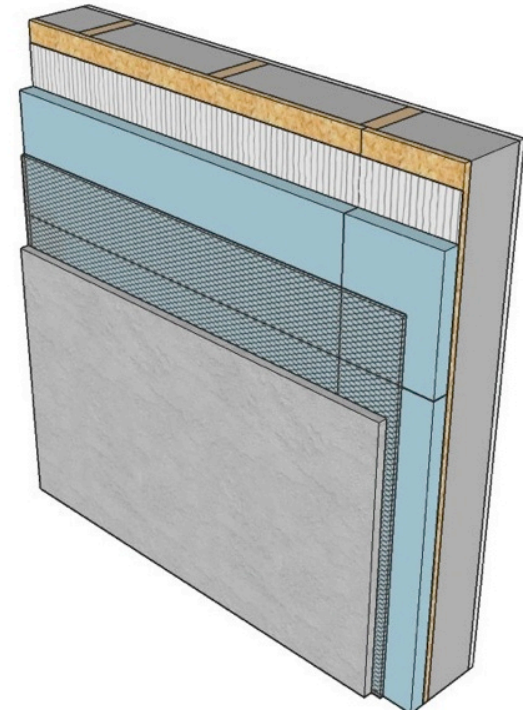

Figure 63. Stucco attached directly through the rigid insulation 
For insulation thicker than 1-1/2-in., we recommend vertical wood furring strips to provide a cladding attachment location (see Figure 62). The approach also provides a drainage and ventilation gap behind the cladding, which is beneficial to the water management performance of the wall assembly.

To adequately support the cladding, we recommend attaching the furring strips back to the structure using \#10 or larger wood screws that are sized to maintain a $1-1 / 4 \mathrm{in}$. minimum embedment in the structural framing. As an example, a 6 -in. long wood screw can be used to attach up to $4 \mathrm{in}$. of insulation ( $4 \mathrm{in}$. of insulation $+3 / 4 \mathrm{in}$. of furring $+1-1 / 4 \mathrm{in}$. of embedment $=6$ in. total). A 4 -in. screw would be adequate for 2 in. of rigid insulation ( 2 -in. of insulation $+3 / 4$ in. of furring $+1-1 / 4$ of embedment $=4 \mathrm{in}$.). With the furring strips attached directly back to the wood framing, the horizontal spacing will generally be either 24 in. o.c. or 16 in. o.c. Table 12 provides a quick reference of recommended vertical screw spacings based on framing spacing and cladding type for up to $4 \mathrm{in}$. of exterior rigid insulation.

Table 12. Vertical Screw Spacings for Attaching Wood Furring Strips to the Structure for up to 4 in. of Rigid Insulation

\begin{tabular}{c|c|c}
\hline Cladding & $\begin{array}{c}\mathbf{1 6} \text { in. o.c. } \\
\text { Stud Spacing }\end{array}$ & $\begin{array}{c}\mathbf{2 4} \text { in. o.c. } \\
\text { Stud Spacing }\end{array}$ \\
\hline Wood, Vinyl, and Fiber Cement (up to $\left.\mathbf{5} \mathbf{~ l b} / \mathbf{f t}^{2}\right)$ & $24 \mathrm{in.}$ & $18 \mathrm{in.}$ \\
Stucco (up to $\mathbf{1 0} \mathbf{l b} / \mathbf{f t}^{2}$ ) & $12 \mathrm{in.}$ & $9 \mathrm{in.}$ \\
\hline Adhered Stone Veneer (up to $\left.\mathbf{2 0} \mathbf{l b} / \mathbf{f t}^{2}\right)$ & $6 \mathrm{in}$. & $4 \mathrm{in}$. \\
\hline
\end{tabular}

Larger spacing can be used if less insulation is used. For claddings that exceed 20 psf, additional design is recommended. For additional options for fastener type, spacing, and thickness of insulation, see Appendix B.

Some claddings (such as stucco and adhered stone veneer) may require additional support between the structural furring strips to facilitate the installation process. In these cases, additional structural furring or nonstructural spacer strips can be added (see Figure 63).
Bridging the insulation with additional wood framing members to provide a cladding attachment location is generally not recommended because thermal resistance is lost. 


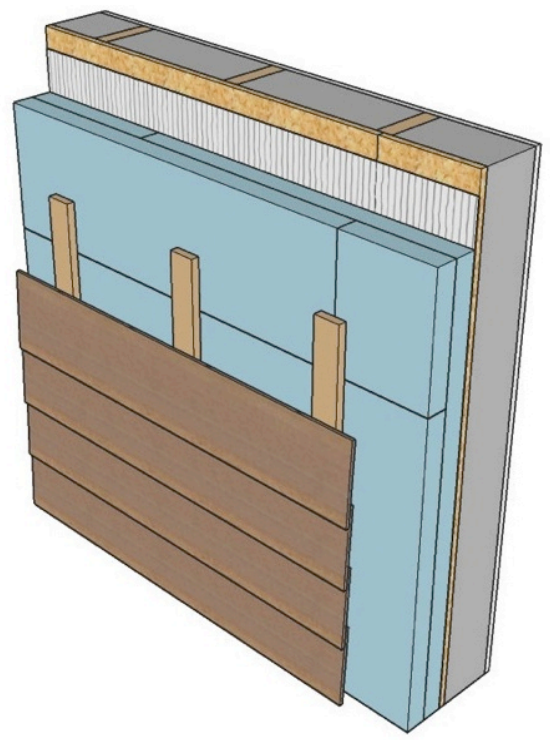

Figure 64. Furring strips attachment location for lap siding

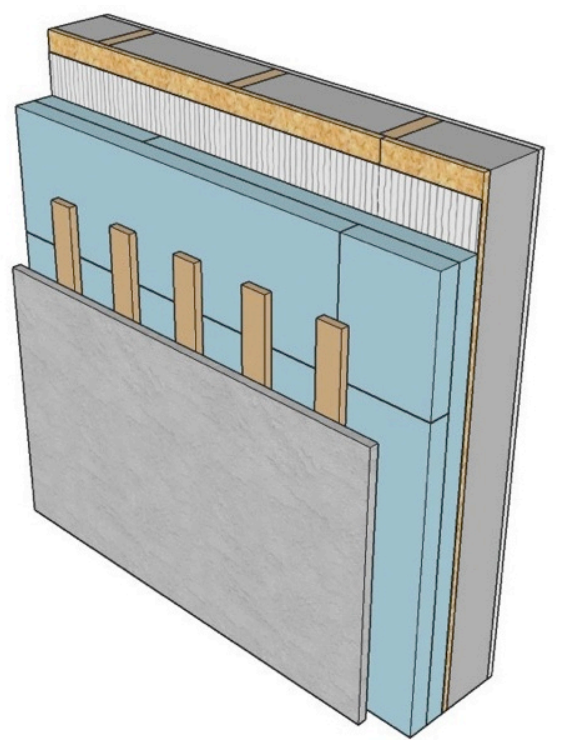

Figure 65. Additional intermediate furring used to facilitate the installation of stucco and adhered stone veneer

A continuous nail base is required for wood shingles. The nail base is best provided by installing another layer of structural sheathing directly over the insulation in place of wood furring strips. For this configuration, the new sheathing becomes analogous to the wood structural sheathing of the wall assembly and so water management details can now be managed exactly per standard construction (i.e., the new sheathing needs to be protected from rainwater absorption by either building paper or house wrap that is integrated with the windows). With this configuration, the assembly dries little or not at all to the interior, so ventilation drying to the exterior is recommended. A drainage mat must be installed behind the wood shingles to provide cladding drainage and ventilation.

At openings such as windows and doors, the details for trim attachment can differ slightly from standard construction practice. At the head and sill, the furring strips that are already in the field of the wall are generally sufficient to attach those elements; however, additional furring strips at the jambs are generally required to attach the jamb trim and support the abutting cladding (see sequences in Figure 64 through Figure 67). 

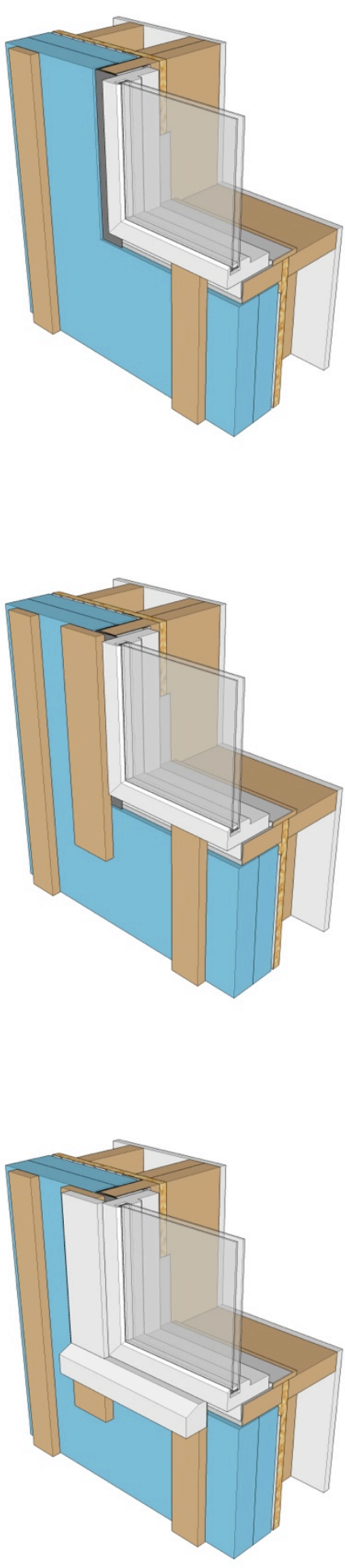

Step 1. Install the furring strips back to the stud framing.

Step 2. Install the jamb furring strips. These should extend about 6 in. past the head and the sill.

Step 3. Install the trim fastened back to the furring strips. 


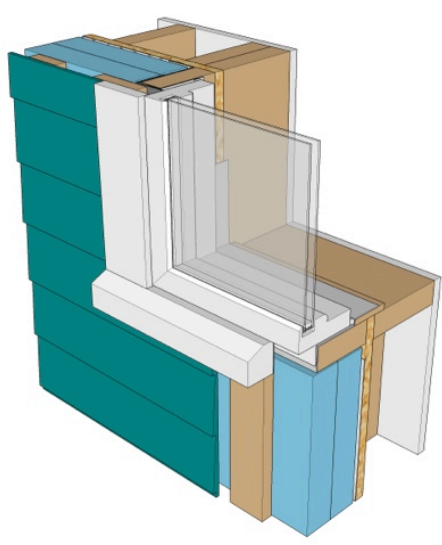

Figure 66. Cladding and trim attachment around a window (sill condition)
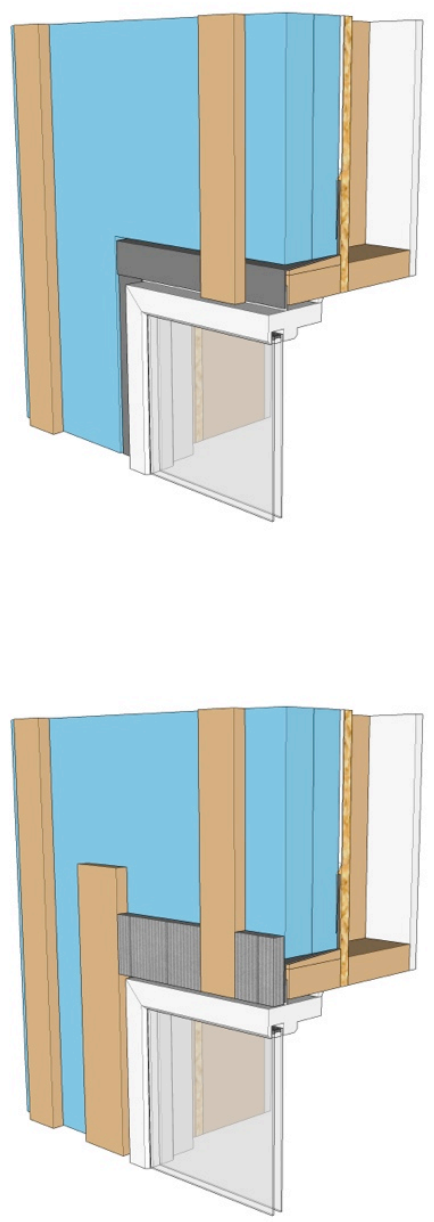

Step 4. Install the siding attached to the furring according to the siding manufacturer's installation recommendations.
Step 1. Install the furring strips back to the stud framing.

Step 2. Install the jamb furring strips. These should extend about 6 in. past the head and the sill. 

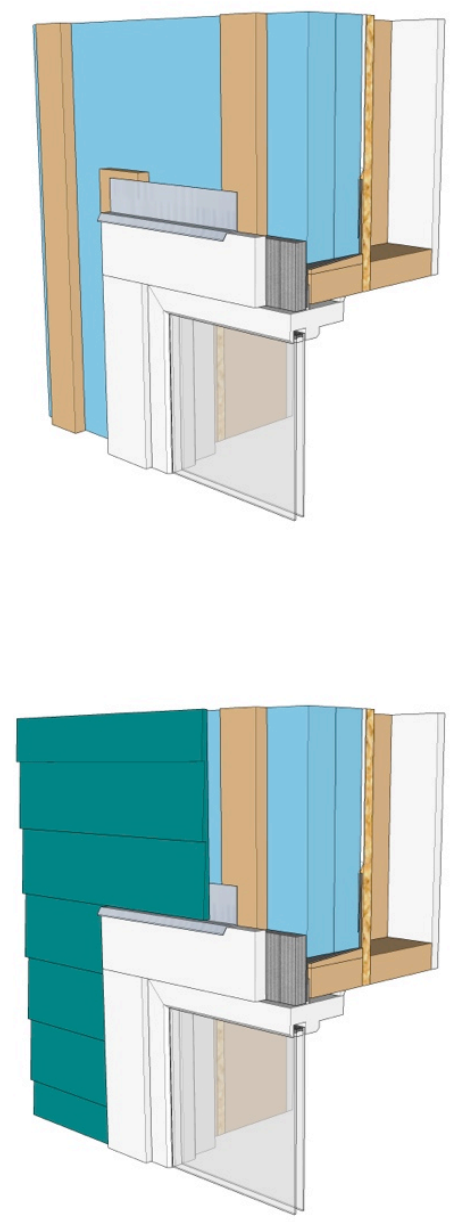

Step 3. Install the trim fastened back to the furring strips. At the head, install a head flashing over the head trim to maintain the shingle lap effect with the siding.
Step 4. Install the siding attached to the furring according to the siding manufacturer's installation recommendations.

Figure 67. Cladding and trim attachment around a window (head condition)

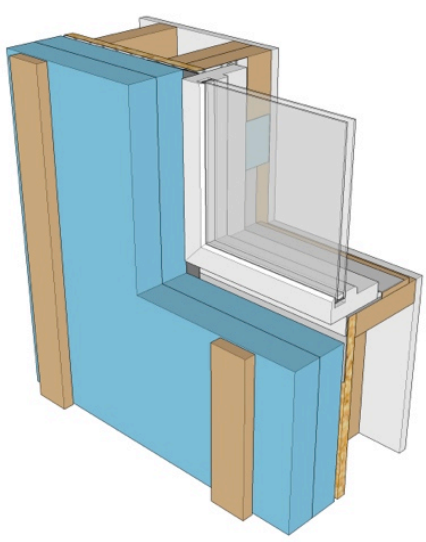

Step 1. Install the furring strips back to the stud framing. 

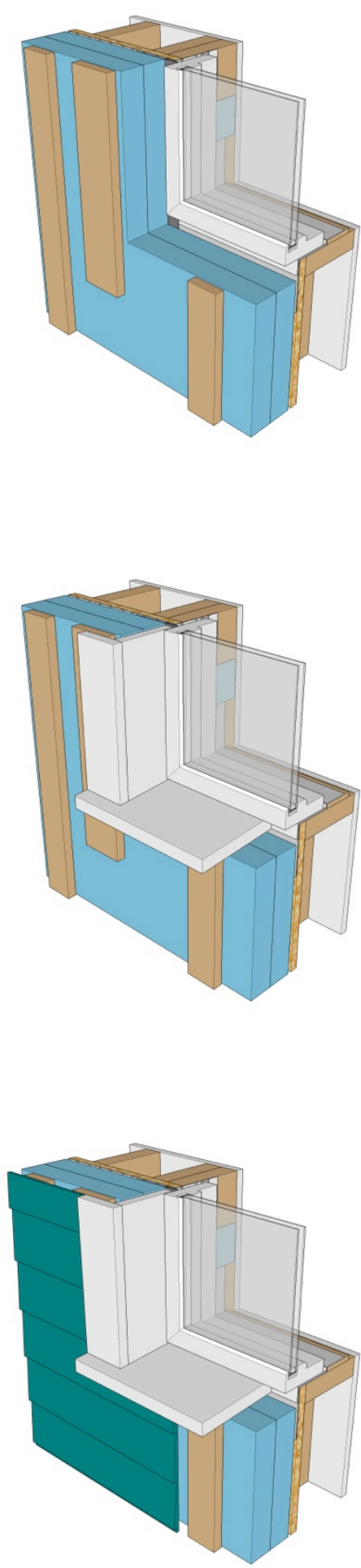

Step 2. Install the jamb furring strips. These should extend about 6 in. past the head and the sill.

Step 3. Install the trim fastened back to the furring strips. For the recessed condition, the trim may need to be assembled as a frame before it is attached to the structure.

Figure 68. Cladding and trim attachment around a window (recessed sill condition) 

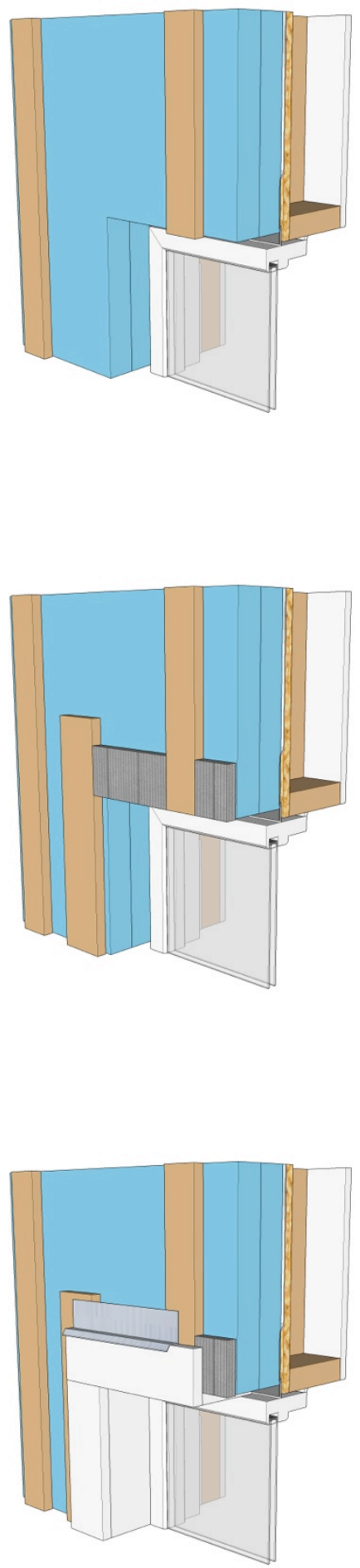

Step 1. Install the furring strips back to the stud framing.

Step 2. Install the jamb furring strips. These should extend about 6 in. past the head and the sill.

Step 3. Install the trim fastened back to the furring strips. For the recessed condition, the trim may need to be assembled as a frame before it is attached to the structure. At the head, install a head flashing over the head trim to maintain the shingle lap effect with the siding. 


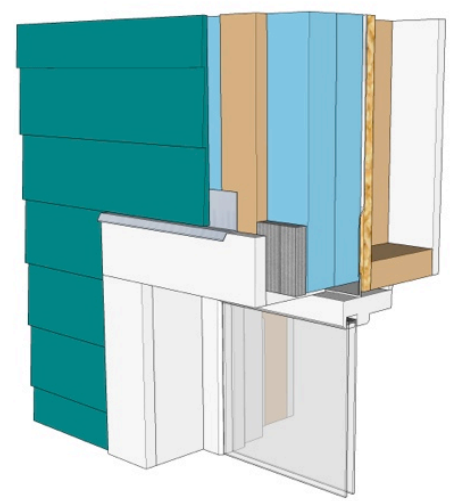

Step 4. Install the siding attached to the furring according to the siding manufacturer's installation recommendations.

Figure 69. Cladding and trim attachment around a window (recessed head condition) 


\section{$5 \quad$ Verification Procedures and Tests}

We recommend reviewing the following list of inspection quality control items to ensure the rigid insulation is properly installed.

\subsection{Water Control Layer in Front of the Rigid Insulation \\ 5.1.1 Substrate}

1. The structural sheathing or braced wall panels are installed and attached adequately.

2. All damaged materials are repaired or replaced.

3. The wall air barrier system is complete and sealed to all penetrations (if part of the project design).

\subsubsection{Insulation}

1. Joints in the insulation are offset and staggered (as much as possible).

2. Joints in the insulation are tight (gaps smaller than $1 / 8$ in.).

3. Gaps in joints larger than $1 / 8$ in. are filled with insulation or closed-cell spray polyurethane foam.

\subsubsection{Water Control Layer ${ }^{3}$}

1. The rigid insulation is clean and dry before the membrane flashings and construction tape are installed.

2. Membrane flashings and construction tape are installed without any fishmouths.

3. All joints are taped and sealed.

4. All penetrations are taped and sealed.

5. All windows and doors are flashed according to the project design.

6. All roof- and deck-to-wall interfaces are flashed according to the project design.

\subsubsection{Furring Strips}

1. Furring strips are attached according to the fastening schedule for the project location and cladding load.

2. Furring fasteners are installed back to the stud framing (inspected from the interior).

3. Furring is installed around windows and mechanical penetrations as required to support trim and cladding. Additional blocking is used on the interior where the furring attachment does not correlate with the stud framing.

\footnotetext{
${ }^{3}$ Checklist for taped rigid insulation - if a sheet WRB is used, follow the industry standard of care for sheet WRB installations.
} 


\subsection{Water Control Layer Behind the Rigid Insulation}

\subsubsection{Substrate}

1. The structural sheathing is installed and attached adequately.

2. All damaged materials are repaired or replaced.

3. The wall air barrier system is complete and sealed to all penetrations (if part of the project design).

\subsubsection{Water Control Layer}

1. The system is installed according to the industry standard of care for the approach used.

2. All penetrations are installed and sealed.

3. All windows and doors are flashed according to the project design.

4. All roof- and deck-to-wall interfaces are flashed according to the project design.

\subsubsection{Insulation}

1. Joints in the insulation are offset and staggered (as much as possible).

2. Joints in the insulation are tight (gaps smaller than $1 / 8$ in.).

3. Gaps in joints larger than $1 / 8$ in. are filled with insulation or closed-cell spray polyurethane foam.

\subsubsection{Furring Strips}

1. Furring strips are attached according to the fastening schedule for the project location and cladding load.

2. Furring fasteners are installed back to the stud framing (inspected from the interior).

3. Furring is installed around windows and mechanical penetrations as required to support trim and cladding. Additional blocking is used on the interior where the furring attachment does not correlate with the stud framing. 


\section{References}

Hutcheon, N.B. (1964). "Principles Applied to an Insulated Masonry Wall." Ottawa, ON:

National Research Council of Canada. Accessed June 2013:

http://web.mit.edu/parmstr/Public/NRCan/CanBldgDigests/cbd050 e.html.

Joyce, D. (2009). "Retrofitting Exterior Insulation.” Journal of Light Construction. Accessed June 2013: http://www.jlconline.com/building-envelope/retrofitting-exterior-insulation.aspx.

Lstiburek, J. (2006). Builder's Guide to Cold Climates. Westford, MA: Building Science Press

Lstiburek, J.W. (2007). "Building Sciences: The Perfect Wall." ASHRAE Journal 50):74-78. Atlanta, GA: American Society of Heating, Refrigeration, and Air-Conditioning Engineers, Inc.

Pettit, B. (2009). "Deep Energy Retrofit of a Sears Roebuck House: A Home for the Next 100 Years.” High Performing Buildings 2, Spring 2009.

Reed Construction Data (2011). RSMeans CostWorks 2011, 15th Annual Edition. Norwell, MA.

Straube, J.F.; Burnett, E.F.P. (2005). Building Science for Building Enclosure Design. Building Science Press: Westford, MA.

Straube, J.F.; Smegal, J. (2009). Building America Special Research Project - High-R Walls Case Study Analysis. RR-0903. Buildingscience.com.

Ueno, K. (2010). "Residential Exterior Wall Superinsulation Retrofit Details and Analysis." Performance of the Exterior Envelopes of Whole Buildings XI. Atlanta, GA: American Society of Heating, Refrigerating and Air-Conditioning Engineers, Inc.

Wilson, E.; Engebrecht-Metzger, C.; Horowitz, S.; Hendron, R. (2014). 2014 Building America House Simulation Protocols. NREL/TP-5500-60988. Golden, CO: National Renewable Energy Laboratory. 


\section{Appendix A: BEopt Simulation Graphs}

\section{Dallas, Texas}

Utility Rates: $\$ 0.13 / \mathrm{kWh}$

$\$ 1.09 /$ therm

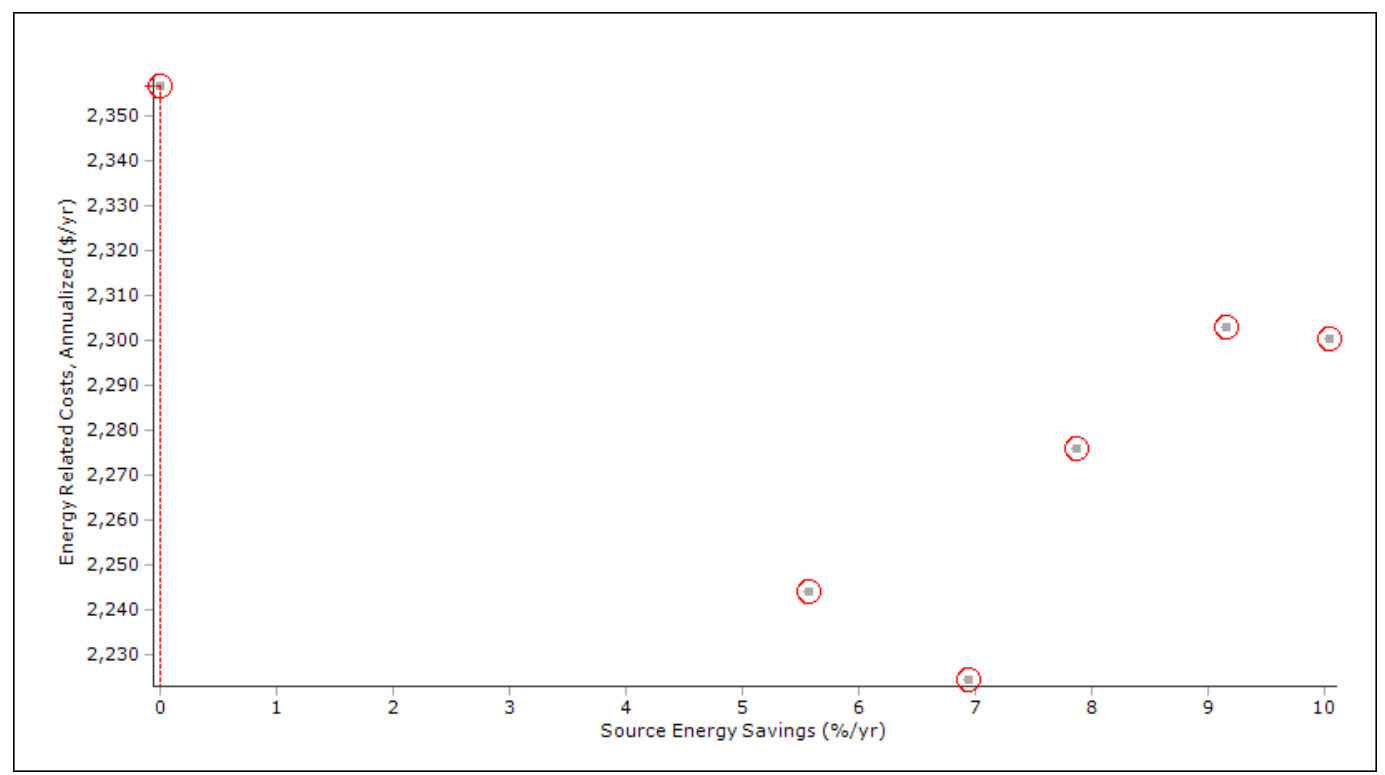

Figure 70. Annualized energy related costs versus average source energy savings for Dallas

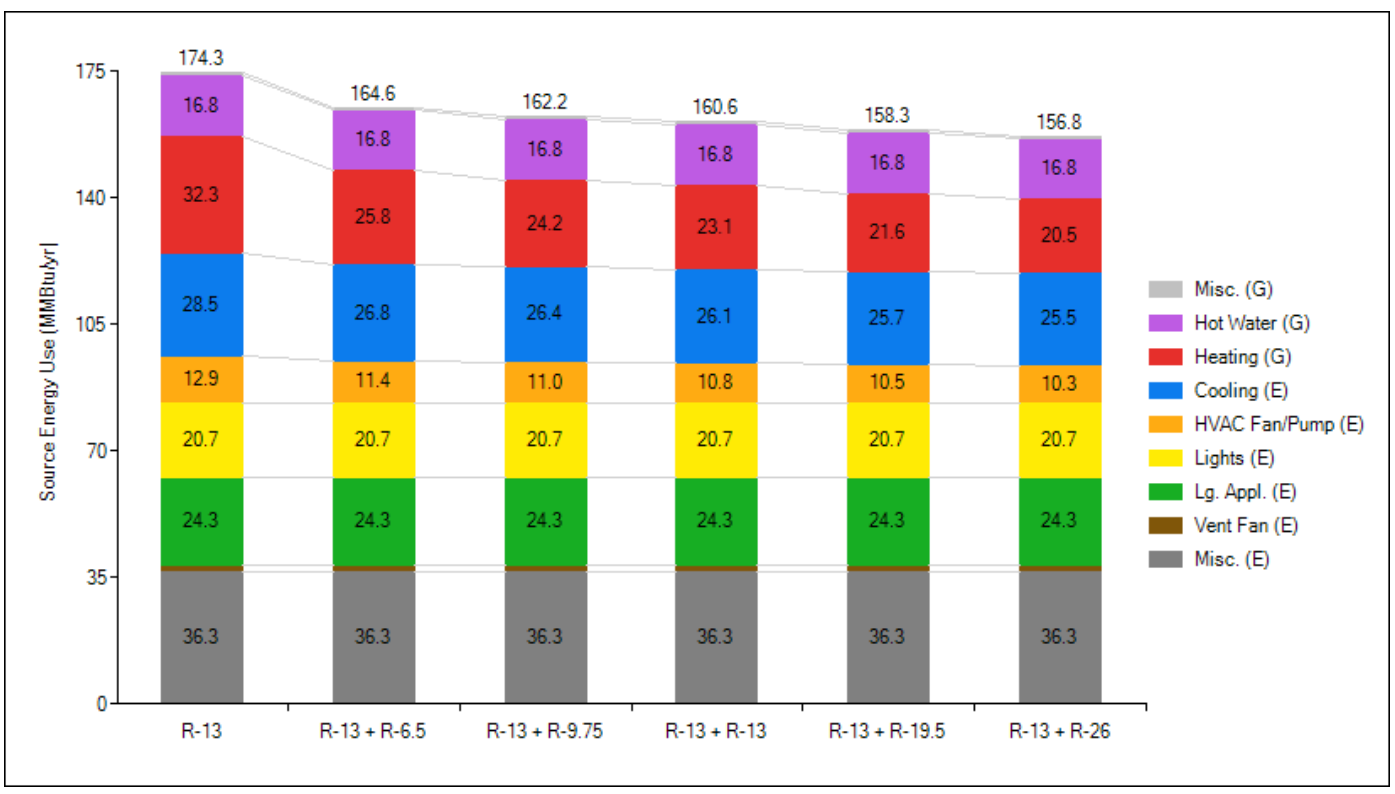

Figure 71. Average source energy savings reduction versus insulation level for Dallas 


\section{Kansas City, Missouri}

Utility Rates: $\$ 0.08 / \mathrm{kWh}$

$\$ 1.23 /$ therm

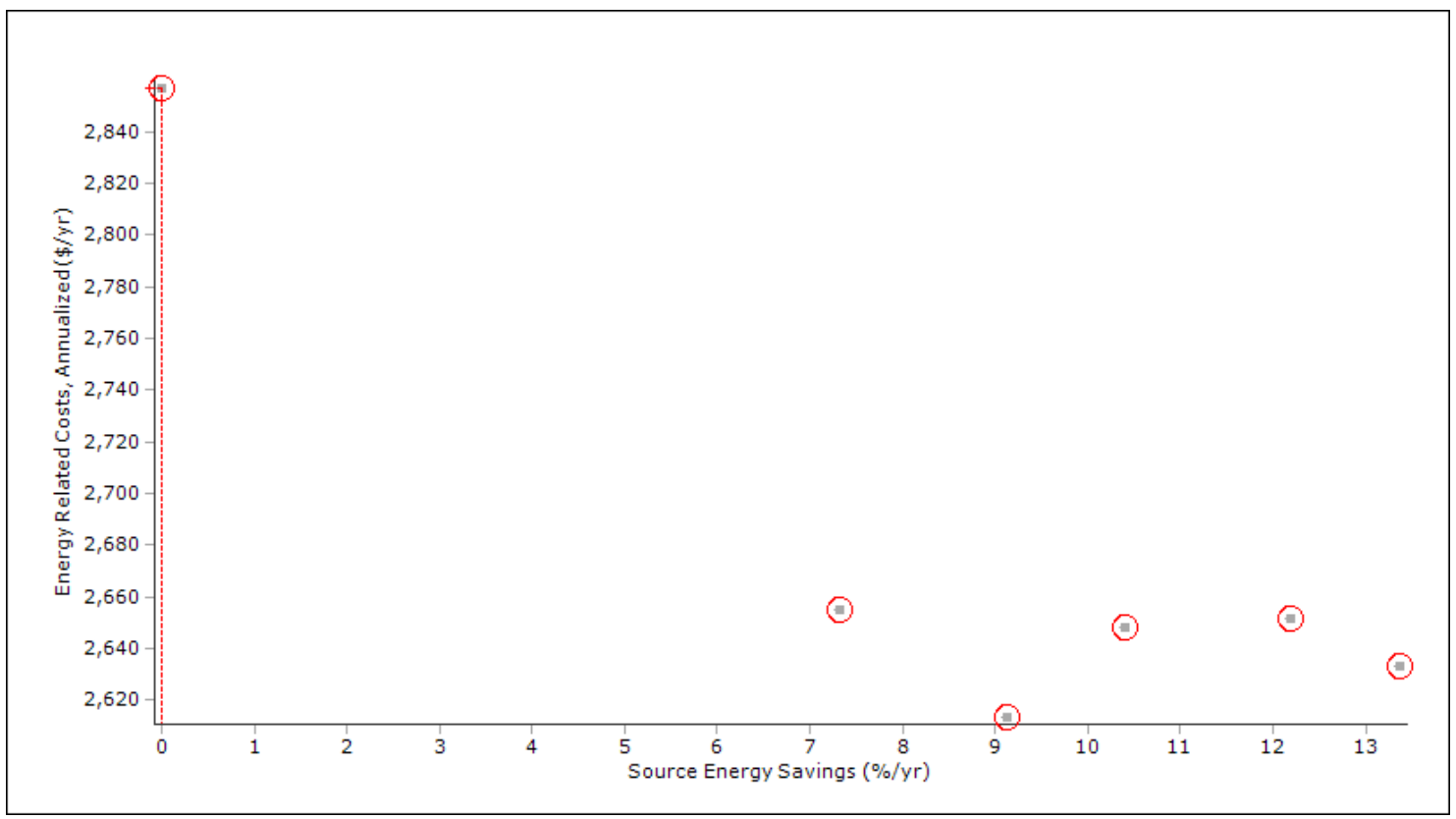

Figure 72. Annualized energy-related costs versus average source energy savings for Kansas City

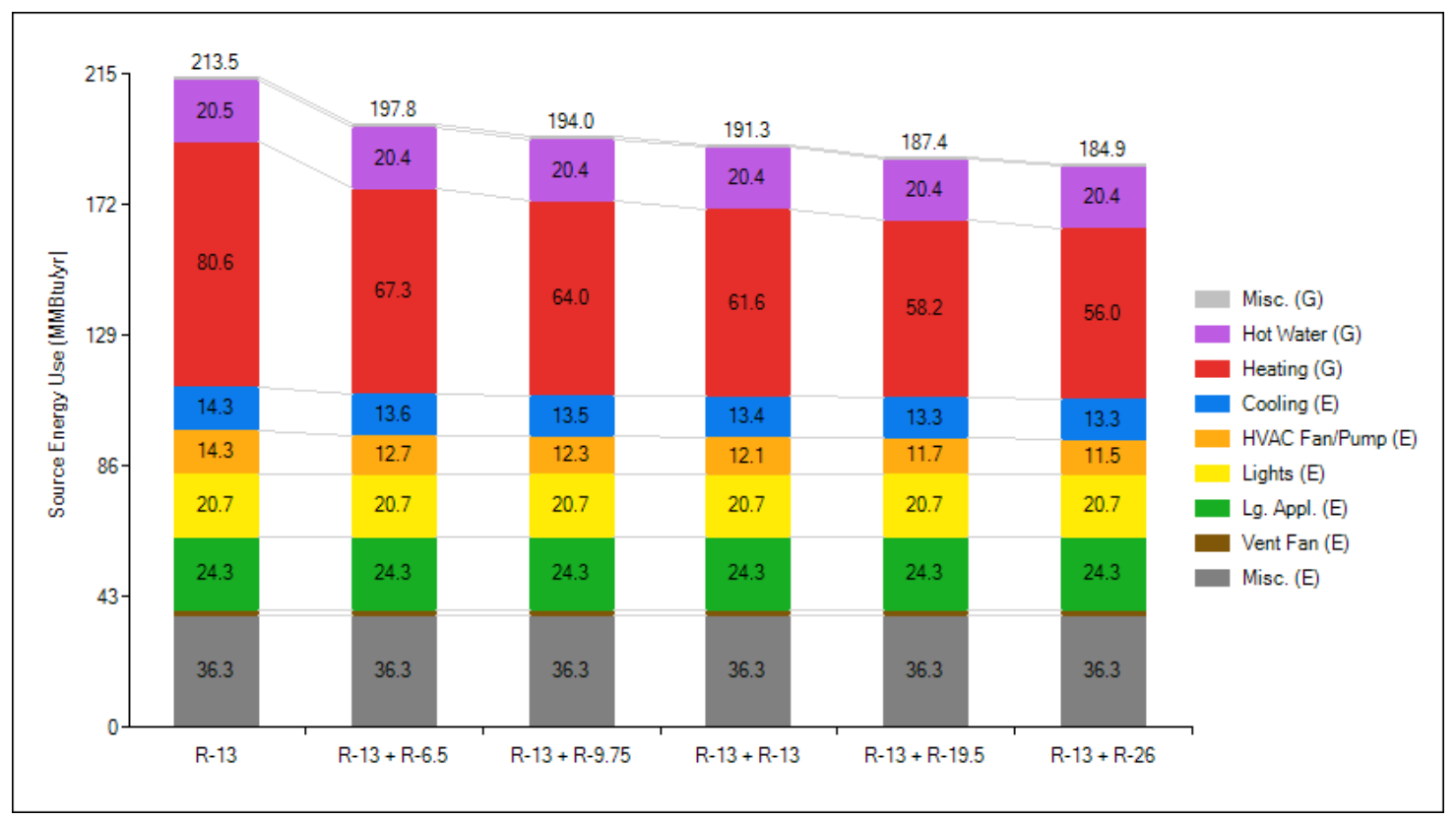

Figure 73. Average source energy savings reduction versus insulation level for Kansas City 


\section{Boston, Massachusetts}

Utility Rates: $\$ 0.18 / \mathrm{kWh}$

$\$ 1.70 /$ therm

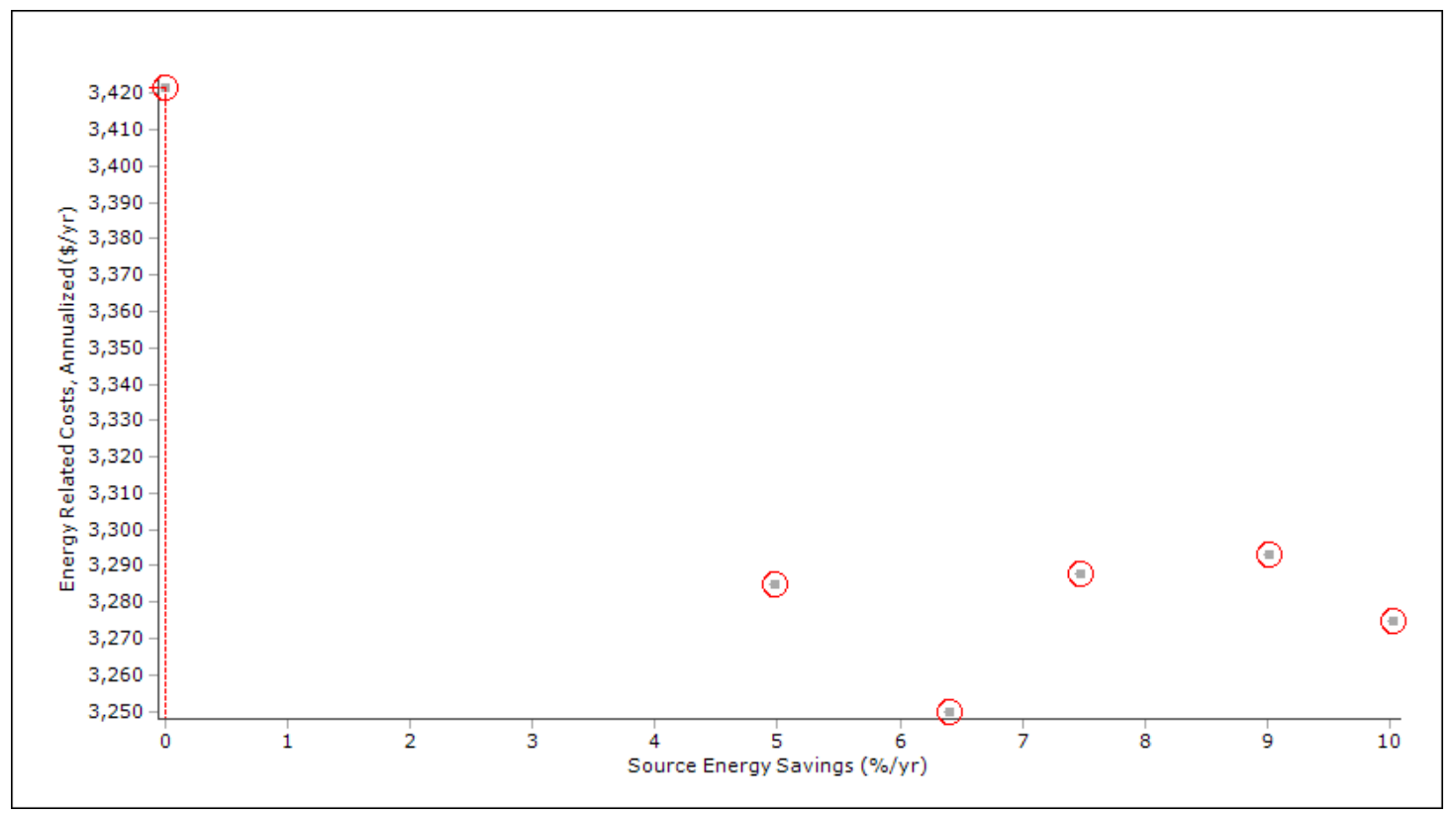

Figure 74. Annualized energy-related costs versus average source energy savings for Boston

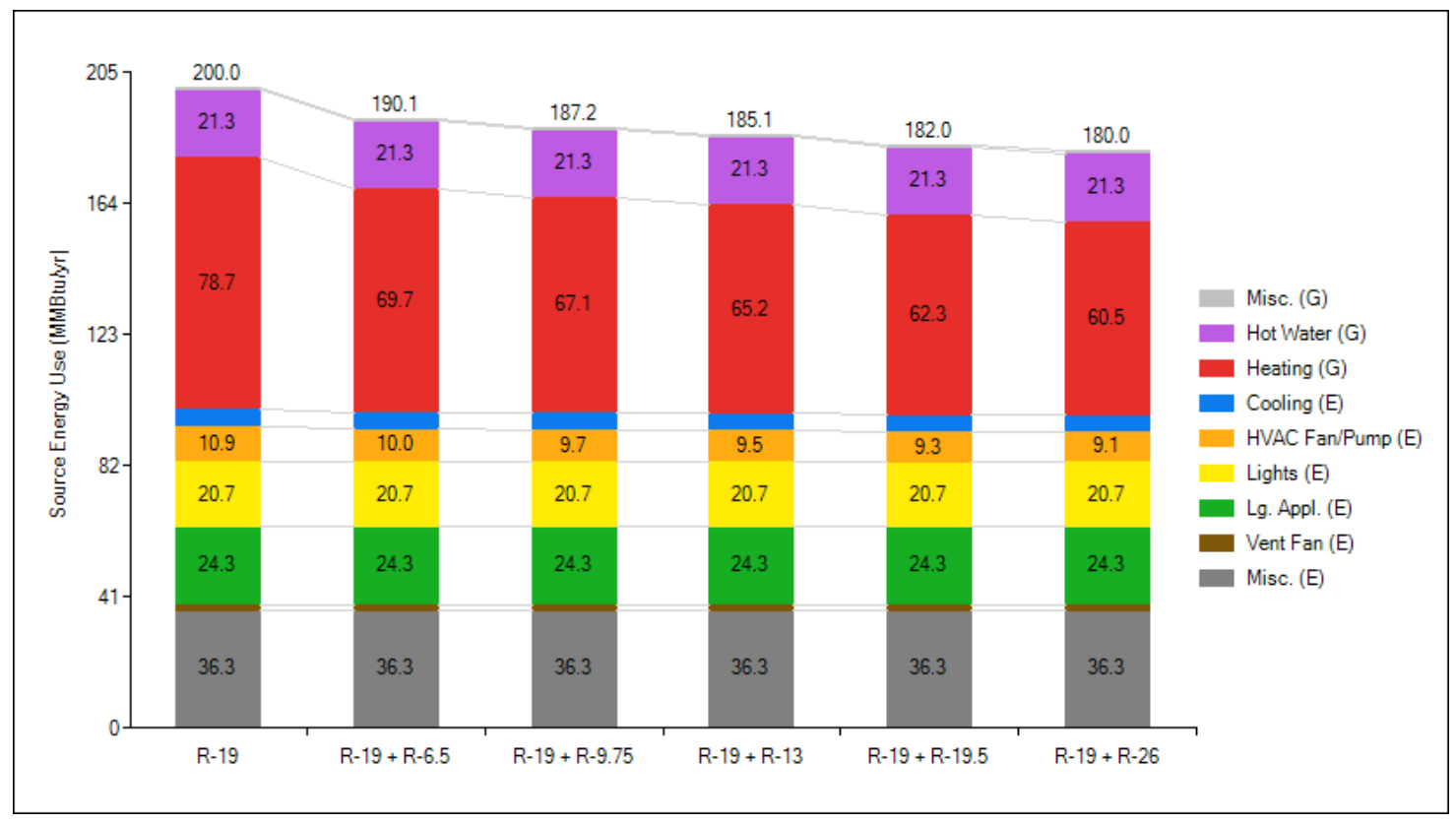

Figure 75. Average source energy savings reduction versus insulation level for Boston 


\section{Duluth, Minnesota}

Utility Rates: $\$ 0.10 / \mathrm{kWh}$

$\$ 0.87 /$ therm

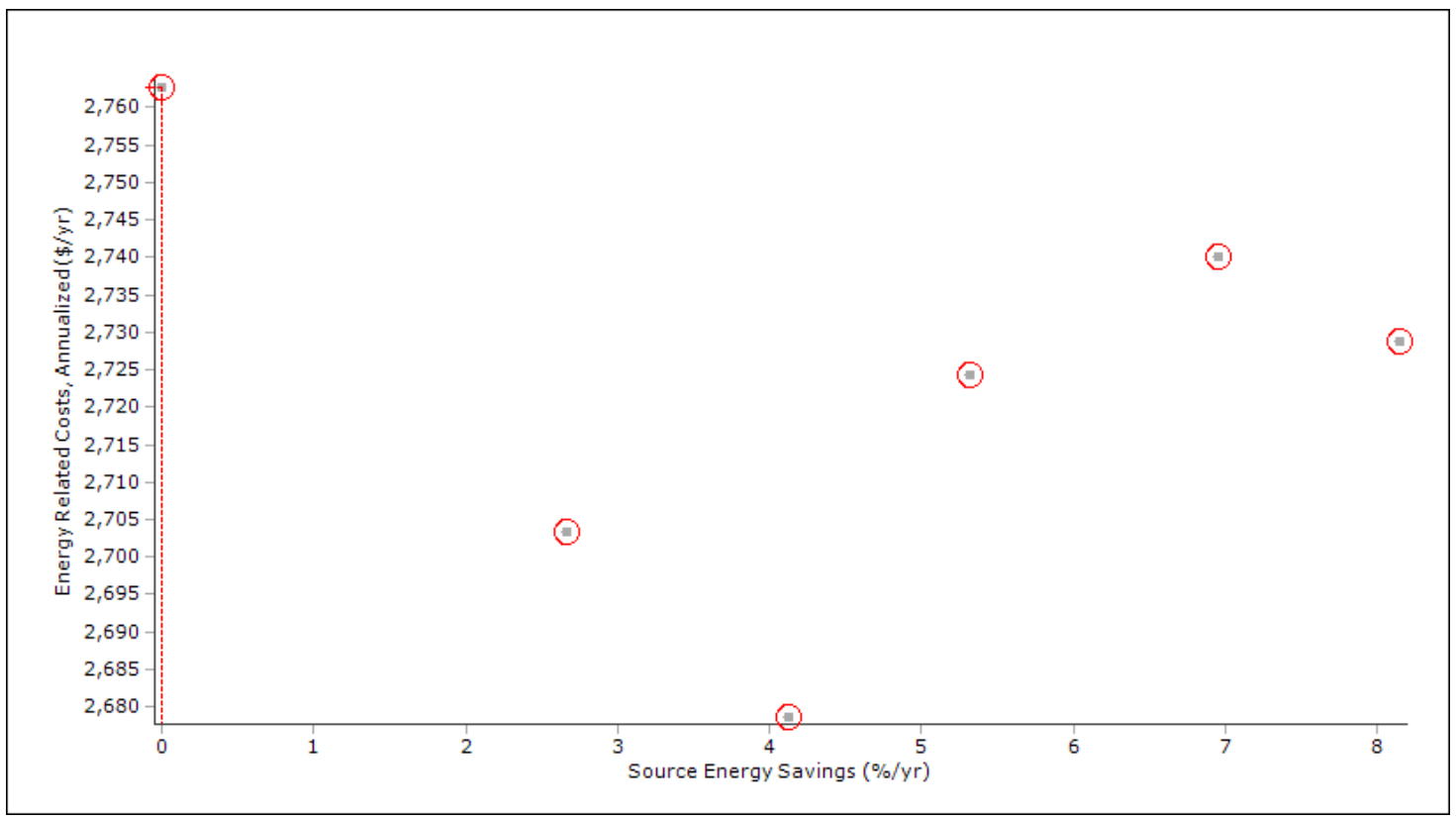

Figure 76. Annualized energy-related costs versus average source energy savings for Duluth

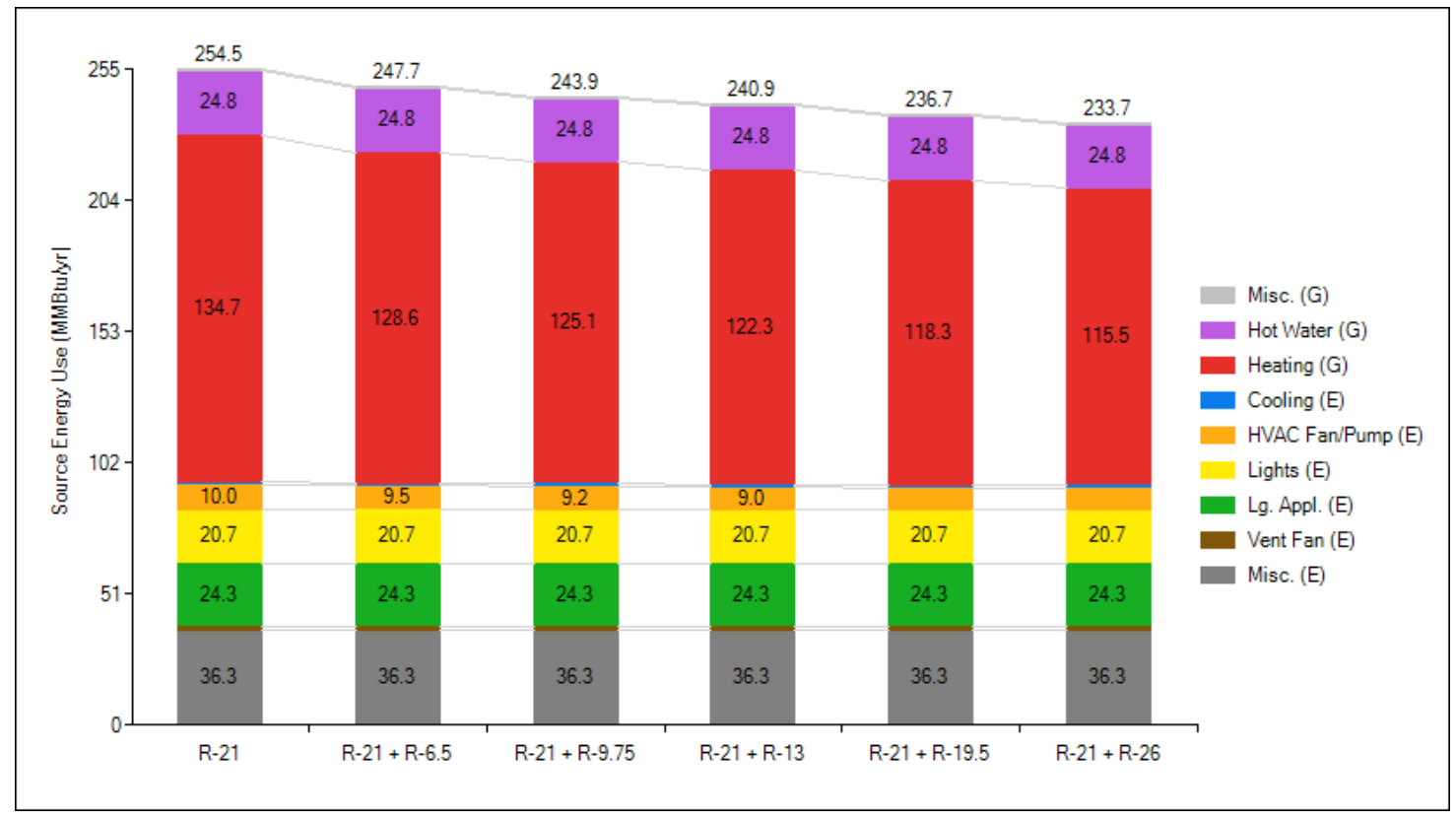

Figure 77. Average source energy savings reduction versus insulation level for Duluth 


\section{Appendix B: Furring Attachment Design Guidelines}

Table 13. Minimum Furring and Attachment Requirements

\begin{tabular}{|c|c|c|c|c|}
\hline \multicolumn{5}{|c|}{$\begin{array}{l}\text { Minimum Furring and Attachment Requirements } \\
\text { To Resist Maximum } 30 \text { psf Design Wind Load }{ }^{1,2}\end{array}$} \\
\hline & \multicolumn{2}{|c|}{16 in. Furring Spacing } & \multicolumn{2}{|c|}{24 in. Furring Spacing } \\
\hline Connection Method & $\begin{array}{l}1 \times 3 \text { wood } \\
\text { furring }\end{array}$ & $\begin{array}{l}1 \times 4 \text { wood } \\
\text { furring }\end{array}$ & $\begin{array}{l}1 \times 3 \text { or } 1 \times 4 \\
\text { wood furring }\end{array}$ & $\begin{array}{l}2 \times 3 \text { wood } \\
\text { furring }\end{array}$ \\
\hline $\begin{array}{c}\text { 8d Common Nail } \\
(2-1 / 2 \text { in. } \times 0.131-i n .) \\
\text { Minimum } \\
\text { 11/4-in. Penetration }\end{array}$ & $\begin{array}{l}1 \text { at } 12 \text { in. o.c. } \\
\text { or } \\
2 \text { at } 16 \text { in. o.c. }\end{array}$ & 2 at 24 in. o.c. & 2 at 16 in. o.c. & 2 at 16 in. o.c. \\
\hline $\begin{array}{l}\text { \#10 Wood Screw } \\
\text { (minimum 1-in. } \\
\text { penetration) }\end{array}$ & 1 at 16 in. o.c. & 1 at 24 in. o.c. & 1 at 16 in. o.c. & 1 at 24 in. o.c. \\
\hline
\end{tabular}

For SI: 1 in. $=25.4 \mathrm{~mm}$

1 Wood furring and wall framing shall be Spruce-Pine-Fir or any wood species with a specific gravity of 0.42 or greater in accordance with AFPA/NDS. Wood structural panel wall sheathing of equal or greater effective specific gravity for withdrawal shall be permitted to be included in the penetration depth. The span of $1 \times 4$ furring across studs or between fastening points shall not exceed 24 in. for a maximum 16 in. o.c. furring spacing. In all other cases, $1 \times 3$ or $1 \times 4$ wood furring shall not exceed a 16 -in. span across studs or between fastening points.

2 Where the required cladding fastener penetration into wood material exceeds $3 / 4 "(19.1 \mathrm{~mm})$ and is not more than 1-1/2 in. $(38.1 \mathrm{~mm})$, a minimum $2 \times 3$ wood furring shall be used or an approved design. Minimum fastener penetration into wall framing shall not be reduced with use of thicker furring member. 
Table 14. Cladding Minimum Fastening Requirements

\begin{tabular}{|c|c|c|c|c|c|c|c|c|}
\hline \multicolumn{9}{|c|}{$\begin{array}{l}\text { Cladding Minimum Fastening Requirements for Direct Attachment } \\
\text { Over Foam Plastic Sheathing to Support Cladding Weight }{ }^{1}\end{array}$} \\
\hline \multirow{4}{*}{$\begin{array}{l}\text { Cladding } \\
\text { Fastener } \\
\text { Through } \\
\text { Foam } \\
\text { Sheathing } \\
\text { Into: }\end{array}$} & \multirow{4}{*}{$\begin{array}{c}\text { Cladding } \\
\text { Fastener } \\
\text { Type and } \\
\text { Minimum } \\
\text { Size }^{2}\end{array}$} & \multirow{4}{*}{$\begin{array}{c}\text { Cladding } \\
\text { Fastener } \\
\text { Type } \\
\text { Vertical } \\
\text { Spacing } \\
\text { (inc.) }\end{array}$} & \multicolumn{6}{|c|}{ Maximum Thickness of Foam Sheathing ${ }^{3}$ (in.) } \\
\hline & & & \multirow{2}{*}{\multicolumn{3}{|c|}{$\begin{array}{c}16 \text { in. o.c. fastener } \\
\text { horizontal spacing } \\
\text { Cladding } \\
\text { weight: }\end{array}$}} & \multicolumn{3}{|c|}{$\begin{array}{l}24 \text { in. o.c. fastener } \\
\text { horizontal spacing }\end{array}$} \\
\hline & & & & & & \multicolumn{3}{|c|}{$\begin{array}{l}\text { Cladding } \\
\text { weight: }\end{array}$} \\
\hline & & & $3 \mathrm{psf}$ & $11 \mathrm{psf}$ & 25 psf & 3 psf & $11 \mathrm{psf}$ & $25 \mathrm{psf}$ \\
\hline \multirow{12}{*}{$\begin{array}{c}\text { Wood } \\
\text { Framing } \\
\text { (minimum } \\
\text { 1-1/4-in. } \\
\text { penetration) }\end{array}$} & 0.113 -in. & 6 & 2 & 1 & DR & 2 & 0.75 & DR \\
\hline & diameter & 8 & 2 & 1 & DR & 2 & 0.5 & DR \\
\hline & nail & 12 & 2 & 0.5 & DR & 2 & DR & DR \\
\hline & 0.120 -in. & 6 & 3 & 1.5 & 0.5 & 3 & 0.75 & DR \\
\hline & diameter & 8 & 3 & 1 & DR & 3 & 0.5 & DR \\
\hline & nail & 12 & 3 & 0.5 & DR & 2 & DR & DR \\
\hline & 0.131-in. & 6 & 4 & 2 & 0.75 & 4 & 1 & DR \\
\hline & diameter & 8 & 4 & 1.5 & 0.5 & 4 & 0.75 & DR \\
\hline & nail & 12 & 4 & 0.75 & DR & 2 & 0.5 & DR \\
\hline & 0.162 in. & 6 & 4 & 4 & 1.5 & 4 & 2 & 1 \\
\hline & diameter & 8 & 4 & 3 & 1 & 4 & 1.5 & 0.75 \\
\hline & nail & 12 & 4 & 2 & 0.75 & 4 & 1 & DR \\
\hline
\end{tabular}

For SI: 1 in. $=25.4 \mathrm{~mm} ; 1 \mathrm{psf}=0.0479 \mathrm{kPa}$

$\mathrm{DR}=$ design required

1 Wood framing shall be Spruce-Pine-Fir or any wood species with a specific gravity of 0.42 or greater in accordance with AFPA/NDS.

${ }^{2}$ Nail fasteners shall comply with ASTM F1667, except nail length shall be permitted to exceed ASTM F1667 standard lengths.

3 Foam sheathing shall have a minimum compressive strength of 15 psi in accordance with ASTM C 578 or ASTM C 1289. 
Table 15. Furring Minimum Fastening Requirements

\begin{tabular}{|c|c|c|c|c|c|c|c|c|c|c|}
\hline \multicolumn{11}{|c|}{$\begin{array}{l}\text { Furring Minimum Fastening Requirements for Application } \\
\text { Over Foam Plastic Sheathing to Support Cladding Weight }{ }^{1,2}\end{array}$} \\
\hline \multirow{4}{*}{$\begin{array}{l}\text { Furring } \\
\text { Material }\end{array}$} & \multirow{4}{*}{$\begin{array}{l}\text { Framing } \\
\text { member }\end{array}$} & \multirow{4}{*}{$\begin{array}{c}\text { Cladding } \\
\text { Fastener } \\
\text { Type and } \\
\text { Minimum } \\
\text { Size }\end{array}$} & \multirow{4}{*}{$\begin{array}{l}\text { Minimum } \\
\text { Penetration } \\
\text { Into Wall } \\
\text { Framing } \\
\text { (in.) }\end{array}$} & \multirow{4}{*}{$\begin{array}{l}\text { Fastener } \\
\text { Spacing } \\
\text { Into } \\
\text { Furring } \\
\text { (in.) }\end{array}$} & \multicolumn{6}{|c|}{$\begin{array}{c}\text { Maximum Thickness of Foam } \\
\text { Sheathing }^{4} \text { (in.) }\end{array}$} \\
\hline & & & & & \multicolumn{3}{|c|}{$\begin{array}{l}16 \text { in. o.c. } \\
\text { Furring }\end{array}$} & \multicolumn{3}{|c|}{$\begin{array}{l}24 \text { in. o.c. } \\
\text { Furring }\end{array}$} \\
\hline & & & & & \multicolumn{3}{|c|}{$\begin{array}{c}\text { Siding } \\
\text { Weight (psf): }\end{array}$} & \multicolumn{3}{|c|}{$\begin{array}{c}\text { Siding } \\
\text { Weight (psf): }\end{array}$} \\
\hline & & & & & 3 & 11 & 25 & 3 & 11 & 25 \\
\hline \multirow{12}{*}{$\begin{array}{l}\text { Minimum } \\
\text { 1x Wood } \\
\text { Furring }\end{array}$} & \multirow{12}{*}{$\begin{array}{c}\text { Minimum } \\
\text { 2x wood } \\
\text { stud }\end{array}$} & 0.131 -in. & & 8 & 4 & 2 & 1 & 4 & 1.5 & DR \\
\hline & & diameter & $1-1 / 4$ & 12 & 4 & 1.5 & DR & 3 & 1 & DR \\
\hline & & nail & & 16 & 4 & 1 & DR & 3 & 0.5 & DR \\
\hline & & 0.162 -in. & & 8 & 4 & 4 & 1.5 & 4 & 2 & 0.75 \\
\hline & & diameter & $1-1 / 4$ & 12 & 4 & 2 & 0.75 & 4 & 1.5 & DR \\
\hline & & nail & & 16 & 4 & 1.5 & DR & 4 & 1 & DR \\
\hline & & 10-in. & & 12 & 4 & 2 & 0.75 & 4 & 1.5 & DR \\
\hline & & wood & 1 & 16 & 4 & 2 & DR & 4 & 1 & DR \\
\hline & & screw & & 24 & 4 & 1 & DR & 3 & DR & DR \\
\hline & & $1 / 4$-in 1 gg & & 12 & 4 & 3 & 1 & 4 & 2 & 0.5 \\
\hline & & $\begin{array}{l}\text { 4-in. lag } \\
\text { screw }\end{array}$ & $1-1 / 2$ & 16 & 4 & 1.5 & DR & 4 & 1.5 & DR \\
\hline & & & & 24 & 4 & 1.5 & DR & 4 & 0.75 & DR \\
\hline
\end{tabular}

For SI: 1 in. $=25.4 \mathrm{~mm} ; 1$ pound per square foot $(\mathrm{psf})=0.0479 \mathrm{kPa}$

$\mathrm{DR}=$ design required

1 Wood framing and furring shall be Spruce-Pine-Fir or any wood species with a specific gravity of 0.42 or greater in accordance with AFPA/NDS.

2 Nail fasteners shall comply with ASTM F1667, except nail length shall be permitted to exceed ASTM F1667 standard lengths.

3 Where the required cladding fastener penetration into wood material exceeds $3 / 4$ in. $(19.1 \mathrm{~mm})$ and is not more than $1-1 / 2$ in. $(38.1 \mathrm{~mm})$, a minimum $2 \mathrm{x}$ wood furring shall be used or an approved design.

${ }^{4}$ Foam sheathing shall have a minimum compressive strength of 15 psi in accordance with ASTM C 578 or ASTM C 1289.

${ }^{5}$ Furring shall be spaced a maximum of 24 in. $(610 \mathrm{~mm})$ o.c. in a vertical or horizontal orientation. In a vertical orientation, furring shall be located over wall studs and attached with the required fastener spacing. In a horizontal orientation, the indicated 8-in. (203.2-mm) and 12-in. (304.8- $\mathrm{mm})$ fastener spacing in furring shall be achieved by use of two fasteners into studs at $16 \mathrm{in.}(406.4 \mathrm{~mm})$ and $24 \mathrm{in.}(610 \mathrm{~mm})$ o.c., respectively. 


\section{Appendix C: Parallel Paths U-Factor and Effective R-Value}

The parallel paths method is a two-dimensional steady-state conductive heat transfer analysis. The analysis works by calculating the area-weighted heat flow through various paths in the assembly (i.e., through the cavity insulation and through the wood studs) and adding them up to determine the total heat flow (or thermal conductance). The thermal conductance is described as the U-factor. The thermal resistance is described as the R-value. The R-value is the reciprocal of the U-factor.

To determine the effective R-value of an assembly using the parallel paths method, the total Rvalue of each path is first calculated by adding the R-Value of each material layer included in the path:

$\mathrm{R} 1_{\text {cavity }}, \mathrm{R} 2_{\text {framing }}$

The total conductance of the assembly is determined by summing the U-factor of each path multiplied by the area weighted percentage of each path:

$\mathrm{U}_{\mathrm{assembly}}=(1 / \mathrm{R} 1) * \mathrm{~A} 1+(1 / \mathrm{R} 2) * \mathrm{~A} 2$

The effective R-Value of the assembly is the reciprocal of the U-factor of the assembly:

$\mathrm{R}_{\mathrm{assembly}}=1 / \mathrm{U}_{\text {assembly }}$

The following is a worked example of the parallel paths method of determining equivalent $U$ Factors and effective R-Values for several wall assemblies. The parallel paths method is described in ASHRAE Fundamentals (2013) Chapter 27. In all examples, the cladding is omitted from the analysis. 


\section{Assembly 1 - High Performance}

The following is an example of a recommended high performance wall assembly:

- Two layers of 2-in. PIC rigid insulation

- 7/16-in. wood structural sheathing

- $2 \times 6$ wood framing (following advanced framing techniques)

- Blown-in cellulose insulation

- $1 / 2$-in. interior gypsum.

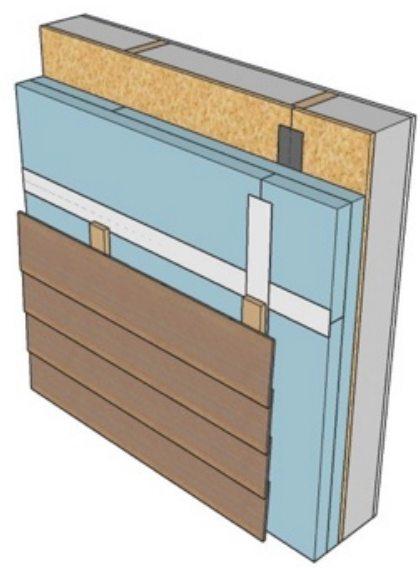

Figure 78. High performance wall assembly

For this assembly the nominal R-value would be listed as:

$\mathrm{R}-20+\mathrm{R}-26=\mathrm{R}-46$ 
Table 16 shows the equivalent U-factor and effective R-value as determined by the parallel paths method.

Table 16. Effective R-Value Calculation Using Parallel Paths Method

\begin{tabular}{|c|c|c|c|c|}
\hline & $\begin{array}{c}\text { Nominal } \\
\text { R-Value/in. }\end{array}$ & $\begin{array}{c}\text { Thickness } \\
\text { (in) }\end{array}$ & $\begin{array}{c}\text { R1 } \\
\text { (cavity) }\end{array}$ & $\begin{array}{c}\mathrm{R} 2 \\
\text { (framing) }\end{array}$ \\
\hline Outdoor Air Film & - & - & 0.17 & 0.17 \\
\hline Rigid Insulation & 6.5 & 4 & 26 & 26 \\
\hline $\begin{array}{c}\text { 7/16-in. Wood Structural } \\
\text { Sheathing }\end{array}$ & - & - & 0.62 & 0.62 \\
\hline Wood Stud Framing & 1.25 & 5.5 & & 6.88 \\
\hline Blown-In Cellulose & 3.7 & 5.5 & 20 & \\
\hline 1/2-in. Gypsum Board & - & - & 0.45 & 0.45 \\
\hline Interior Air Film & - & - & 0.68 & 0.68 \\
\hline R-Total per Path & & & 47.9 & 34.8 \\
\hline U-Factor per Path & & & 0.021 & 0.029 \\
\hline Framing Fraction per Path* & & & $80 \%$ & $20 \%$ \\
\hline Weighted U-Factor & & & 0.017 & 0.006 \\
\hline Equivalent U-Factor & \multicolumn{4}{|c|}{0.022} \\
\hline Effective R-Value & \multicolumn{4}{|c|}{44.6} \\
\hline
\end{tabular}

* Advanced framing can significantly reduce the area ratio between wood framing and cavity insulation. The advanced wood wall framing factor can range from $15 \%-20 \%$, and depends on the combination of 24 in. o.c. spacing between studs, insulated corners, insulated interior-exterior wall intersections, single top plates, headers placed in the rim cavity, aligned framing and limited cripple supports at door and window openings. The APA Advanced Framing Construction Guide has additional details. Advanced wood wall framing factors below $20 \%$ should be verified for each project, and are subject to approval by the authority having jurisdiction. 
